\title{
Identifying key players in the mashup ecosystem
}

by

Monique Bardawil

A thesis submitted to the Faculty of Graduate Studies and Postdoctoral Affairs

in partial fulfillment of the requirements for the degree of Master of Applied Science in Technology Innovation Management

Department of Systems and Computer Engineering

Carleton University

Ottawa, Canada K1S 5B6

December 2010

(C) Copyright 2010 Monique Bardawil 


$\begin{array}{ll}\begin{array}{l}\text { Library and Archives } \\ \text { Canada }\end{array} & \begin{array}{l}\text { Bibliothèque et } \\ \text { Archives Canada }\end{array} \\ \begin{array}{l}\text { Published Heritage } \\ \text { Branch }\end{array} & \begin{array}{l}\text { Direction du } \\ \text { Patrimoine de l'édition }\end{array} \\ \begin{array}{l}\text { 395 Wellington Street } \\ \text { Ottawa ON K1A ON4 } \\ \text { Canada }\end{array} & \begin{array}{l}395, \text { rue Wellington } \\ \text { Ottawa ON K1A ON4 } \\ \text { Canada }\end{array}\end{array}$

Your file Votre reférence
ISBN: 978-0-494-79591-0
Our file Notre réference
ISBN: 978-0-494-79591-0

NOTICE:

AVIS:

The author has granted a nonexclusive license allowing Library and Archives Canada to reproduce, publish, archive, preserve, conserve, communicate to the public by telecommunication or on the Internet, loan, distribute and sell theses worldwide, for commercial or noncommercial purposes, in microform, paper, electronic and/or any other formats.

The author retains copyright ownership and moral rights in this thesis. Neither the thesis nor substantial extracts from it may be printed or otherwise reproduced without the author's permission.

L'auteur a accordé une licence non exclusive permettant à la Bibliothèque et Archives Canada de reproduire, publier, archiver, sauvegarder, conserver, transmettre au public par télécommunication ou par l'Internet, prêter, distribuer et vendre des thèses partout dans le monde, à des fins commerciales ou autres, sur support microforme, papier, électronique et/ou autres formats.

L'auteur conserve la propriété du droit d'auteur et des droits moraux qui protège cette thèse. Ni la thèse ni des extraits substantiels de celle-ci ne doivent être imprimés ou autrement reproduits sans son autorisation.
In compliance with the Canadian Privacy Act some supporting forms may have been removed from this thesis.

While these forms may be included in the document page count, their removal does not represent any loss of content from the thesis.
Conformément à la loi canadienne sur la protection de la vie privée, quelques formulaires secondaires ont été enlevés de cette thèse.

Bien que ces formulaires aient inclus dans la pagination, il n'y aura aucun contenu manquant.

\section{Canadä}




\section{ABSTRACT}

Through the application of trusted mathematical and analytical techniques, this research examines the network structure of mashup ecosystem, and the positions and roles of entities in that ecosystem. This research provides complementary analytical methods for identifying key players in an ecosystem, while delivering new insights into the structure of the mashup ecosystem. 


\section{ACKNOWLEDGMENTS}

I would like to thank my supervisor, Professor Michael Weiss, for his guidance and advice throughout the research process and the writing process of this thesis.

I would also like to thank Professor Tony Bailetti for his insights and advice during this research process.

I am also thankful for my friends in the TIM program. Thank you for your continuous encouragement and support and for the endless hours we spent at the Carleton University library. 


\section{Table of Content}

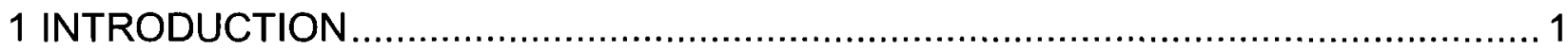

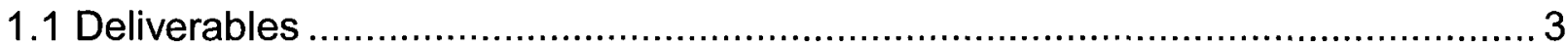

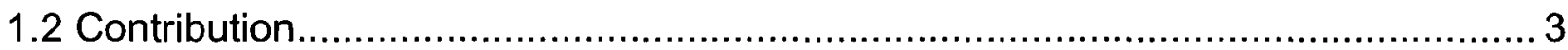

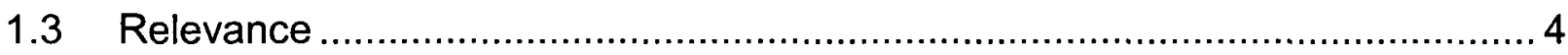

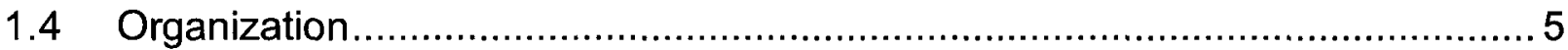

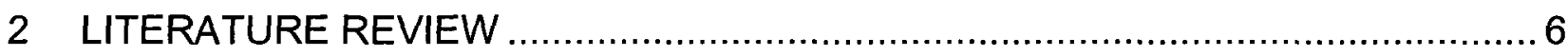

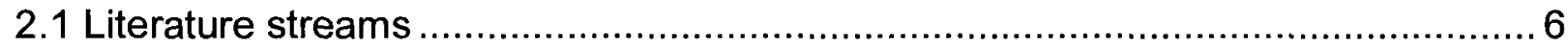

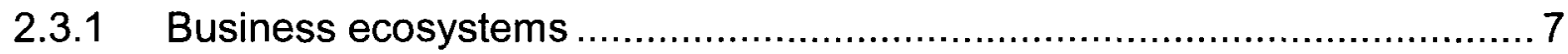

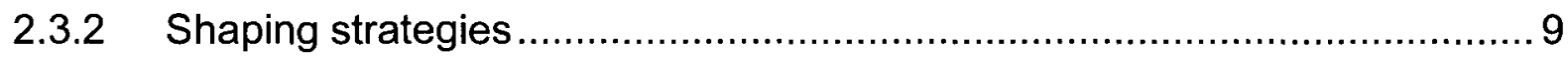

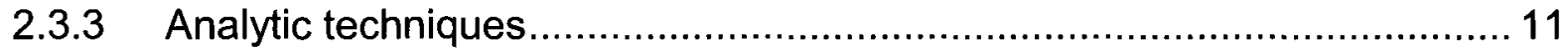

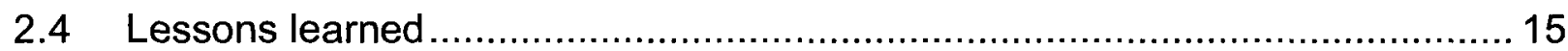

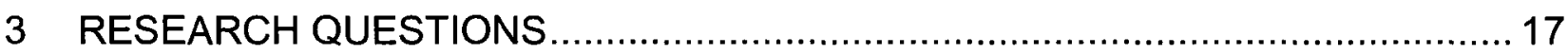

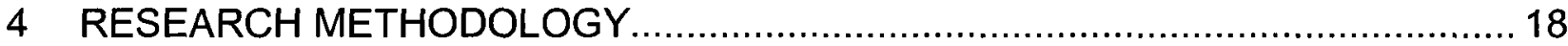

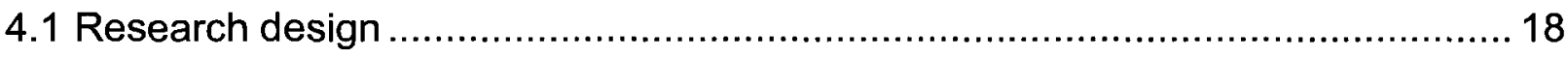

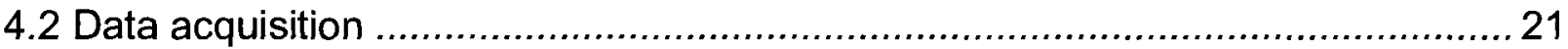

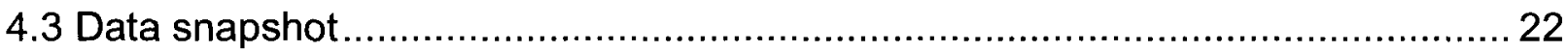

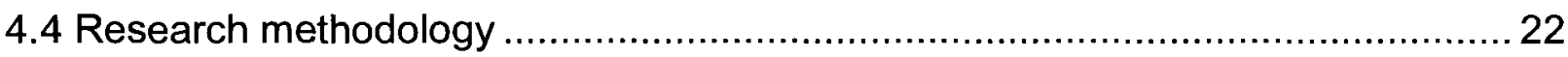

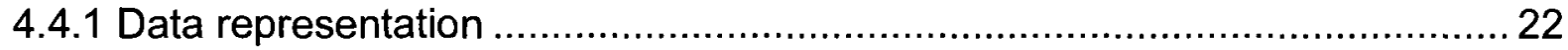

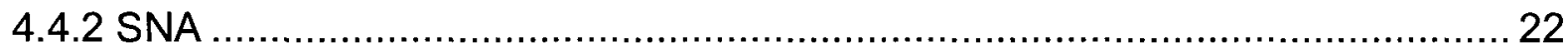

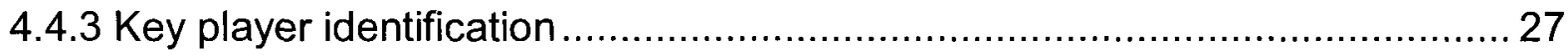

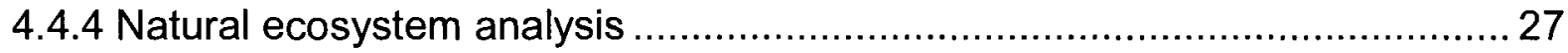

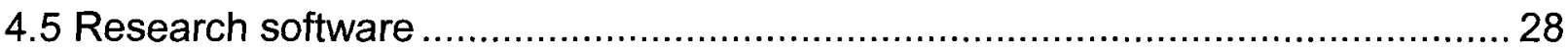

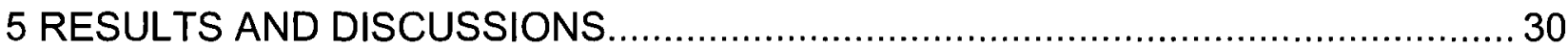

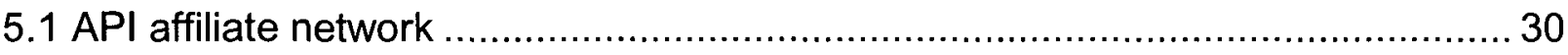

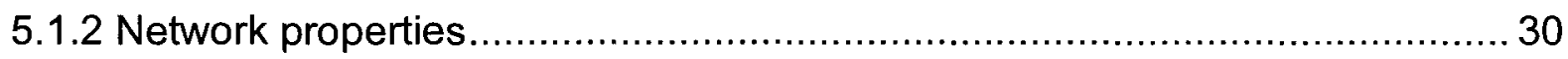

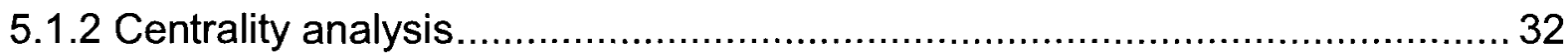

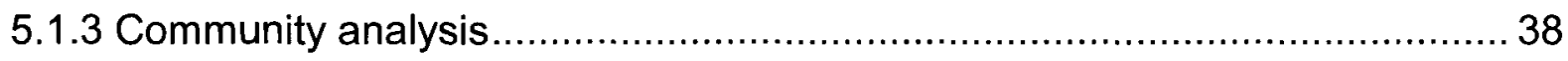

5.1.4 Key player analysis ........................................................................... 42

5.1.5 Topological importance analysis ............................................................ 47 


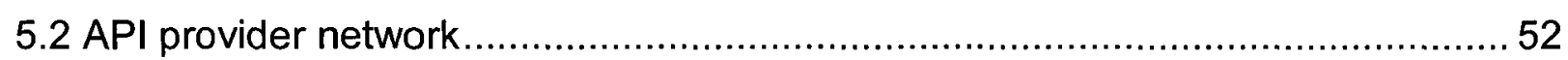

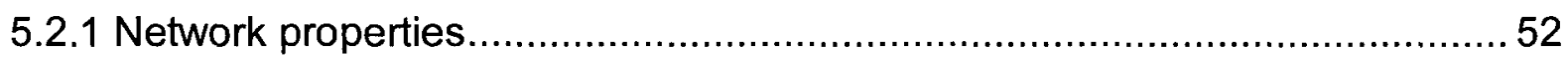

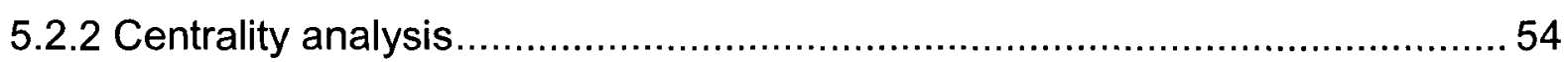

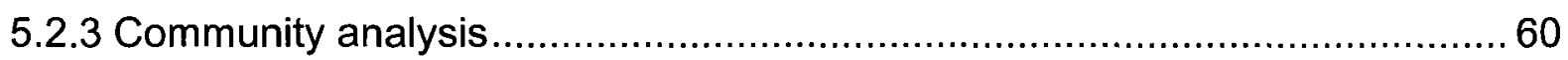

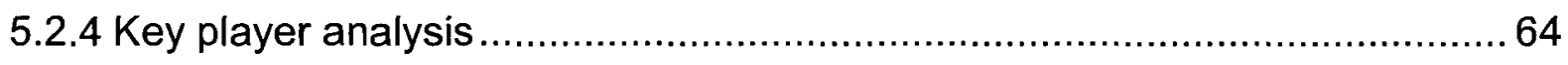

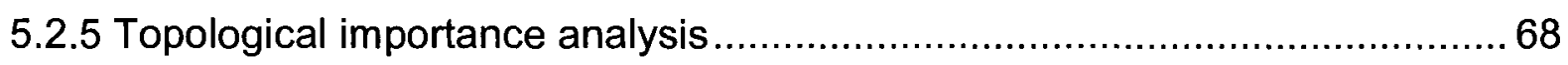

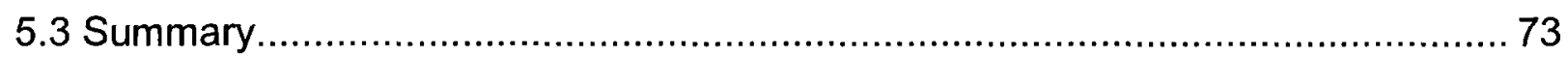

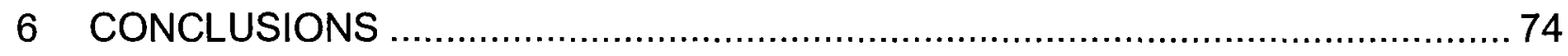

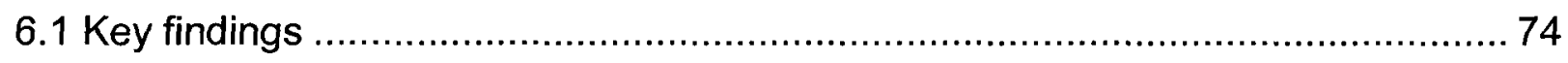

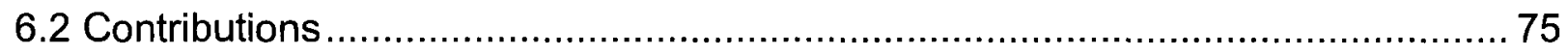

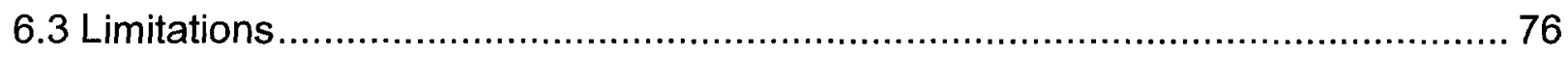

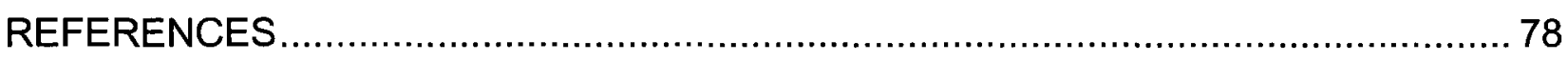

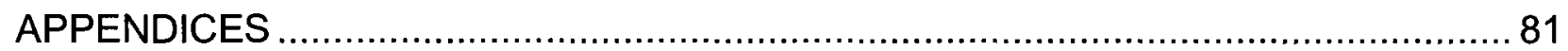

Appendix A - Sample of edgelist for the API affiliate network ...............................81

Appendix B - Sample of centrality measurements for the API affiliate network .........8 82

Appendix C - Sample of community detection results for API affiliate network ......... 83

Appendix D - KPP-Negative results for API affiliate network ...................................86

Appendix E - KPP-Positive results for API affiliate network ................................... 91

Appendix F - Sample of topological importance results for the API affiliate network. 95 Appendix G - Sample of edgelist for the API provider affiliate network ....................96 Appendix $\mathrm{H}$ - Sample of centrality measurements for the API provider affiliate network

Appendix I - Sample of community detection results for API provider affiliate network

Appendix J - KPP-Negative results for API provider affiliate network..................... 101

Appendix K - KPP-Positive results for API provider affiliate network...................... 105

Appendix $L$ - Sample of topological importance results for the API provider affiliate network 


\section{List of Tables}

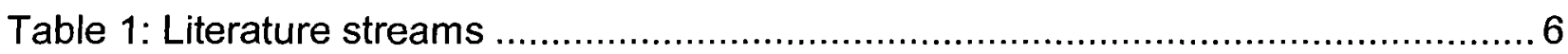

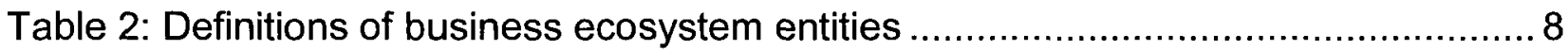

Table 3: Definitions of mashup ecosystem entities ............................................... 19

Table 4: Sample of degree centrality measurements for API affiliate network ..............33

Table 5: Sample of betweenness centrality measurements for API affiliate network .... 35

Table 6: Closeness centrality measurements in the API affiliate network .....................36

Table 7: Sample of eigenvector centrality measurements for API affiliate network ....... 37

Table 8: Sample of the communities in the API affiliate network ................................. 41

Table 9: Optimal key player sets in the API affiliate network .................................... 46

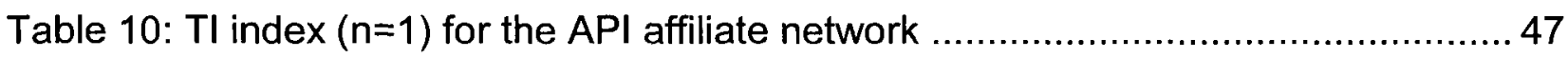

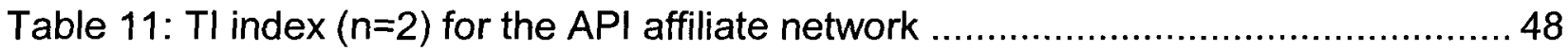

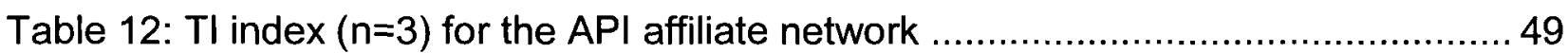

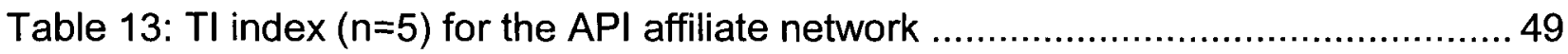

Table 14: Comparison of TI measurements for API affiliate network ...........................51

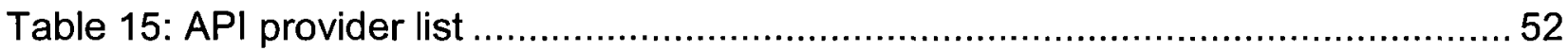

Table 16: Sample of degree centrality measurements for API provider affiliate network

Table 17: Sample of betweenness centrality measurements for API provider affiliate

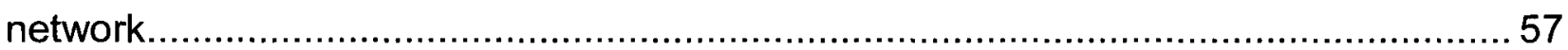

Table 18: Closeness centrality measurements in the API provider affiliate network ....58

Table 19: Sample of the communities in the API provider affiliate network ..................63 63

Table 20: Optimal key player sets in the API provider affiliate network .......................67 67

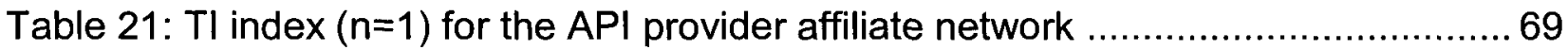

Table 22: TI index $(n=2)$ for the API provider affiliate network ................................ 70

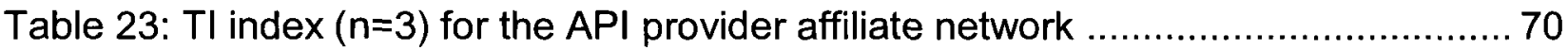

Table 24: $\mathrm{TI}$ index $(n=5)$ for the API provider affiliate network ............................... 71

Table 25: Comparison of TI measurements for API provider affiliate network.............. 72 


\section{List of Figures}

Figure 1: Example of API relations in the API affiliate network.................................20

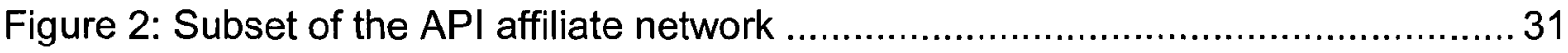

Figure 3: Subset of the API affiliate network (30 minimum connections) .....................31

Figure 4: Degree centrality measurements in the API affiliate network ........................34

Figure 5: Betweenness centrality measurements in the API affiliate network ...............35

Figure 6: Eigenvector centrality measurements in the API affiliate network ................. 38

Figure 7: Community structure in the API affiliate network ...................................... 39

Figure 8: Fragmentation of the API affiliate network ..............................................4 43

Figure 9: Network fragmentation level for the API affiliate network .......................... 44

Figure 10: Reciprocal distance index for the API affiliate network .............................45

Figure 11: Subset of the API provider affiliate network..........................................5 53

Figure 12: Degree centrality measurements in the API provider affiliate network .........56

Figure 13: Betweenness centrality measurements in the API provider affiliate network 57

Figure 14: Sample of eigenvector centrality measurements for API provider affiliate

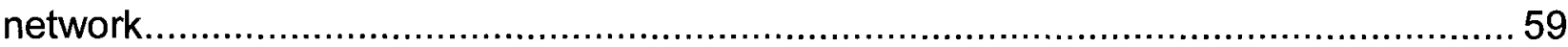

Figure 15: Eigenvector centrality measurements in the API provider affiliate network .. 60

Figure 16: Community structure in the API provider affiliate network ..........................61 61

Figure 17: Network fragmentation level for the API provider affiliate network ...............6 65

Figure 18: Fragmentation of the API provider affiliate network.................................66

Figure 19: Reciprocal distance index for the API provider affiliate network.................67 


\section{INTRODUCTION}

Moore (1996) defined the business ecosystem as "an economic community supported by a foundation of interacting organizations and individuals - the organisms of the business world." Similar to interactions observed between species in natural ecosystems, members of business ecosystems interact through complex business ventures and collaborations. Companies within business ecosystem have certain roles and tend to "to align themselves with the directions set by one or more central companies" (Moore, 2003). These central companies, referred to as keystones, are essential entities that lead other ecosystem members in collaborative exchanges to ensure the success of the ecosystem as a whole (Weiss and Gangadharan, 2010).

Using this model, a business ecosystem is set to have a central keystone entity that focuses on the health and success of the ecosystem and niche entities that deliver specialised solutions into the ecosystem (lansiti, 2004). lansiti (2004) remarks that business ecosystems are not static and are constantly evolving. He adds that companies can be keystones in one domain and niche players in others and that niche players can evolve to become keystones. Literature related to business strategies suggests that companies in an ecosystem have diverse roles that vary depending on their plans (Hagel, 2008). Mobile ecosystem research revealed that a dominant keystone does not. Basole (2009) explains that the centralization in the mobile ecosystem is not strong and that firms are more interconnected without a central hub or keystone. 
The literature reveals that the current business ecosystem model is not well-defined. The ecosystem model in natural system is supported by various analytical techniques that examine the ecosystem network structure, entity positions, and relationships between entities. However, few studies have focused on analytical research to support the current business ecosystem model.

The mashup ecosystem, studied in this research, presents and innovative and unique business ecosystem that relies on user innovation for its growth and success (Weiss and Gangadharan, 2010). Facilitated with evolution of Web2.0, the mashup ecosystem grew and evolved through interactions between data providers, developers, mashup platforms and users (Weiss and Gangadharan, 2010). Data providers offer developers access to their data via Application Programming Interfaces (APIs), who then build web applications, called mashups that combine data from multiple APIs (Yu and Woodward, 2009). Based on its innovative and evolving nature, the mashup ecosystem presents an ideal research context to analytically and systematically examine its structure. This research will apply a number of analytical techniques to inspect the mashup ecosystem.

The thesis with address the following questions:

- What can analytical techniques reveal about the ecosystem structure and the position and roles of its entities?

- Does the ecosystem have a sole keystone entity or a set of key players or keystones?

In this research, the mashup ecosystem will be presented through an API affiliate network and an API provider affiliate network. The API affiliate network is formed 
through the relationships between mashups and APIs, where APIs are linked together when they are used in the same mashup (Weiss and Gangadharan, 2010). The API provider affiliate network is formed through relationships between data providers. In this case, providers are linked when their APIs are used together in the same mashup.

Social Network Analysis (SNA) measurements are used to build and examine the relative importance of the entities within the network. Community analysis is applied to study network clustering and to identify closer ties between entities. Fragmentation and network reach techniques are applied to identify sets of key players within the network. Finally, natural ecosystem analysis is applied to study the topological importance of entities within the network.

\subsection{Deliverables}

This research has two deliverables:

- A comparison of analytical methods for identifying and classifying key players within the mashup ecosystem

- A set of network characteristics of key players within the mashup ecosystem

\subsection{Contribution}

This research yields three contributions.

- First, the research will contribute through the application of proven analytical methods on a new dataset and within a new research context.

- Second, the research will identify key player roles based on the combinatory and complementary nature of network metrics. 
- Third, the research will provide new entrants and incumbents with a better understanding of existing key players in the mashup ecosystem.

\subsection{Relevance}

This research is valuable to a three primary groups interested in business ecosystem research. These are:

1) Academia

2) Entrepreneurs

3) Management

The first group interested in this research is academia. Business ecosystem research is evolving especially with the convergence of new business domains; however, few studies have applied analytic research to support the current business ecosystem model. This research will be of interest to the academic community as it will apply trusted and well established analytic techniques to a new research context. In addition, the explosion of the mashup ecosystem presents research prospects in ecosystem structure, strategies, evolution and innovation. Yu and Woodard (2009), remark that future research into business ecosystem can lead to a more rigorous theoretical framework for explaining patterns and predicting how the mashup ecosystem will evolve. This research will study and explore the current structure of the mashup ecosystem and will lay the groundwork needed for studying business ecosystem structure and organization.

The second group interested in this research is entrepreneurs. Entrepreneurs play a critical role in emerging and existing ecosystems and rely on educated decisions when 
entering a pre-existing ecosystem. To make wise business decisions in collaborative environments, entrepreneurs must have an understanding of the business ecosystem structure and the roles of the entities within it. According to Moore (2006), marketing and visionary ideas are what attracts contributors, including customers, to a new business ecosystem. He states that "entrepreneurial leaders declare a new "space" for invention and investment, and provide a broad template to which members of the community can identify potential contributions and step forward to join the community." The analytical results derived from this research can be used by entrepreneurs to guide their business strategies and collaborative efforts in the mashup ecosystem.

The third group with interest in this research is management. Insights into ecosystem structure and dynamics will empower managerial decisions and shaping strategies within that ecosystem. Hagel (2008) observes that "well-executed shaping strategies mobilize masses of players to learn from and share risk with one another - creating a profitable future for all." Management teams in the mashup ecosystem would benefit from insights related to the structure and roles of entities within their ecosystem in order to develop intelligent and beneficial business shaping strategies.

\subsection{Organization}

This is the introduction chapter. The rest of the thesis is organized as follows: chapter two covers the literature review. Chapter three describes the research questions. Chapter four presents the research methodology. Chapter five will present the results and discussions and chapter six will include conclusions, key findings, contribution, limitations and future research opportunities. 


\section{LITERATURE REVIEW}

This chapter will describe the literature review in two sections. The first section will review the literature and the second will discuss the lessons learned.

\subsection{Literature streams}

The literature review revealed three main streams that are directly relevant to the research: business ecosystems, shaping strategies and analytical techniques. These streams are discussed in this chapter and Table 1 outlines the three streams, some of the key highlights in each, and the associated literature.

\begin{tabular}{|l|l|l|}
\hline Stream & Key highlights of the stream & Key references \\
\hline Business & $\begin{array}{l}\text { - Identify different business structures and interactions } \\
\text { between ecosystem entities } \\
\text { - Defines entity roles as keystones, dominators, and } \\
\text { niche players } \\
\text { - The mashup ecosystem presents research } \\
\text { prospects in ecosystem structure, strategy, and } \\
\text { innovation. }\end{array}$ & $\begin{array}{l}\text { lyer \& Davenport (2008) } \\
\text { lyer et al (2006) } \\
\text { Moore (1996) } \\
\text { Weiss (2010) } \\
\text { Yu \& Woodard (2009) }\end{array}$ \\
\hline $\begin{array}{l}\text { Shaping } \\
\text { strategies }\end{array}$ & $\begin{array}{l}\text { - Shaping strategies are critical to the success of an } \\
\text { ecosystem and impact the role the role of ecosystem } \\
\text { entities } \\
\text {-Shaping strategies must be dynamic and flexible to } \\
\text { adapt to the ecosystem environment and ensure } \\
\text { success }\end{array}$ & $\begin{array}{l}\text { Adner (2006) } \\
\text { Basole (2009) } \\
\text { Hagel, Brown \& Davison (2008) } \\
\text { lansiti \& Levien (2004) } \\
\text { Moore (2005) }\end{array}$ \\
\hline $\begin{array}{l}\text { Analytical } \\
\text { Techniques } \\
\text { - Social Network Analysis provides theoretical and } \\
\text { practical understanding of various types of networks } \\
\text { and ecosystems } \\
\text { - Ecological ecosystem modelling uncovers the } \\
\text { interactions between entities based on their role, } \\
\text { interactions and relations }\end{array}$ & $\begin{array}{l}\text { Borgatti \& Everett (2006) } \\
\text { Borgatti (2006) } \\
\text { Jordan et al (2008) } \\
\text { Jordan et al (2009) } \\
\text { Newman (2004) } \\
\text { Newman (2006) }\end{array}$ \\
\hline
\end{tabular}

\section{Table 1: Literature streams}




\subsubsection{Business ecosystems}

Economic collaboration and associations between companies has been presented and examined through the business ecosystem model and is analogous to the ecosystem concept as defined in the natural systems. To provide a better understanding of these concepts the literature review examined the concepts of the ecosystem ecology, business ecosystems, and the mashup ecosystem.

\section{Ecosystems and ecology}

According the American Heritage Science Dictionary (2002), an ecosystem is "a community of organisms together with their physical environment, viewed as a system of interacting and interdependent relationships and including such processes as the flow of energy through trophic levels and the cycling of chemical elements and compounds through living and nonliving components of the system". Ecology, on the other hand, is the study of ecosystems through the use of mathematical models that examine the structure and function of ecosystems. Thereby, ecology provides an understanding of natural ecosystem structure and organization, as well as the roles of organisms inhabiting the ecosystem.

Natural ecosystem research has focused on system structure, composition, function and interaction. Through these, key ideas emerged relating to community structure, relations and interactions between species, as well as, the roles and functions of species. One of the roles that emerged is the role of the keystone species that are essential to the health and balance of the entire ecosystem. Other species take on the roles of producers, engineers and predators. An ecosystem prospers when there are 
balanced and fruitful interactions between its members that benefit its members and the ecosystem in its entirety.

\section{Business and mashup ecosystems}

The concept of the business ecosystem has been studied and examined by a number of researchers in management science and is based on natural ecosystem concepts.

Moore (2005) refers to the business ecosystem model as "a community of economic actors whose individual business activities share in some large measure the fate of the whole community" (Moore 2005). A business ecosystem is viewed as a network of producers, competitors, suppliers, customers, government institutions, and a number of other stakeholders that work to support each other and the ecosystem as a whole. Similar to natural ecosystems, entities in a business ecosystem exhibit different roles and behaviours. Iansiti and Levin (2004) classify three entity roles in business ecosystems: keystone players, dominators and niche players. These entities are described in the table below.

\begin{tabular}{|l|l|}
\hline Entity name & Role description \\
\hline Keystone & $\begin{array}{l}\text { Focuses on the wellbeing of the entire ecosystem, } \\
\text { thereby assuring its own survival and success. }\end{array}$ \\
\hline Dominator & $\begin{array}{l}\text { Focuses on controlling the ecosystem with little } \\
\text { consideration for other members of the ecosystem. }\end{array}$ \\
\hline Niche player & $\begin{array}{l}\text { Focuses on its specific expertise that differentiate it in the } \\
\text { ecosystem and enhances its contribution, while } \\
\text { continuing to collaborate with other entities in the } \\
\text { ecosystem }\end{array}$ \\
\hline
\end{tabular}

Table 2: Definitions of business ecosystem entities 
The mashup ecosystem emerged with the Web2.0 evolution and continues to grow as more companies provide open APIs to access their data and as more mashup creation tools are released (Fichter, 2009). A mashup is defined as a web application developed by combining content and information from multiple sources. A mashup allows developers to create and deliver unique services for free. As a result, the mashup ecosystem can be defined as an ecosystem of providers, platforms, developers, and users (Weiss and Gangadharan, 2010). It is a model for an emerging and evolving ecosystem as it reflects the changes and developments in web technologies. Thereby, the mashup ecosystem represents a complex and ground-breaking business environment where the collaboration between ecosystem entities is driven by independent user innovation through mashup development.

\subsubsection{Shaping strategies}

Strategy is simply defined as the action required for achieving a goal or an objective. The term shaping strategies can be defined as the actions or plans put by a company to shape it business environment or ecosystem in order to reach its goals. In a collaborative business environment, a company's role is dynamic and evolving to adapt to its surrounding changes (lansiti, 2004), and is impacted by its business strategy (Hagel, 2008).

\section{Strategies of shapers and participants}

Hagel (2008) defines two types of companies, a "shaper" and a "participant". He defines shaping strategy taken by the "shaper" as "an effort to broadly redefine the terms of competition for a market sector through a positive, galvanizing message that promises benefits to all who adopt the new terms." He further outlines three elements of a 
shaping strategy taken by the "shaper". A shaper provides direction, attractive opportunities to the other participants, while encouraging collaboration between participants. Participants actively contribute in their collaborative business environments by taking on the role of an influencer, a hedger, or a disciple.

\section{Keystone and niche player strategies}

Entities in business collaborations have been identified to be keystones or niche players. Keystone and niche player strategies must be dynamic and flexible to adapt to the ecosystem environment and ensure success (lansiti, 2004). Hagel (2008) states that "well-executed shaping strategies mobilize masses of players to learn from and share risk with one another-creating a profitable future for all."

Keystone players have a critical role in a business ecosystem. lansiti and Levin (2004) note that a keystone aims to improve the health of their ecosystem by increasing productivity, enhancing robustness and encouraging niche creation. Similar to keystone players, niche players must also examine their operating strategy within a business ecosystem to ensure their success and growth within that ecosystem. lansiti discusses niche strategy in his paper "Strategy for small fish," where he notes that a niche player should focus on value creation and innovation to develop a unique speciality, while leveraging the capabilities provided by the keystone and sustaining their innovations (lansiti, 2004). A niche player's strategy must be dynamic so they are not completely reliant on the keystone player, while maintaining its influence on the keystone through its technological specialisation. The reviewed literature highlights the fact that there are no agreed and well-defined roles for companies in a collaborative environment or a 
business ecosystem. However, it is evident that a company's role is not static and is constantly evolving to adjust and adapt to its surrounding changes.

\subsubsection{Analytic techniques}

The analytical technique reviewed here focus on those used in network and ecosystem studies and how they can be applied to study business ecosystems. From this review, three main techniques are prominent:

- Data representation

- Social Network Analysis (SNA)

- Natural ecosystem analysis

\section{Data representation}

Data representation is structural and visual. Collaborative networks can be represented structurally through node lists, edge lists, and algebraic matrices. A node list is a directory of the nodes in a network. The edge list would represent the edges between nodes and the matrix would represent the relationship between nodes. A network graph contains a collection of nodes connected via edges representing relationships the nodes. Visual inspections a network graph can provide preliminary information about a network, however, this becomes more difficult and virtually impossible when examining larger networks. More elaborate mathematical techniques are used to gain a better understanding of the network structure. 


\section{Social Network Analysis (SNA)}

Social Network Analysis (SNA) provides theoretical and practical tools to study various types of networks. SNA techniques have been used in fields like sociology, biology, and communications to understand network structure, the positions and roles of network entities, as well as the relationship between entities. SNA measures relevant in the identification of key network entities are reviewed below. Prominent SNA techniques evident in the literature review are: network density measurements, centrality measurements, community detection techniques, and key player identification.

\section{- Network density}

Network density provides information about the network as a whole and reveals the degree of interaction between nodes within a network.

\section{- Centrality measurements}

Various centrality measurements, such as degree, betweenness, closeness, and eigenvector centralities provide information about the position of nodes within a network. In general, centrally located nodes would have a more strategic and important position in the network and have faster access to information and resources. Thus centrality values indicate the extent a node strategic position is defined by its strategic ties to other nodes in the network (Gnyawali and Madhavan, 2001).

\section{- Community detection}

SNA also provides various techniques and clustering algorithms to study community formation within networks. Communities are sub-networks of nodes that are more densely linked internally that externally (Newman, 2006). They can be linked by nodes 
or links that are labelled as cutpoints or bridges, respectively. A number of algorithms have been developed to identify communities within networks, such as clustering techniques, minimum-cut method, and Girvan-Newman algorithms.

Community identification can provide information about network structure and topology, as well as common properties shared between nodes within that community (Scott, 1991). In some SNA studies, community identification provides information about location, interests, functionalities, etc. Furthermore, SNA techniques can be used to analyze communities to expose further network and entity structural details within communities.

\section{- Key player identification}

Key player identification techniques have been used in a number of network analysis studies to identify key nodes within a network. This methodology focuses on identifying a set of key players in a network rather than identifying a single key player and provides a good alternative to centrality measurements that may not always identify the key nodes in the network (Borgatti, 2003).

Borgatti (2003) identifies key players through two distinct methods, labelled as the "Key Player Problem (KPP)".

- The first, KPP-Negative, identifies a set of key players through network disruption. In this case, the removal of the set of key players would cause the most disruption in a network and decreases its cohesiveness. 
- The second, KPP-Positive, identifies a key player set by examining connectedness and reach within the network. The identified key players would have the maximal reach within a network.

These key player techniques have been used to study terrorist networks, organizational identifies a set of key players (Borgatti, 2003).

\section{Natural ecosystem analysis}

Since basic business ecosystem modeling is rooted in natural systems, it is not surprising that natural ecosystem modeling would be evident in this literature review. Natural ecosystem analysis has uncovered structure and entity relations within ecosystems. Jordan et al (2008) and Libralato et al (2006) examine the structure and function of species within natural ecosystems.

SNA techniques in conjunction with more specialized methods have been applied to the study of natural ecosystems and to identify central entities. One of these techniques measures the Topological Importance (TI) index of species (Jordan and Wyatt, 2006). The TI measurement is relevant to this research because it examines undirected and unweighted networks, where relationship and link direction does not add any bias to the analysis. This index measures the positional importance of a node by considering how effects generated from this node can spread to other nodes after a pre-defined n-step length (Jordan et al, 2006). 


\subsection{Lessons learned}

Based on the literature review, a number of lessons have been identified that are related to business ecosystem structure, modelling and strategy. These lessons are explained below.

The first lesson highlights the need for further analytical research to support the current business ecosystem model. lyer (2006) examines the roles of network entities within the software sector and their complex relations through SNA. Weiss and Gangadharan (2010) used SNA to measure an APl's popularity and the complementary nature of APIs. In addition, the literature is rich with papers on the collaborative nature of business ecosystems; however, the literature lacks extensive analytical research into the structure of business mashup ecosystems.

The second lesson indicates that there is a gap between the ecosystem literature describing the ecosystem structure and mapping it to data to support that structure.

The third lesson addresses the fact that certain business ecosystems do not comply with the existing model and lack a central keystone. The current model of business ecosystem states that the ecosystem has a keystone player and niche players. Basole's (2009) research into the mobile ecosystem revealed that a single hub or entity has not emerged in the mobile ecosystem.

The fourth lesson states that the roles of key players in ecosystems are poorly defined. Business ecosystem literature identifies two types of entities in a business ecosystem: keystone player and niche players. However, other research as noted by Hagel (2008) notes that in a business environment, there are two types of entities, shapers and 
participants. Furthermore, Hagel identifies three types of participants: influencers, hedgers or disciples. This emphasises the fact that there are discrepancies in the literature related to the types of key player roles and what these roles represent.

The fifth lesson addresses how shaping strategies are critical and impact entity roles within an ecosystem. It is evident from the literature review, that the success of a business ecosystem is dependent on the strategies executed by its. Shaping strategies taken by keystone players must create value and share that value with the members of that ecosystem (lansiti and Levien, 2004). In addition, strategies of niche players must focus on its contribution to the ecosystem, while maintaining flexibility to adapt to the strategies taken by the keystone player (lansiti and Levien, 2004).

The sixth lesson states that the roles of entities within a business ecosystem are not static (lansiti and Levien, 2004). An entity can be a keystone player in one domain but a niche player in another domain. In addition, it is possible for niche players create their own ecosystems where they are the keystone player.

The seventh lesson notes that ecological ecosystem analysis has identified multiple keystone species and revealed that conventional analysis has in some studies underestimated the value of certain species. 


\section{RESEARCH QUESTIONS}

The literature review raises a number of research questions relating to the mashup ecosystem network and structure.

The research will address the following questions:

- Question 1: What can analytical techniques reveal about the mashup ecosystem structure?

- Question 2: What can be learned about the roles and positions of key players in the mashup ecosystem? 


\section{RESEARCH METHODOLOGY}

The following chapter is organised into four sections describing the research methodology used in thesis. The four sections are:
1) Research design
2) Data acquisition
3) Research methodology
4) Research software

\subsection{Research design}

The following section describes the mashup ecosystem and the associated design aspects of the research, which detail the unit of analysis, study time period, and population.

\section{The mashup ecosystem}

The mashup ecosystem is defined as an ecosystem of providers, platforms, developers, and users (Weiss 2009). It is a model for an emerging and evolving ecosystem as it reflects changes and developments in web technologies. The mashup ecosystem is unique because its growth is dependent on the developers versus the companies involved. According to (Fichter, 2009), "the fundamental component of the mashup ecosystem is the "open" data providers operating in the internet "cloud." Providers, like Google and Yahoo, release that data through APIs, such as Google Maps and Yahoo Search, which are then used by developers to create mashups. 
In this research, the mashup ecosystem is examined by studying the API affiliate network and the API provider affiliation network. Table 3 provides a quick overview of the mashup ecosystem entities used when describing the two affiliate networks.

\begin{tabular}{|l|l|}
\hline Entity & Role \\
\hline API & $\begin{array}{l}\text { A programming interface that provides access to data made } \\
\text { available by the API provider }\end{array}$ \\
\hline $\begin{array}{l}\text { API } \\
\text { provider }\end{array}$ & A company providing access to its data via an API \\
\hline Mashup & $\begin{array}{l}\text { A custom web application that uses various data sources to } \\
\text { deliver new services }\end{array}$ \\
\hline
\end{tabular}

Table 3: Definitions of mashup ecosystem entities

\section{API affiliate network}

The API affiliate network is formed as mashups are created when two or more APIs are combined to provide functionality to the user. This network can be used to map and study the mashup ecosystem (Weiss and Gangadharan, 2010) as it represents the relationship between APIs through mashups. This mapping delivers a network that can be used to study the structure, position and role of various APIs in the network. The unit of analysis for this network is APIs. The entire population in question is the set of APIs identified via the ProgrammableWeb.com.

The network is an undirected and unweighted network, where nodes represent the APIs and the edges represent mashups. An edge exists between two APIs when these APIs are used together in the same mashup. Based on this definition, the API affiliate network would not contain isolated APIs that are not connected to any other APIs, known in network analysis as isolates. The figure below demonstrates how APIs in the 
affiliate network diagram are connected when used in the same mashup. For example, Prodigem and del.icio.us are used in one mashup and linked by an edge. In addition, Google Maps, Amazon eCommerce, and del.icio.us are used in a different mashup and therefore are also linked.

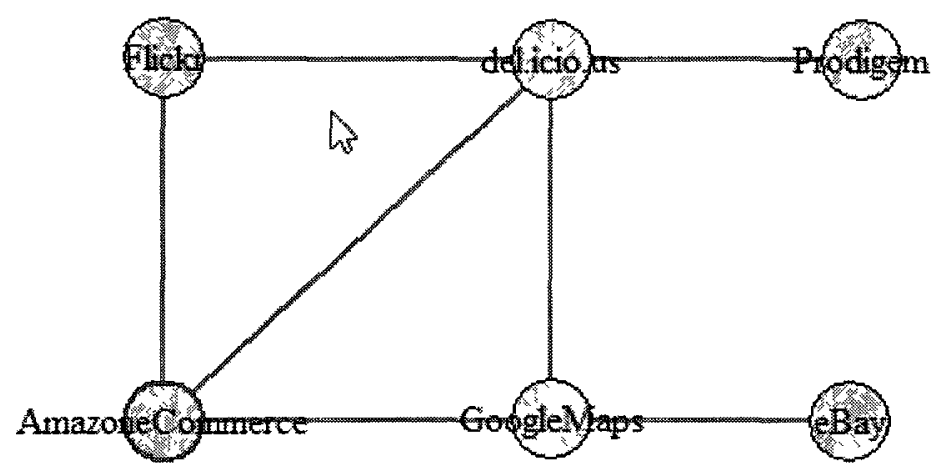

Figure 1: Example of API relations in the API affiliate network

\section{API provider network}

The API provider affiliate network was constructed from the API affiliate network, where an API node was replaced with its respective provider. Therefore connections between providers exist when their APIs are used in the same mashup. Since this network was based on the API affiliate network, then the unit of analysis is also the APIs. For example, all APIs released by Google were represented as one entity in the API provider network. The researcher manually extracted a list of APIs released by the most popular API providers from the ProgrammableWeb.com. The list of APIs belonging to a provider would include APIs developed by the provider and those acquired by the provider through business acquisitions. For instance, all APIs released by Yahoo, such 
as Yahoo Search and Yahoo Maps, and those acquired by Yahoo, such as Flickr, were all represented by Yahoo as an API provider.

\subsection{Data acquisition}

The data acquisition was focused on building the affiliate networks by extracting all relevant data from ProgrammableWeb.com, as it is considered to be one of the largest online repositories of mashups and APIs. In addition, it provides its own API to retrieve mashup and API data, making it a perfect choice for this research.

The following steps were taken to build the API affiliate network:

1) A Perl program was written and used to query the ProgrammableWeb API and retrieve mashup and API data.

2) The extracted data was formatted in JSON and required further manual manipulation and formatting.

3) Altova XML Spy was then used to convert the data into a spreadsheet. The original data was rich and included some information not relevant to this research. The data was cleansed to include creation date, mashup name and APIs used in each mashup.

4) An additional step was taken to create an API edgelist representing the API affiliate network. Each edge was formed when two or more APIs are used in the same mashup. The edgelist was used to map the API affiliate network examined in this research. 
5) The API provider edgelist was formed by replacing the API with the respective API provider. The API provider edgelist was then used to build the API provider affiliate network.

\subsection{Data snapshot}

The data were manually gathered from ProgrammableWeb.com and included mashups created between September 2005 and August 2010. September 2005 marks the earliest mashup creation date as noted on ProgrammableWeb.com. Mashups up to and including August 2010 were included to limit the researcher's data collection while providing an up-to-date picture of the mashup ecosystem.

\subsection{Research methodology}

The key research concepts used in this research are those identified in the literature review. These are: network visualisation, SNA, and ecological system analysis techniques. Below are more detailed descriptions of the specific methods.

\subsubsection{Data representation}

As noted earlier, the networks studied were represented through an API edgelist and an API provider edgelist. Using R software program, the edgelists were converted into graphs that represented the networks. Visual representation is used throughout this research to demonstrate network complexity and to highlight significant results.

\subsubsection{SNA}

Popular SNA measurements were used to analyse and evaluate the properties and characteristics of the API affiliation network and the provider affiliation network. When studying a network one must examine the structural properties of the network entities to 
gain a better understanding of the network as a whole. A node's position within the network will impact its role, interactions, and its influence. An edge is a reflection of the degree of interaction between two nodes. Descriptions of the various SNA measurements utilized in this research are provided below.

\section{Network density}

Network density is a measurement of node interaction and network cohesiveness. It measures the proportion of all existing ties in a network over the maximum number of possible ties. High network density indicates a high degree of interaction within the network. If all nodes are connected, then the density measurement would be $100 \%$. Network density would be zero for an unconnected network and 100 for a highly connected network. The formula for network density of an undirected network is (Scott, 1991):

$$
\frac{\frac{l}{n(n-1)}}{2}
$$

where $l$ is the number of edges and $n$ is the number of nodes in the network.

\section{Centrality measurements}

Centrality measurements quantify how central a node is to a network or how much a network is centered around that node. The more central a node is the more strategic its structural position is within the network, thus easily gaining access to resources available through that network. Centrality measurements can be viewed as attributes of a node's position in a network that define its role in that network. Therefore, it is critical to investigate every node's positions in order to determine its role. For instance, in a star shaped network, the hub node would have the highest centrality in the network. A 
number of centrality measurements were used in this research, which are outlined below. All the centrality measurements used in this research are based on eigenvector formulas as implemented using the igraph software package in the $\mathrm{R}$ software suite.

\section{Degree centrality}

Degree centrality is a measurement of all the direct links a node has to other nodes in the network and therefore indicates a node's contribution to the network. This measurement however, does not provide any information on how the node fits within the network because it is concerned with direct connections only. For instance, a node can have a high degree centrality and yet be disconnected from the network as a whole because its affiliate nodes are not connected to the network. Degree centrality can be misleading because it does not provide an assessment of how nodes fit structurally within the network as a whole.

\section{Betweenness centrality}

Betweenness centrality ranks a node in a network when it lies in the path between other nodes and therefore connects nodes that may not otherwise be connected (Scott, 1991). It is a measurement of a node's influence over the flow of information or resources between nodes and can identify brokers, gatekeepers and liaisons nodes. A node with high betweenness centrality is located on many "shortest paths" between other nodes. The algorithm for computing node betweenness centrality for a graph with $n$ vertices is as follows:

- Calculate the shortest path between each pair of vertices

- Determine the fraction of shortest paths that pass through a vertex, for each pair of vertices

- Sum the fractions over all the pairs of vertices 
The equation for betweenness for a node $v$ is $\sum_{s \neq v \neq t \in V} \frac{\sigma_{s t}(v)}{\sigma_{s t}}$, where

- $\sigma_{s t}$ is the number of shortest paths from $s$ to $t$, and

- $\sigma_{s t(v)}$ is the number of shortest paths from $s$ to $t$ that pass through vertex $v$

\section{Closeness centrality}

Closeness centrality measures how close a node is to other nodes by computing the steps required to access all other nodes in the network. In other words, it measures the sum geodesic distances or the shortest paths between a node and all other nodes. A node with high closeness reveals that it can interact with a high number of other nodes and therefore has fast access to information and resources. The closeness centrality measurement is the inverse of the average length of the shortest path from or to all other vertices in the graph (Scott, 1991). The closeness centrality formula is:

$$
\frac{|V|-1}{\sum_{i \neq v} d_{v} i}
$$

where, $V$ is the network connectivity component from vertex $v$, and $d_{v} i$ is the shortest path between vertex $v$ and any vertex in the network.

\section{Eigenvector centrality}

Eigenvector centrality is a measurement of how much a node is connected to other central nodes within the network. Therefore a node with high eigenvector centrality is connected to many other nodes that are also connected to many other nodes. As stated by Bonacich (2007), Eigenvector centrality considers the entire network as it accounts for the "weighted sum of not only direct connections but indirect connections."

Eigenvector centrality takes the centrality measurements of all the nodes and re- 
computes the measurement for each node as the weighted sum of centralities of all its neighbours (Bonacich, 2007).

\section{Community detection}

Community detection is derived from the concepts of clique detection in graph theory through the detection of sub-graphs based on specific structural properties of the network. Communities are formed when a network divides into groups of densely interconnected nodes in comparison to the connections between communities. Community detection can expose thematic structure and relations in a network and between communities (Newman, 2004). It can provide information as to the main players within a community and what approach a company should take when entering a community. The Girvan-Newman algorithm was implemented in this research to identify communities in the API affiliate network.

The algorithm uses the edge betweenness measurement to identify edges that connect communities together. According to Girvan and Newman (2002), edge betweenness is defined "as the number of shortest paths between pairs of nodes that run along it." By that definition, an edge that connects communities would have a high edge betweenness value and therefore removing these edges would naturally reveal communities in the network. As edges are removed from the network, the structural properties of the edges change and therefore a recalculation of the edge betweenness values is necessary. The Girvan-Newman algorithm recursively identifies communities by removing edges from the network graph.

The algorithm can be divided into the following steps (Girvan and Newman 2002): 
1) Calculate the edge betweenness values for all the edges in the network graph

2) Remove the edge with the highest edge betweenness value

3) Recalculate the edge betweenness value of the remaining edges

4) Repeat steps 2 and 3, until no edges are left

\subsubsection{Key player identification}

Both KPP-Negative and KPP-Positive techniques are used in this research to identify sets of key players in the API affiliate network. The two techniques are defined below (Borgatti, 2003):

1) KPP-Negative - is described as the identification of key players that would optimally disrupt and disconnect a network.

2) KPP-Positive - is described as the identification of key players that would have optimal network reach within a network.

Borgatti's algorithms for both KPP-Positive and KPP-Negative are detailed in his paper "Identifying sets of key players in a social network" and are implemented in Borgatti's KeyPlayer software program. The KPP-Negative implementation measures the fragmentation of the network as a set of nodes is removed from the network. The KPPPositive implementation measures the reach value of a set of nodes as the percentage of the network reached.

\subsubsection{Natural ecosystem analysis}

Analytical methods used in natural ecosystem analysis tend to rely on graph theory and network analysis to reveal interactions between entities and identify their roles within the system (Jordan et al, 2006). In ecological networks the Topological Importance (TI) index quantifies the network position of a species and is particularly used in food web 
networks. By measuring the effect a node on other nodes within a pre-defined n-step length, researchers are considering the effect of a node in a network outside it is immediate neighbourhood. Therefore, this measurement examines a nodes effect on its indirect neighbours. The $\mathrm{TI}$ measurement is relevant to this research because it examines undirected and unweighted networks, where relationship and link direction does not add any bias to the analysis. Similar to the food web network, the API affiliate network and the API provider network have indirect links were the effects of one node may spread in many directions.

$\mathrm{Tl}^{\mathrm{n}}$ index is used in this research to measure the uniqueness and importance of nodes in the API affiliate network. The $\mathrm{TI}^{\mathrm{n}}$ implementation is described in details in "Network analysis in CoSBiLab Graph" and is implemented in the CoSBiLab Graph 1.0 software (Jordan and Valentini, 2010). The algorithm assumes a network with undirected links and hence it can be applied to the API affiliate network.

\subsection{Research software}

Listed below are the tools that were used in this research:

- $\mathrm{R}$ software suite - version 2.12.0. The $\mathrm{R}$ programming suite was used to implement the graphical representations and the SNA techniques used in this research. The igraph software package was used to conduct the SNA analysis in this research.

- KeyPlayer software - version 1.45. The KeyPlayer software, developed by Steve Borgatti, was used to conduct the key player analysis techniques examined in this research. 
- The CoSBiLab Graph - version 1 0.0.91112.1. The CoSBiLab software was used in this research to calculate the $\mathrm{Tl}$ analysis. 


\section{RESULTS AND DISCUSSIONS}

This chapter focuses on the observed results obtained from the analytical techniques described in previous chapters. The first and second sections summarise and discuss the results from the API affiliate network and API provider affiliate network. The third section provides a summary and an overall discussion of the results.

\subsection{API affiliate network}

This section will present and discuss the results of the analysis performed on the API affiliate network.

\subsubsection{Network properties}

As previously noted, the API affiliate network was constructed from the API edgelist extracted from the ProgrammableWeb.com. Appendix A provides a sample of the API edgelist extracted from 2168 mashups using 638 APIs. The API affiliate network is an undirected and unweighted network containing 638 nodes and 8498 unique edges. The network is large and with a high number of connections is very difficult to analyse using simple graphing techniques. Figure 2 presents a sample of the API affiliate network based on the top 10 most popular APIs.

Figure 3 presents the network where each API has a minimum of 30 connections to other APIs. Visually examining these graphs, one can speculate that there is a core network where APIs are densely connected due to their popularity and use in the majority of mashups. 


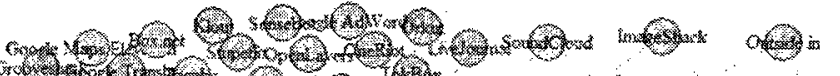

1. T.

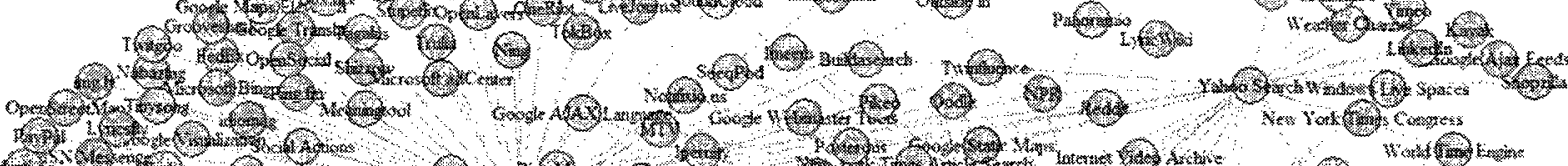

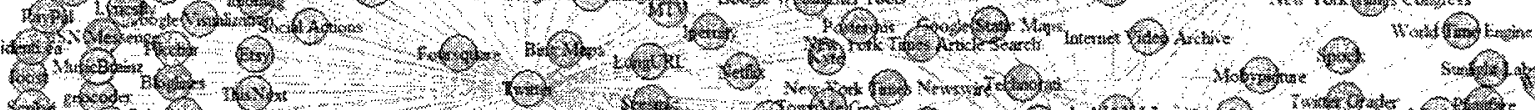

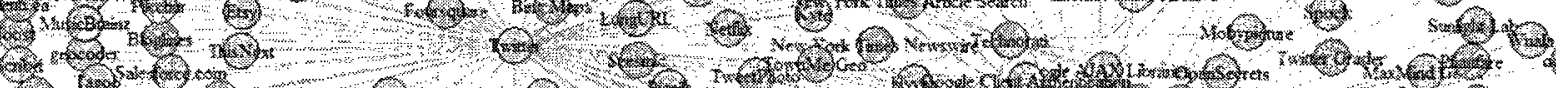

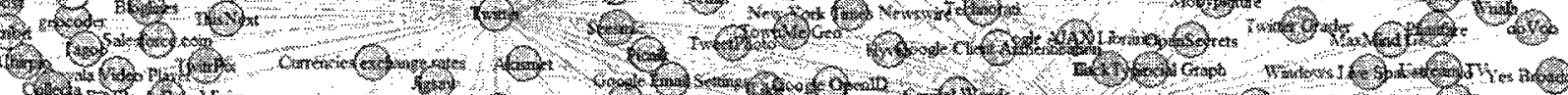

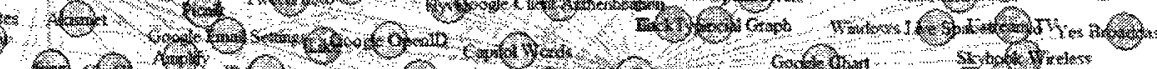

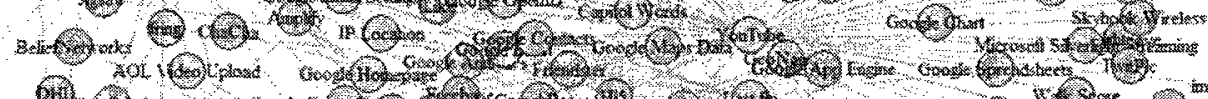

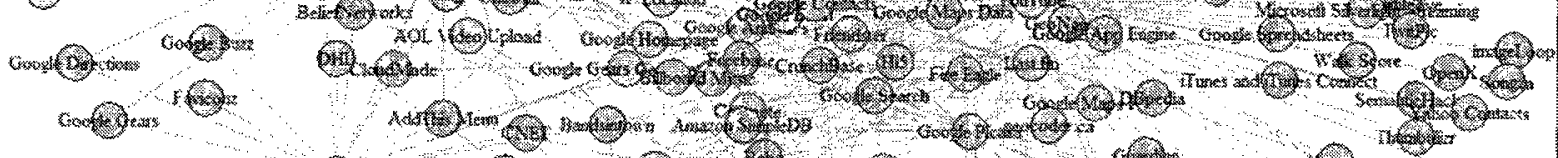

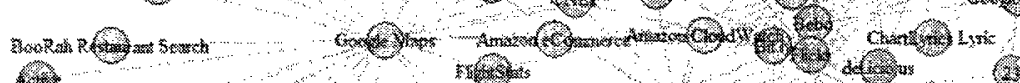

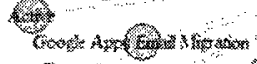
cofer.

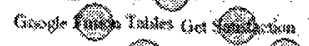
Beses

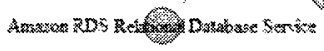

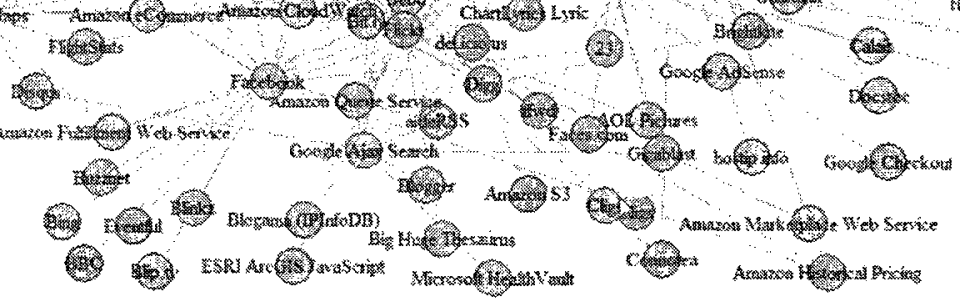

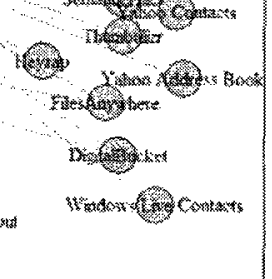

Figure 2: Subset of the API affiliate network

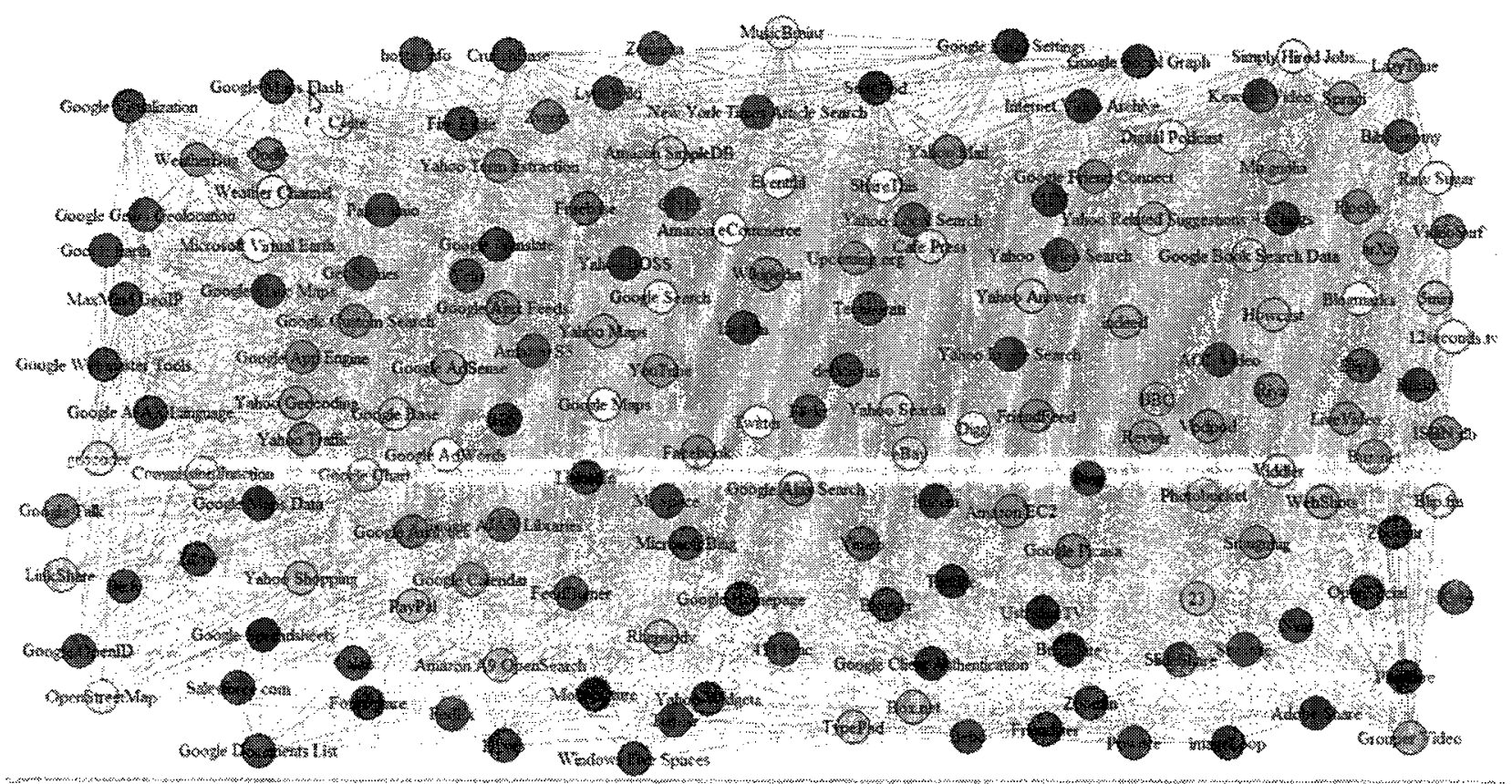

Figure 3: Subset of the API affiliate network (30 minimum connections) 


\section{Network density analysis}

The measurement of network density for the API affiliate network is 0.042 . This is a fairly low value since the highest possible value for network density is 1 , indicating a low degree of interaction between APIs. Figures 2 and 3 of the API affiliate network, presented above, indicate a central core network, however, the network density measurement is low, which is not expected. One can assess that the low network density measurement is because the central core network is comprised of a smaller percentage of the APIs in the network. This also reveals that the majority of the APIs in the network are loosely connected to the rest of the APIs. This reflects that the majority of the APIs are specialized, appeal to a smaller group of mashup developers and are hence used in less mashups.

\subsubsection{Centrality analysis}

Appendix B presents a sample of the various centrality measurements for the 638 APIs in the affiliation network. Degree, betweenness, closeness and eigenvector centrality were measured in this study.

\section{Degree centrality}

Looking at the API affiliate network, a node with high degree centrality value indicates that that node is connected to a large number of APIs in the network and therefore contributes heavily to the ecosystem. Degree centrality can be used to measure an APl's direct contribution to the mashup ecosystem. However, as this measurement only accounts for direct connections, it does not provide any information related to how the API fits within the entire network. The degree centrality of the top 15 APIs is presented 
in Table 4. The Google Maps API has the highest degree centrality with 329 direct links to other APIs, followed by Flickr, YouTube, Twitter, Facebook and Amazon eCommerce. The degree centrality measurements confirm that there are no isolates in the network as there are no nodes with a degree measurement of 0 .

The degree centrality measurements indicate that $4.2 \%$ of the APIs have a degree centrality higher than 100 . The measurements indicate that 27 of the 638 APIs in the network contribute to $27 \%$ of the total degree of the network. Such a high contribution level indicates that these APIs are used heavily by API developers and play a central role in the mashup ecosystem. Figure 4 presents a plot of degree centrality measurements versus API rank.

\begin{tabular}{|l|r|}
\hline API name & Degree centrality \\
\hline Google Maps & 329 \\
\hline Flickr & 301 \\
\hline YouTube & 294 \\
\hline Twitter & 290 \\
\hline Facebook & 221 \\
\hline Amazon eCommerce & 218 \\
\hline Google Search & 199 \\
\hline del.icio.us & 198 \\
\hline Yahoo Search & 194 \\
\hline Last.fm & 180 \\
\hline Google Ajax Search & 179 \\
\hline Digg & 169 \\
\hline Technorati & 162 \\
\hline Google Picasa & 149 \\
\hline FriendFeed & 139 \\
\hline
\end{tabular}

Table 4: Sample of degree centrality measurements for API affiliate network 


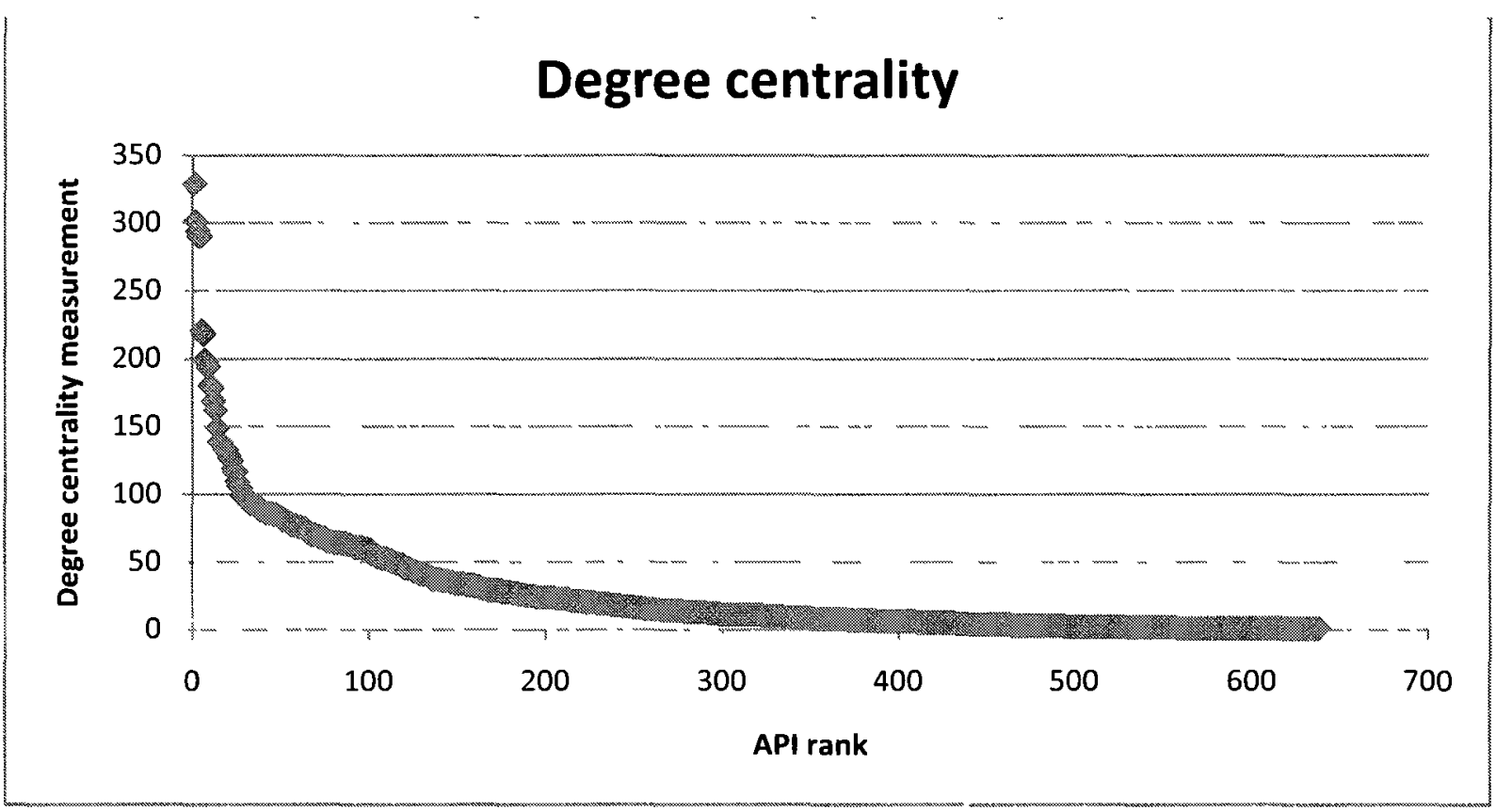

Figure 4: Degree centrality measurements in the API affiliate network

\section{Betweenness centrality}

Nodes with a high betweenness centrality measurements act as brokers and gatekeepers in a network. In the API affiliate network, a node with high betweenness centrality indicates that a node has been used in a number of mashups and indicates the complementary nature of the API as it is used with a number of other APIs. Table 5 below presents a sample of betweenness centrality measurements in this network and figure 5 presents a plot of betweenness centrality measurements versus API rank. The top 6 APIs with highest degree centrality measurements are Google Maps, Twitter, Flickr, YouTube, Amazon eCommerce, and Facebook. 


\begin{tabular}{|l|l|}
\hline API name & Betweenness centrality \\
\hline Google Maps & 39002.08 \\
\hline Twitter & 24429.70 \\
\hline Flickr & 18044.54 \\
\hline YouTube & 16756.21 \\
\hline Amazon eCommerce & 12502.03 \\
\hline Facebook & 10663.73 \\
\hline del.icio.us & 6710.02 \\
\hline Digg & 6574.39 \\
\hline Box.net & 6192.99 \\
\hline Yahoo Search & 6054.00 \\
\hline Google Search & 5663.24 \\
\hline Google Homepage & 5464.53 \\
\hline Last.fm & 5213.02 \\
\hline Google Ajax Search & 3601.54 \\
\hline Yahoo Maps & 3277.52 \\
\hline
\end{tabular}

Table 5: Sample of betweenness centrality measurements for API affiliate network

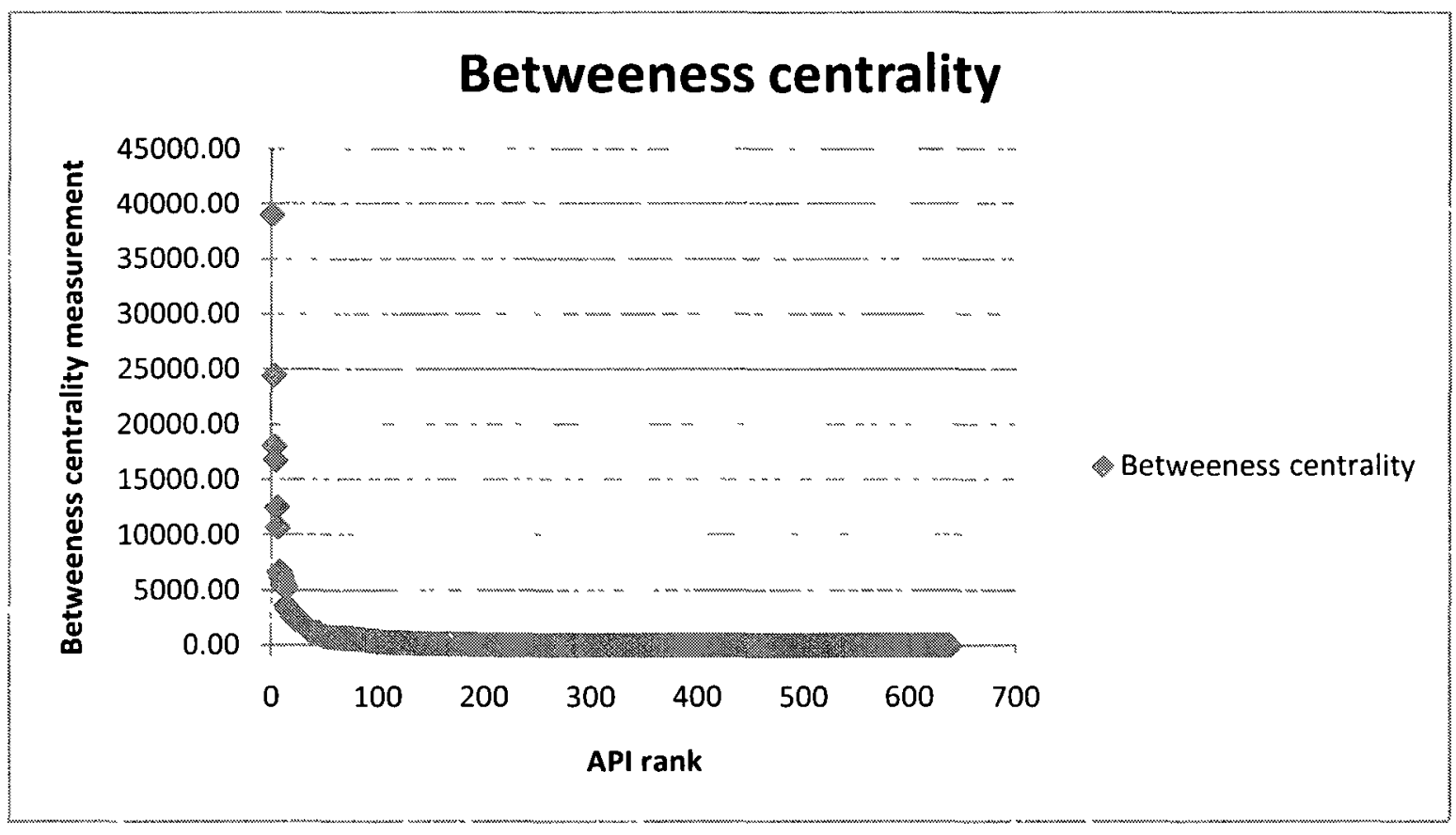

Figure 5: Betweenness centrality measurements in the API affiliate network 


\section{Closeness centrality}

The nodes in the API affiliate network have closeness centrality values of $0,0.10,0.11$, 0.12 and 0.13 . Table 6 summarises the closeness centrality measurements observed in this network.

\begin{tabular}{|l|l|l|}
\hline $\begin{array}{l}\text { Closeness centrality } \\
\text { measurement }\end{array}$ & Total number of APIs & Percentage of APIs (\%) \\
\hline 0.13 & 67.00 & 10.50 \\
\hline 0.12 & 459.00 & 72.00 \\
\hline 0.11 & 99.00 & 15.50 \\
\hline 0.10 & 7.00 & 1.10 \\
\hline 0.00 & 6.00 & 0.90 \\
\hline
\end{tabular}

Table 6: Closeness centrality measurements in the API affiliate network

The measurements presented in Table 6 demonstrate that the majority of nodes in the network are connected through other nodes. However, the top 67 APIs have are more closely connected than others in the network. With such similar values it is difficult to identify which specific APIs hold a more prominent position in the network based on closeness centrality. One can conclude that closeness centrality measurements are not ideal in identifying high ranking APIs in the API affiliate network. However, based on these results, one can speculate that the group of $67 \mathrm{APIs}$ are the most visible within the network as they have the shortest paths to all other APIs and therefore have direct and indirect to the rest of nodes in the network.

\section{Eigenvector centrality}

The top 15 eigenvector centrality measurements of the API affiliate network are presented Table 7. As not earlier, the network does not contain any isolates and therefore all of the APIs are included when determining which APIs are connected to 
other central APIs. Flickr, YouTube, Twitter, and Google Maps are the highest ranking APIs with eigenvector centrality measurements of $1.00,0.99,0.96$, and 0.92 . All of these APIs hold key positions in the network as they are connected to other central APIs.

\begin{tabular}{|l|l|}
\hline API name & Eigenvector centrality \\
\hline Flickr & 1.00 \\
\hline YouTube & 0.99 \\
\hline Twitter & 0.96 \\
\hline Google Maps & 0.92 \\
\hline del.icio.us & 0.84 \\
\hline Google Search & 0.84 \\
\hline Yahoo Search & 0.82 \\
\hline Amazon eCommerce & 0.82 \\
\hline Google Ajax Search & 0.79 \\
\hline Facebook & 0.79 \\
\hline Digg & 0.79 \\
\hline Last.fm & 0.78 \\
\hline Technorati & 0.77 \\
\hline Google Picasa & 0.77 \\
\hline FriendFeed & 0.73 \\
\hline
\end{tabular}

Table 7: Sample of eigenvector centrality measurements for API affiliate network

These measurements indicate that mashup developers tend to use APIs that are already central and are already connected to other central APIs. API providers entering the mashup ecosystem may want to look at releasing APIs that are compatible with these APIs as it may encourage developers to use their APIs when developing mashups. 
It is apparent that another set of APIs hold a secondary central position in the network with eigenvector centrality measurements of 0.84 and 0.82 . These APIs are del.icio.us, Google Search, Yahoo Search, and Amazon eCommerce. In addition, 9.4\% of the APIs have an eigenvector centrality measurement of zero and therefore are not connected to any other central APIs in the network.

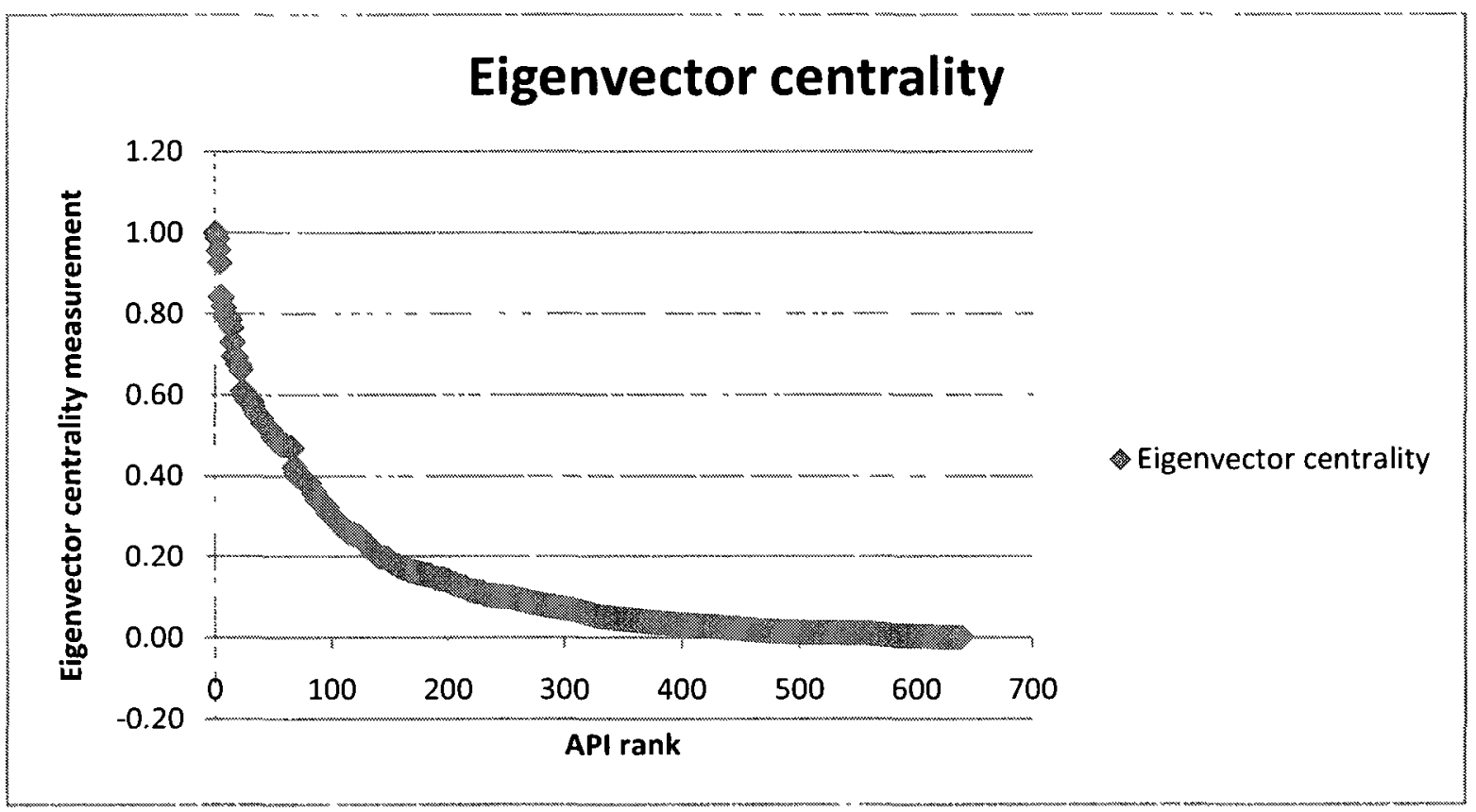

Figure 6: Eigenvector centrality measurements in the API affiliate network

\subsubsection{Community analysis}

The Girvan-Newman community detection algorithm was applied to the API affiliate network and a sample of the results is represented in Appendix C. The algorithm identified one large, central community with 56 APIs, 27other smaller communities, and 507 singleton communities that contain a single API. These communities can be viewed as API collectives that are formed because they are deployed in the mashup development. 
The results indicate no overlap and a clear split between the collectives since none of the nodes belong to more than one collective, as seen in Appendix C. Examining the Figure 7 presents a subset of the collective structure of the API affiliate network. In this figure all the smaller collectives were removed to better present of the collectives detected in this analysis.

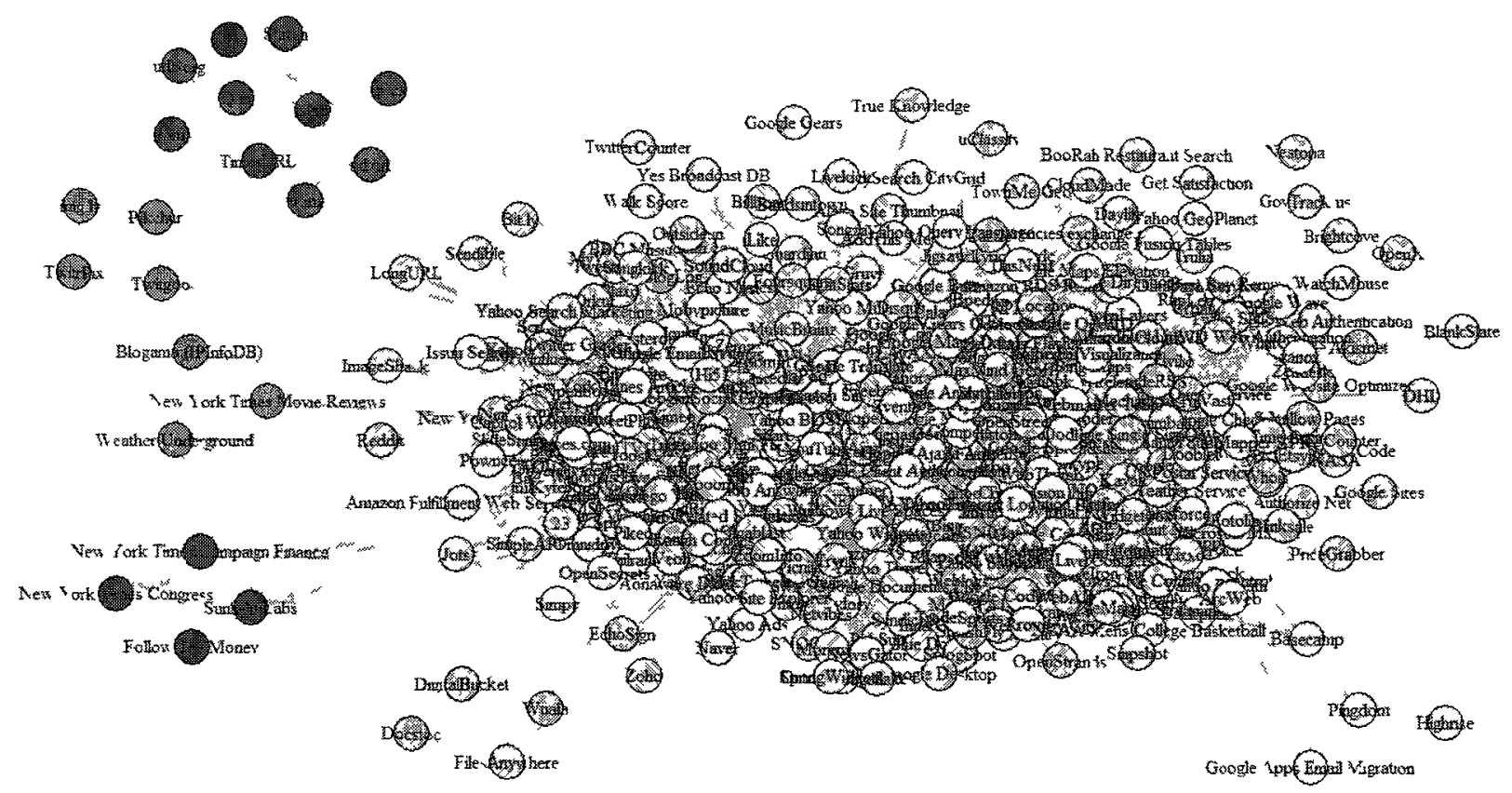

Figure 7: Community structure in the API affiliate network

The largest collective identified by the analysis contains 56 APIs, which reflects the popularity of these APIs as they are used together in a large number of mashups and as a consequence the connections between these APls are stronger than their connections to the remainıng APIs in the network. The strong connections between these APIs reflect their complementary nature as they tend to be used together in varıous mashups. This also suggests that various API developers tend to the same APIs in mashup development. 
The smaller collectives identified are presented in Table 8. There are 27 collectives composed of two to ten APIs. These groups of APIs are identified as smaller cluster because they are closely linked to each other than other APIs in the affiliate network. This speaks to the complementary nature of these APIs and that mashup developers tend to use them together when creating mashups. However, when examining the API's it is becomes apparent that they are specialised and tend to appeal to a smaller set of developers

The algorithm also identified 507 single APIs that can be viewed as a "collective of one". These singleton APIs are an indication that these APIs are specialized and are used rarely used in mashup development. 


\begin{tabular}{|c|c|c|}
\hline $\begin{array}{l}\text { Newman cluster } \\
\text { number }\end{array}$ & $\begin{array}{l}\text { Total APIs per } \\
\text { cluster }\end{array}$ & API name \\
\hline 358 & 10 & $\begin{array}{l}\text { Cligs } \\
\text { is.gd } \\
\text { nd url } \\
\text { qr.cx } \\
\text { Qurl } \\
\text { r.im } \\
\text { Shrten } \\
\text { TimesURL } \\
\text { tr.im } \\
\text { urlBorg }\end{array}$ \\
\hline 169 & 6 & $\begin{array}{l}\text { Follow The Money } \\
\text { Sunlight Labs } \\
\text { Maplight } \\
\text { New York Times Campaign Finance } \\
\text { New York Times Congress } \\
\text { OpenSecrets }\end{array}$ \\
\hline 354 & 4 & $\begin{array}{l}\text { DigitalBucket } \\
\text { Docstoc } \\
\text { FilesAnywhere } \\
\text { Wuala }\end{array}$ \\
\hline 440 & 4 & $\begin{array}{l}\text { img.ly } \\
\text { Pikchur } \\
\text { Twitgoo } \\
\text { TwitrPix }\end{array}$ \\
\hline 242 & 3 & $\begin{array}{l}\text { Google Apps Email Migration } \\
\text { Highrise } \\
\text { Pingdom }\end{array}$ \\
\hline 360 & 3 & $\begin{array}{l}\text { Blogama (IPInfoDB) } \\
\text { New York Times Movie Reviews } \\
\text { Weather Underground }\end{array}$ \\
\hline 403 & 3 & $\begin{array}{l}\text { Dun and Bradstreet Business } \\
\text { Verification } \\
\text { QuickBase }\end{array}$ \\
\hline 129 & 2 & $\begin{array}{l}\text { Geograph } \\
\text { Geocubes }\end{array}$ \\
\hline
\end{tabular}

Table 8: Sample of the communities in the API affiliate network 


\subsubsection{Key player analysis}

The KPP-Negative and KPP-Positive results are presented in Appendix D and E. For KPP-Negative, the fragmentation criterion was used and reciprocal distance index was used for KPP-Positive.

In KPP-Negative analysis, the research identified a set of key players in the network that optimally disrupt the network structure when removed. The algorithm was run through a number of times, where APIs were gradually removed, while measuring network fragmentation. The analysis started by removing one node, then two nodes, then three nodes and so on. In addition, the change in fragmentation was calculated to determine the percentage increase in fragmentation as more nodes were removed.

Removing the first node, identified by the algorithm to be, Google Maps, generates a network fragmentation measurement of 0.068 and thereby increasing the network fragmentation by $258 \%$. The removal of Google Maps disconnects 16 APIs from the rest of the network and causes the removal of 329 edges from the network. However, the fragmentation caused by the removal of Google Maps does not optimally disrupt the network.

With continual removal of nodes, the researcher identified an optimal set of APIs that yields the most network disruption. The set contains the following six APIs: Google Maps, Flickr, Google Homepage, Twitter, Facebook, and Box.net. The removal of this set of APIs increases the fragmentation of the network by $895 \%$ and results in the isolations of $107 \mathrm{APIs}$ from the rest of the network and the removal of 1274 edges. This also results in the isolation of 2 smaller networks, comprised of 2 APIs each from the 
rest of the network, as presented in the figure below.

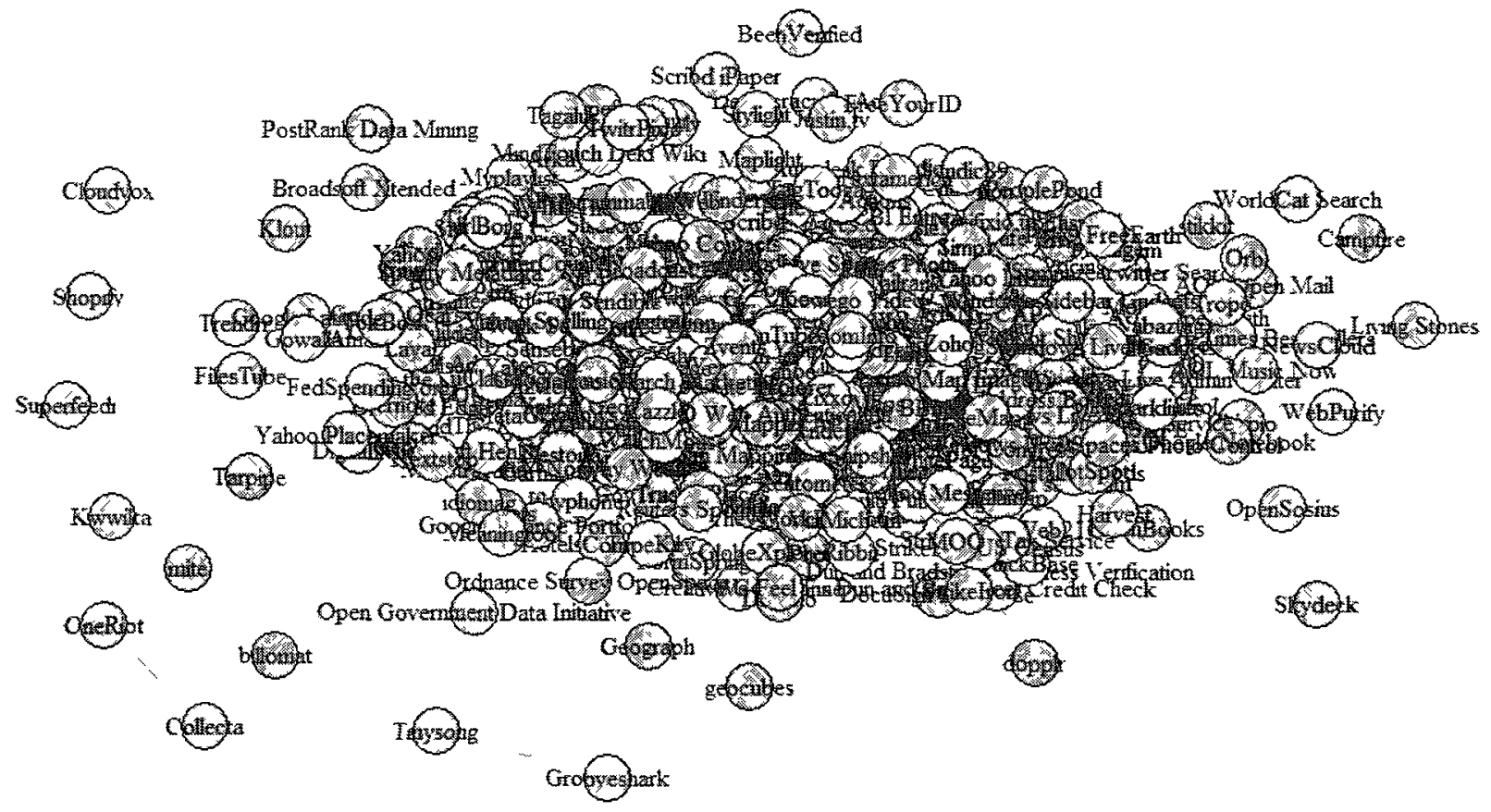

\section{Figure 8: Fragmentation of the API affiliate network}

As more nodes are removed fragmentation continues and can potentially continue until all the nodes are isolates. The figure below, presents the increase in fragmentation level as a function of number of nodes removed. 


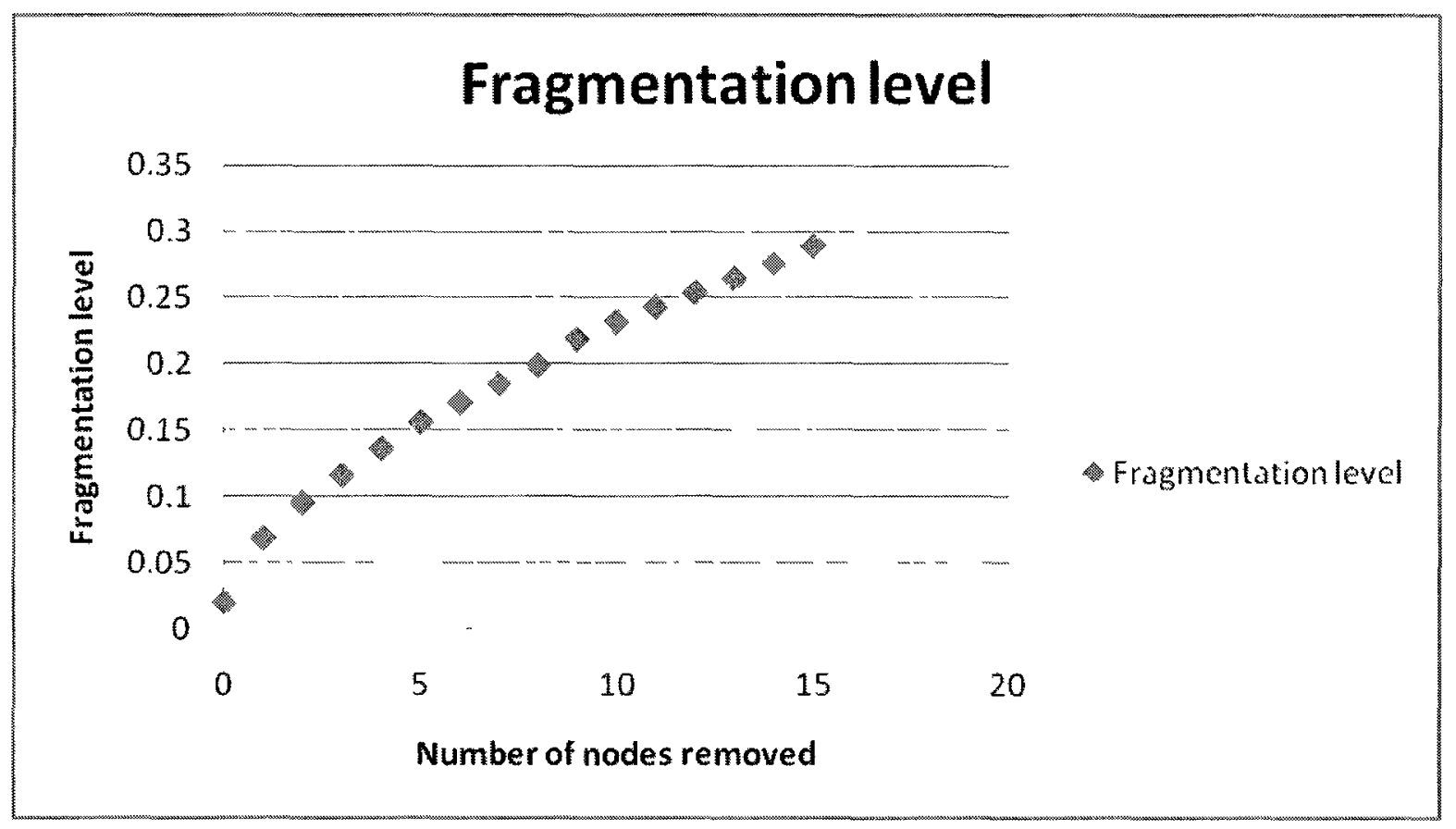

Figure 9: Network fragmentation level for the API affiliate network

The second problem in key player identification is KPP-Positive used to identify a set containing the least number of nodes that are the most connected in the network and would reach all other nodes quickly and thereby exert a high influence in the network. By measuring the reciprocal index of a set of APIs, the researcher identified a set of nodes that have more influence in the network as a group rather than individually. KPPPositive measures the sum of the reciprocal distance from the set of key players to all the nodes, where the distance between the set to a node is defined as minimum distance.

Based on the KPP-Positive results, Google Maps has a reciprocal distance index of $73.9 \%$ and therefore is essential to the mashup ecosystem due its ability to reach other nodes. By calculating the increase in reciprocal index, it is apparent the optimal set containing the least number of APIs with the highest connectivity in the network 
contains six APIs. These are Google Maps, Amazon eCommerce, Flickr, YouTube, Twitter, and Box.net. The reciprocal distance index for this set of APIs is $89.7 \%$, indicating their core position in the network as they can collectively reach a large portion of the network. The plot below presents the increase in reciprocal distance index as the set of key player increases.

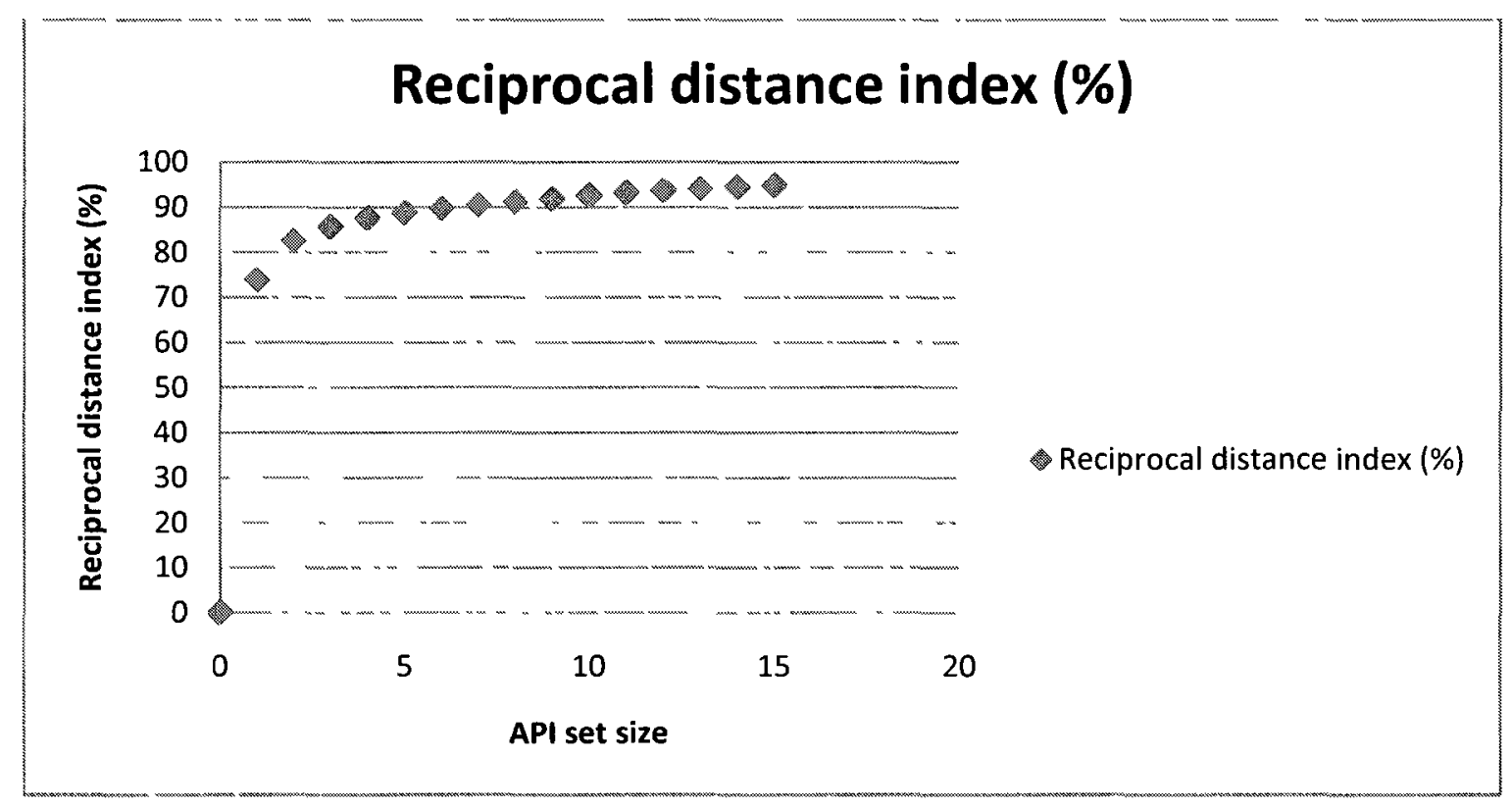

Figure 10: Reciprocal distance index for the API affiliate network

As seen in table 9, the two algorithms reveal two different sets of key players. KPP-

Negative demonstrates that graph becomes disconnected without these APIs, indicating that these APIs are used in more mashups than other APIs in the network. On the other hand, KPP-Positive reveals the set's reach and influence with the API affiliate network. Thereby, this measurement indicates that these APIs are influential and are used with different APIs in various mashups and therefore have a stronger reach into the network. The comparison also reveals an overlap between the two sets of APIs. Google Maps, 
Flickr, Twitter and Box.net are identified as key players by both KKP-Negative and KPPPositive calculations.

However, there are some differences. KPP-Negative reveals that Google Homepage and Facebook belong to this optimal set of key player. This finding is justified by examining the centrality measurements of these APIs. Both Google Homepage and Facebook have relatively high betweenness centrality values and therefore their removal would disconnect other APIs in the network. On the other hand, KPP-Positive reveals that Amazon eCommerce and YouTube have strong reach within the network. Again by examining their centrality measurements one observes that they both have relatively high degree, betweenness, and eigenvector centrality values, which increases their direct and indirect reach to other nodes in the network.

\begin{tabular}{|l|l|l|}
\hline KPP algorithm & Group size & Key players \\
\hline KPP-Negative & 6 & $\begin{array}{l}\text { Google Maps } \\
\text { Flickr } \\
\text { Google Homepage } \\
\text { Twitter } \\
\text { Facebook } \\
\text { Box.net }\end{array}$ \\
\hline KPP-Positive & 6 & $\begin{array}{l}\text { Google Maps } \\
\text { Amazon eCommerce } \\
\end{array}$ \\
& & $\begin{array}{l}\text { Flickr } \\
\text { YouTube } \\
\text { Twitter } \\
\text { Box.net }\end{array}$ \\
\hline
\end{tabular}

Table 9: Optimal key player sets in the API affiliate network 


\subsubsection{Topological importance analysis}

The topological importance results are presented in Appendix F. The $\mathrm{TI}$ was calculated with various values for $n$, which assesses that effect an entity has on others within $n$ steps from its position. In this research $\mathrm{TI}^{n}$ was calculated for $n=1, n=2, n=3$, and $n=5$.

Examining the results where $n=1$, outline in table 10 , it is evident that with a path length of 1 , Google Maps has the highest topological index value $(\mathrm{TI}=38.60)$ representing its unique importance to the network and its impact on other entities within one step from it. It is followed by Amazon eCommerce, Flickr, Facebook, Amazon EC2, with TI values of $31.08,21.12,16.18$, and 13.45, respectively. Based on this Google Maps has the highest positional importance in the network.

\begin{tabular}{|l|l|}
\hline API & TI index $(\mathbf{n = 1})$ \\
\hline Google Maps & 38.60 \\
\hline Amazon eCommerce & 31.08 \\
\hline Flickr & 21.12 \\
\hline Facebook & 16.18 \\
\hline AmazonEC2 & 13.45 \\
\hline Box.net & 12.36 \\
\hline del.icio.us & 11.72 \\
\hline Digg & 8.80 \\
\hline AmazonS3 & 8.27 \\
\hline Google Homepage & 7.66 \\
\hline Google Search & 7.61 \\
\hline AOL Video & 6.76 \\
\hline Google App Engine & 6.46 \\
\hline Google Ajax Search & 6.10 \\
\hline Blogger & 6.05 \\
\hline
\end{tabular}

Table 10: TI index $(n=1)$ for the API affiliate network 
Conducting the same TI calculations with a path length of two, results in a change in the topological mapping of the network. This is represented in Table 11. In this case, Amazon eCommerce has the highest TI measurement of 27.19 , followed by Google Maps, Amazon EC2, and Flickr, and with TI values of 24.16, 16.41, and 15.42, respectively.

\begin{tabular}{|l|l|}
\hline API & Tl index $(\mathbf{n}=\mathbf{2})$ \\
\hline Amazon eCommerce & 27.19 \\
\hline Google Maps & 24.16 \\
\hline AmazonEC2 & 16.41 \\
\hline Flickr & 15.42 \\
\hline 12seconds.tv & 12.45 \\
\hline Facebook & 11.68 \\
\hline AmazonS3 & 10.32 \\
\hline 23 & 10.01 \\
\hline del.icio.us & 9.22 \\
\hline Box.net & 8.93 \\
\hline AOL Video & 8.42 \\
\hline Digg & 7.79 \\
\hline Blogger & 7.68 \\
\hline 43Things & 7.26 \\
\hline Amazon A9 OpenSearch & 6.42 \\
\hline
\end{tabular}

\section{Table 11: TI index $(n=2)$ for the API affiliate network}

Examining the TI results when a path length of three yields a further change in the topological mapping of the API affiliate network. As seen in table 12, Amazon eCommerce remains as the API with the highest $\mathrm{TI}$ value of 27.58 . It is followed by Amazon eCommerce, 12seconds.tv, Amazon EC2, Google Maps, and 23.

The $\mathrm{TI}$ index measurements continue to change as the path length increases to 5 . In this case, 12 seconds.tv is distinguished with a higher $\mathrm{TI}$ index of 34.20 , followed by Amazon eCommerce, Amazon EC2 and 23. 


\begin{tabular}{|l|l|}
\hline API & TI index $(\mathbf{n}=\mathbf{3})$ \\
\hline Amazon eCommerce & 27.58 \\
\hline 12seconds.tv & 22.58 \\
\hline AmazonEC2 & 18.35 \\
\hline Google Maps & 17.70 \\
\hline 23 & 13.19 \\
\hline Flickr & 12.22 \\
\hline AmazonS3 & 11.05 \\
\hline 43Things & 10.46 \\
\hline Facebook & 9.41 \\
\hline AOL Video & 8.99 \\
\hline 5min & 8.12 \\
\hline Amazon A9 OpenSearch & 7.85 \\
\hline Blogger & 7.66 \\
\hline del.icio.us & 7.56 \\
\hline Box.net & 7.19 \\
\hline
\end{tabular}

Table 12: TI index $(n=3)$ for the API affiliate network

\begin{tabular}{|l|l|}
\hline API & TI index $(\mathbf{n}=5)$ \\
\hline 12seconds.tv & 34.20 \\
\hline Amazon eCommerce & 22.90 \\
\hline Amazon EC2 & 18.16 \\
\hline 23 & 13.90 \\
\hline 43Things & 12.65 \\
\hline Google Maps & 11.32 \\
\hline Amazon S3 & 9.29 \\
\hline 5min & 8.91 \\
\hline 30Boxes & 8.37 \\
\hline Amazon A9 OpenSearch & 8.12 \\
\hline AOL Video & 8.02 \\
\hline Flickr & 7.93 \\
\hline 411Sync & 7.54 \\
\hline Facebook & 6.21 \\
\hline Blogger & 6.01 \\
\hline
\end{tabular}

Table 13: $\mathrm{Tl}$ index $(n=5)$ for the API affiliate network 
Based on the above results it is clear that the TI value is impacted by the path length used to conduct the calculation because it takes into consideration the length of indirect effects a nodes has on the others. As the path length increases, there is a shift in the positional importance of some APIs and their effect on others in the network.

Comparing the results of the $\mathrm{Tl}$ calculations with path lengths of $1,2,3$, and 5 is critical in understanding the changes in the Topological Importance indices measured. This comparison, presented in Table 14 reveals some APIs decrease in positional importance as the path length increases, while others decrease. In addition, the comparison reveals that some APIs maintain a similar positional importance despite the changes in path length. For instance, Blogger, AOL Video, and Amazon S3 have similar TI values, revealing their unique position in the network and are able to maintain their influence at the different levels of reach.

When examining an API's influence on its immediate neighbourhood, APIs like Google Maps, Amazon eCommerce and Flickr appear to have high influence but with by examining wider and in-direct neighbourhood with an increase in path length, that influence decreases. Surprisingly, other APIs like Amazon EC, 12seconds.tv, 23 and 43Things exhibit an increase in influence with an increase in path length. These APIs; however have a unique interaction with the network that was underestimated by other measurements. These APIs are not extremely popular in comparison to APIs like Google Maps and Flickr but when examining their centrality measurements it becomes evident that they have high eigenvector centralities and therefore are connected to high ranking APIs. Thus the increase in their network reach is influenced by their connectivity to central APIs and they gain their influence by "proxy". 


\begin{tabular}{|l|l|l|l|l|l|}
\hline API & $\begin{array}{l}\text { TI index } \\
(\mathbf{n}=\mathbf{1})\end{array}$ & $\begin{array}{l}\text { TI index } \\
(\mathbf{n}=\mathbf{2})\end{array}$ & $\begin{array}{l}\text { TI index } \\
(\mathbf{n}=\mathbf{3})\end{array}$ & $\begin{array}{l}\text { TI index } \\
(\mathbf{n}=\mathbf{5})\end{array}$ & Change \\
\hline Google Maps & 38.60 & 24.16 & 17.70 & 11.32 & $\downarrow$ \\
\hline $\begin{array}{l}\text { Amazon } \\
\text { eCommerce }\end{array}$ & 31.08 & 27.19 & 27.58 & 22.90 & $\downarrow$ \\
\hline Flickr & 21.12 & 15.42 & 12.22 & 7.93 & $\downarrow$ \\
\hline Facebook & 16.18 & 11.68 & 9.41 & 6.21 & $\downarrow$ \\
\hline Amazon EC2 & 13.45 & 16.41 & 18.35 & 18.16 & $\uparrow$ \\
\hline Box.net & 12.36 & 8.93 & 7.19 & 4.90 & $\downarrow$ \\
\hline del.icio.us & 11.72 & 9.22 & 7.56 & 5.09 & $\downarrow$ \\
\hline Digg & 8.80 & 7.79 & 6.56 & 4.41 & $\downarrow$ \\
\hline Amazon S3 & 8.27 & 10.32 & 11.05 & 9.29 & $\leftrightarrow$ \\
\hline AOL Video & 6.76 & 8.42 & 8.99 & 8.02 & $\leftrightarrow$ \\
\hline Blogger & 6.05 & 7.68 & 7.66 & 6.01 & $\leftrightarrow$ \\
\hline 23 & 5.61 & 10.01 & 13.19 & 13.90 & $\uparrow$ \\
\hline 12seconds.tv & 4.80 & 12.45 & 22.58 & 34.20 & $\uparrow$ \\
\hline Twitter & 4.57 & 2.41 & 1.62 & 0.98 & $\downarrow$ \\
\hline 43Things & 2.93 & 7.26 & 10.46 & 12.65 & $\uparrow$ \\
\hline 5min & 2.30 & 6.35 & 8.12 & 8.91 & $\uparrow$ \\
\hline
\end{tabular}

Table 14: Comparison of TI measurements for API affiliate network 


\subsection{API provider network}

This section will present and discuss the results preformed on the API provider network. Table 18 below lists the API providers that offer more than one API.

\begin{tabular}{|l|}
\hline \multicolumn{1}{|c|}{ API provider (with more than one API) } \\
\hline Adobe \\
\hline Amazon \\
\hline AOL \\
\hline BBC \\
\hline eBay \\
\hline Google \\
\hline Microsoft \\
\hline New York Times \\
\hline Ooyala \\
\hline Photobucket \\
\hline Strikelron \\
\hline Yahoo \\
\hline
\end{tabular}

Table 15: API provider list

\subsubsection{Network properties}

Appendix G presents a sample of the API provider edgelist used to build the API provider affiliate network. The API provider affiliate network is an undirected, unweighted network manually built by replacing APIs with their respective. The network contains 483 API provider nodes and 4471 edges. A representation of the API provider affiliation network is represented in Figure 11 below. 


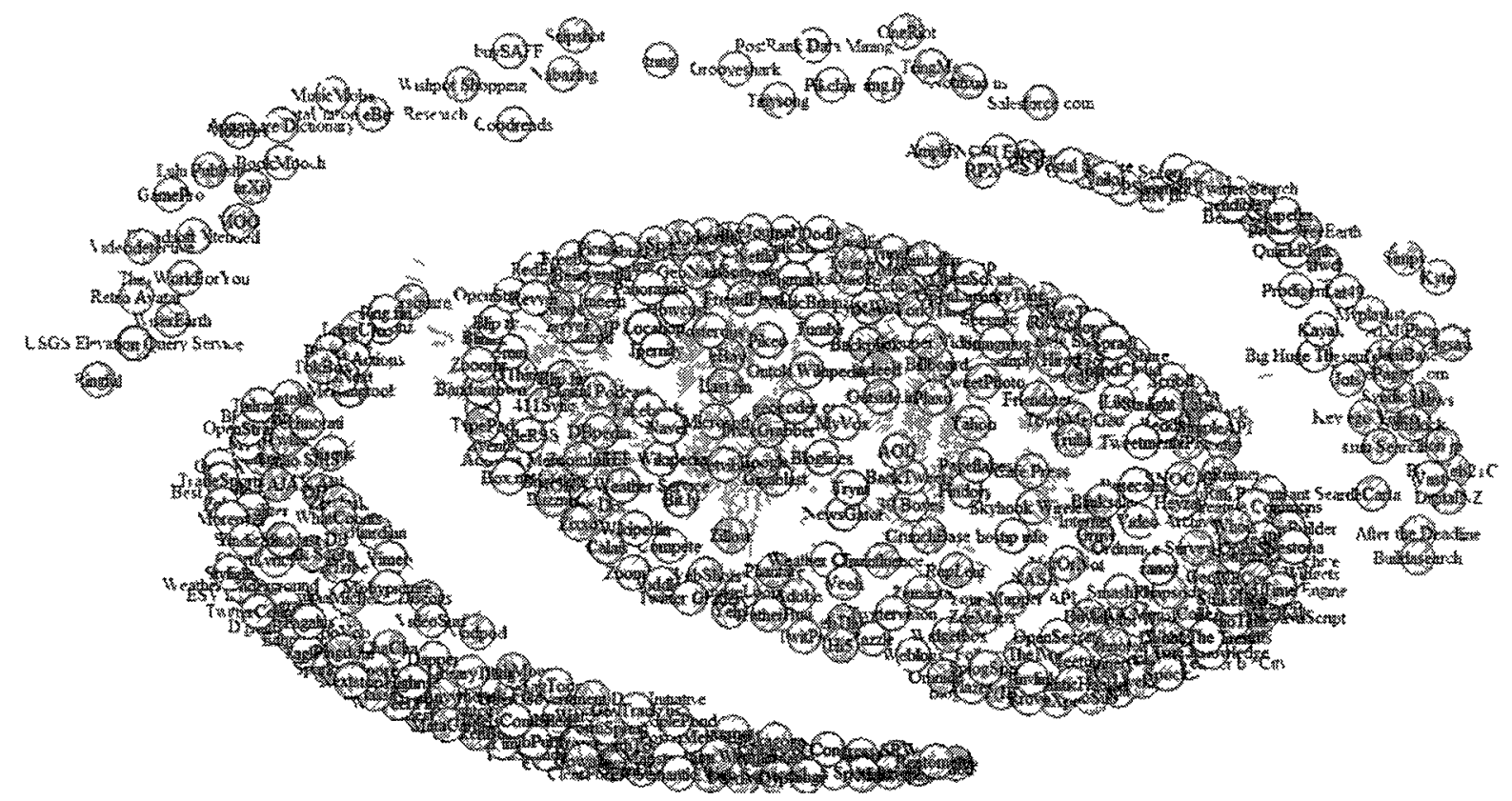

Figure 11: Subset of the API provider affiliate network

It should be noted, that self-loops can occur withın the API provider affiliate network since APIs from the same provider can be used in the same mashup. This could not occur in the API affiliate network because a mashup is created when data from two different APIs are combined to provide a service.

\section{Network density analysis}

The network density for the provider affiliate network is 0038 . This value is similar to that of the API affillate network of 0.041 and indicates that there is a low degree of interaction between providers. Since the network has many providers and low network density, one can assess that it is loosely connected where the providers have a low number of connections between the providers in comparison to the total number of possible connections in the network. 


\subsubsection{Centrality analysis}

The centrality measurements for the API provider affiliation network are presented in Appendix $\mathrm{H}$.

\section{Degree centrality}

A node with a high degree centrality measurement indicates that a provider is directly connected to a large number of other providers. It is a measurement of the provider's popularity in the mashup ecosystem. A high degree centrality also indicates that a provider contributes heavily to the mashup ecosystem through the release of APIs. However, this contribution does not reflect the number of APIs released or which APIs are more popular. This measurement does not provide an accurate reflection of how a provider fits within the network because it only accounts for direct connections.

Table 16 presents the top 15 API providers based on degree centrality measurements. The results indicate that Google has the highest degree centrality with 497 direct links to other provider, followed by Yahoo, Amazon, Twitter, Amazon, and Microsoft. Google and Yahoo account for $10 \%$ of the total degree measurements of the network as they provide a large number of the APIs in the mashup ecosystem. These degree centrality measurements indicate that the top 15 providers contribute to approximately $30 \%$ of the total degree of the network. It is not surprising that Google has the highest degree centrality, since this measurement represents Google's entire API contribution to the mashup ecosystem. However, companies like Yahoo, Amazon and Microsoft great influence in the ecosystem based on these measurements. Yahoo's status increase in the network is gained because it inherited all of Flickr's associations. Consequently, 
Amazon and Microsoft become more significant players because all their APIs are represented at the provider level.

\begin{tabular}{|l|l|}
\hline API provider & Degree centrality \\
\hline Google & 497 \\
\hline Yahoo & 409 \\
\hline Twitter & 210 \\
\hline Amazon & 196 \\
\hline Microsoft & 159 \\
\hline Facebook & 147 \\
\hline eBay & 134 \\
\hline Last.fm & 134 \\
\hline Digg & 127 \\
\hline Technorati & 111 \\
\hline AOL & 108 \\
\hline FriendFeed & 108 \\
\hline Eventful & 92 \\
\hline Wikipedia & 91 \\
\hline Vimeo & 81 \\
\hline
\end{tabular}

Table 16: Sample of degree centrality measurements for API provider affiliate network 


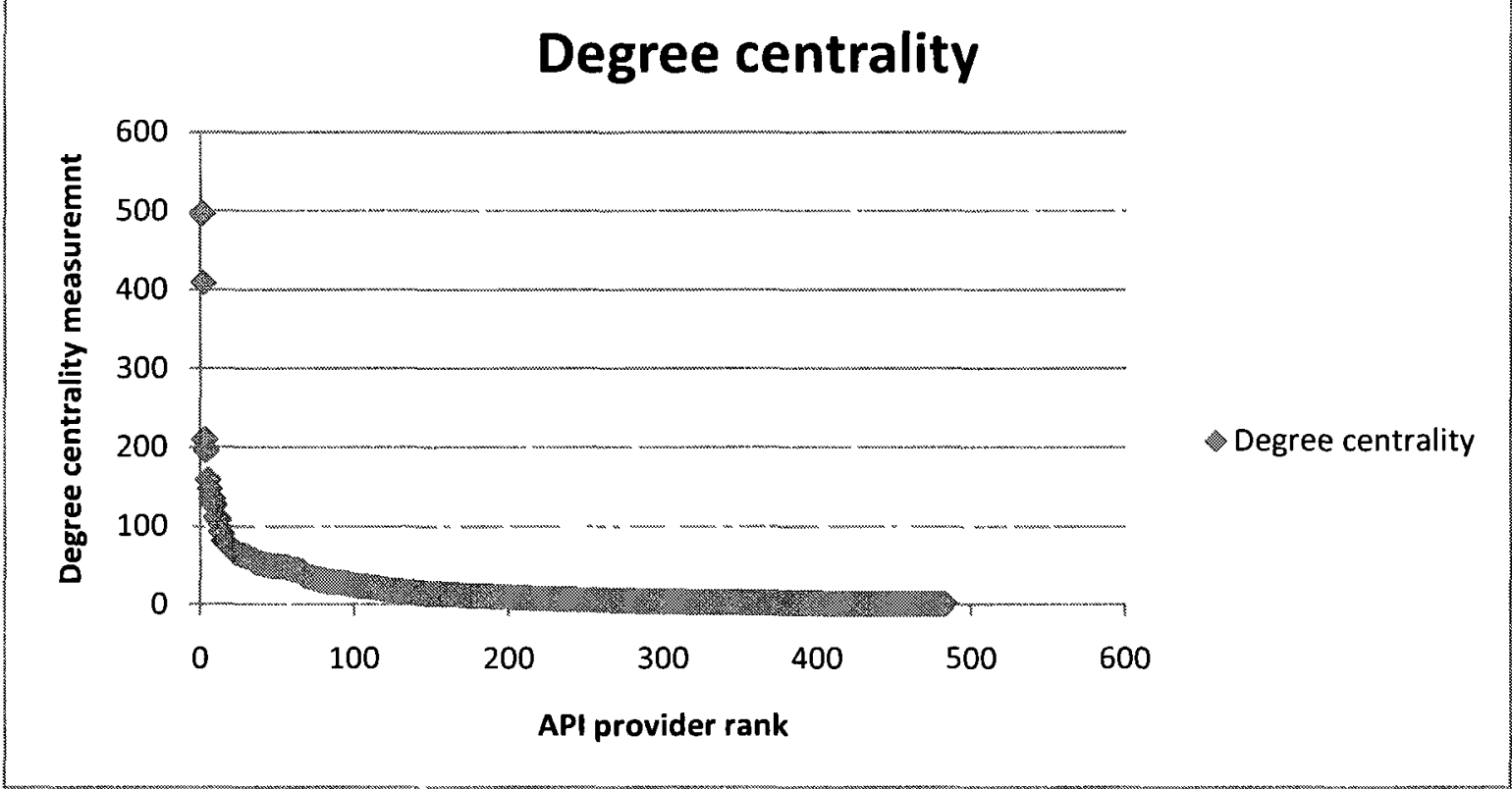

Figure 12: Degree centrality measurements in the API provider affiliate network

\section{Betweenness centrality}

Betweenness centrality is used to identify brokers, gatekeepers and liaisons in a network. Providers with high betweenness centrality measurements become single points of failures because removing them from the network will disconnect other providers. The top 15 providers with high levels of betweenness centrality values are listed in the Table 17.

It is not surprising that Google ranks highest with a betweenness centrality value of 51237.38 , indicating that it has a strong liaison or gatekeeper role within the network as it occurs on many shortest paths between other providers. Google is followed by Yahoo and Twitter that have considerably high betweenness centrality measurements in comparison to other providers in the network. 


\begin{tabular}{|l|l|}
\hline API provider & Betweenness centrality \\
\hline Google & 51237.38 \\
\hline Yahoo & 25355.46 \\
\hline Twitter & 11240.71 \\
\hline Amazon & 7886.92 \\
\hline Facebook & 4154.29 \\
\hline Digg & 4130.92 \\
\hline Box.net & 4051.20 \\
\hline eBay & 2832.85 \\
\hline Last.fm & 2617.81 \\
\hline Microsoft & 2375.15 \\
\hline AOL & 1051.87 \\
\hline Bit.ly & 1012.05 \\
\hline 411Sync & 981.33 \\
\hline Wikipedia & 960.45 \\
\hline Twilio & 958.93 \\
\hline
\end{tabular}

Table 17: Sample of betweenness centrality measurements for API provider affiliate network

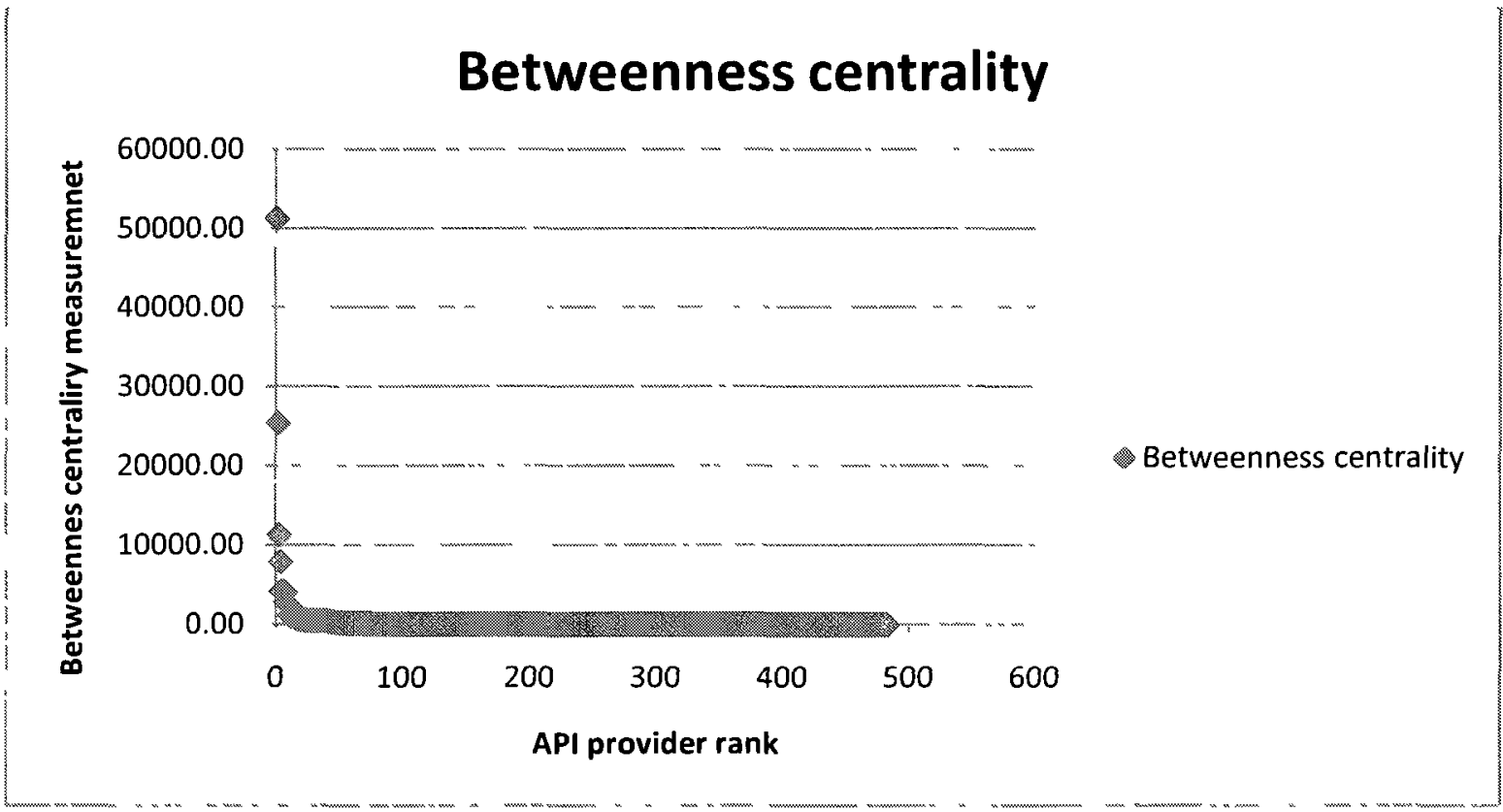

Figure 13: Betweenness centrality measurements in the API provider affiliate network 


\section{Closeness centrality}

The results of closeness centrality measurements of the API provider affiliation network, is similar to that observed in the API affiliate network. Closeness centrality values for the provider network are $0,0.10,0.11,0.12,0.13$, and 0.14 . Table 22 presents the distribution of the closeness centrality measurement for this network.

\begin{tabular}{|l|l|l|}
\hline $\begin{array}{l}\text { Closeness centrality } \\
\text { measurement }\end{array}$ & Number of providers & $\begin{array}{l}\text { Percentage of providers } \\
(\%)\end{array}$ \\
\hline 0.14 & 1 & 0.20 \\
\hline 0.13 & 72 & 15.00 \\
\hline 0.12 & 346 & 71.60 \\
\hline 0.11 & 53 & 11.00 \\
\hline 0.10 & 5 & 1.00 \\
\hline 0.00 & 6 & 1.20 \\
\hline
\end{tabular}

Table 18: Closeness centrality measurements in the API provider affiliate network

Google has the highest closeness centrality value of 0.14 , while the remaining providers range between 0 and 0.13 . This analysis reveals that Google has the most prominent network position as it the most closely connected to other providers in the network.

Similar to what was observed in the API affiliate network, the provider closeness centrality measurements are similar, making it difficult to identify prominent providers in the network. Therefore, one concludes that closeness centrality is not ideal for identifying central providers in this network. 


\section{Eigenvector centrality}

The top 15 eigenvector centrality measurements for the API provider affiliation network are presented in the table below.

Google has the highest eigenvector centrality measurement at 1.00 followed by Yahoo at 0.94 . This indicates that these two API providers are the most connected to other central API providers and that they produce APIs that are complementary in nature to each other and to other APIs in the network. To aid their success in the mashup ecosystem, API providers should develop align and model their business strategies with successful API providers, such as Google and Yahoo.

\begin{tabular}{|l|l|}
\hline API provider & Eigenvector centrality \\
\hline Google & 1.00 \\
\hline Yahoo & 0.94 \\
\hline Microsoft & 0.58 \\
\hline Twitter & 0.52 \\
\hline Amazon & 0.47 \\
\hline Digg & 0.45 \\
\hline Last.fm & 0.45 \\
\hline eBay & 0.44 \\
\hline FriendFeed & 0.43 \\
\hline Facebook & 0.43 \\
\hline AOL & 0.41 \\
\hline Technorati & 0.41 \\
\hline Eventful & 0.37 \\
\hline Photo bucket & 0.37 \\
\hline Viddler & 0.36 \\
\hline
\end{tabular}

Figure 14: Sample of eigenvector centrality measurements for API provider affiliate network 
In addition, it appears that $89 \%$ of the API providers have an eigenvector centrality value that is lower than 0.25 and are not connected to other central providers. One can speculate that providers with low eigenvector centrality release specialised APIs that appeal to few mashup developers and hence have less connections to central APIs. Furthermore, these APIs may not be compatible with more popular APIs and therefore are less popular with mashup developers.

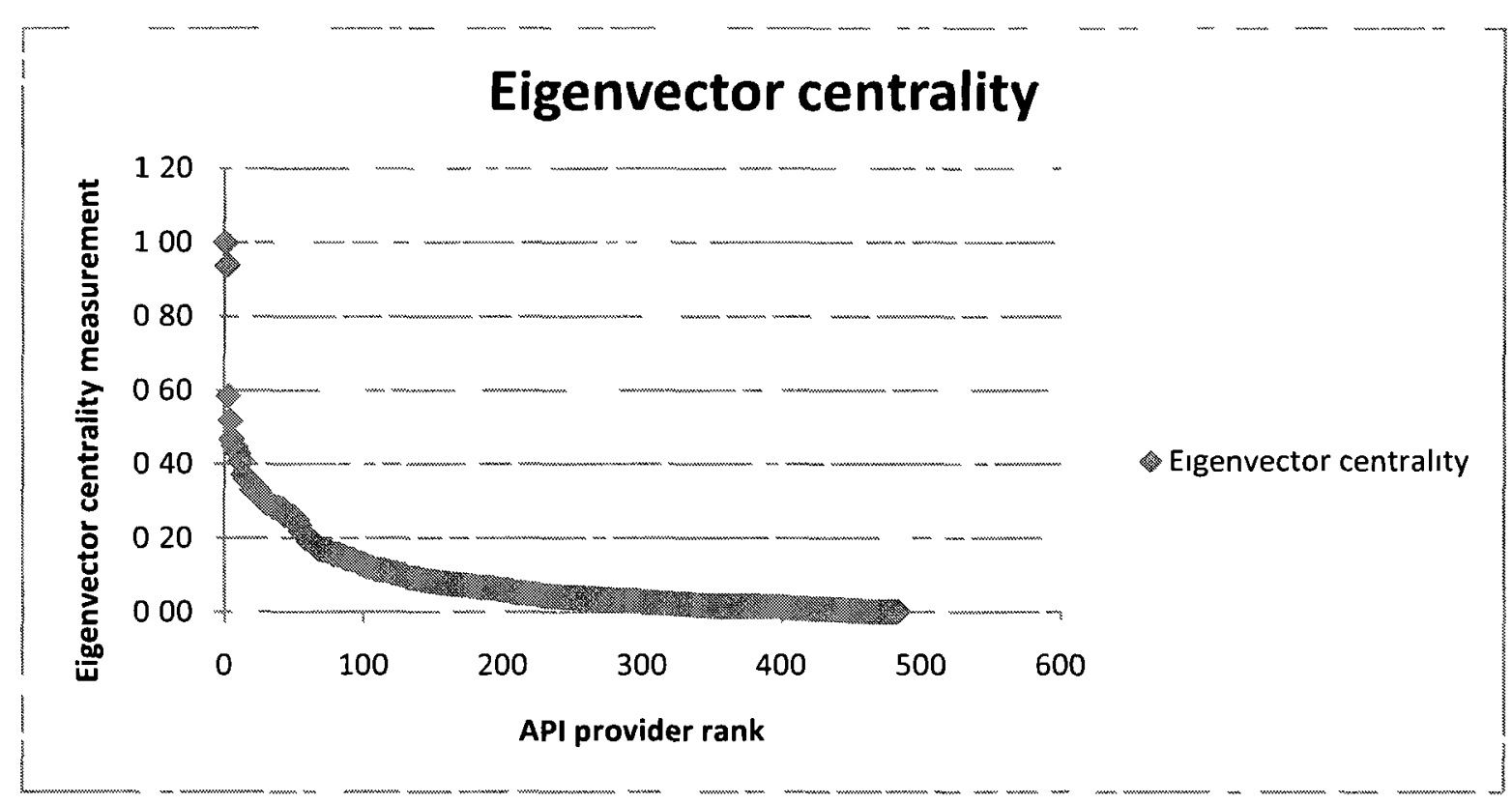

Figure 15: Eigenvector centrality measurements in the API provider affiliate network

\subsubsection{Community analysis}

The Girvan-Newman community detection algorithm was also applied to the API provider affiliation network. A sample of the community analysis results are presented in Appendix I. These communities are best represented as collectives of providers that are linked together due to developer innovation. A central collective containing $45 \mathrm{API}$ providers emerges from this analysis, in addition to, 29 smaller collectives and 355 
single providers. The figure below visualizes the structure of the provider affiliate network, where some of the smaller and the singleton entities were removed to provide a clearer representation of the findings.

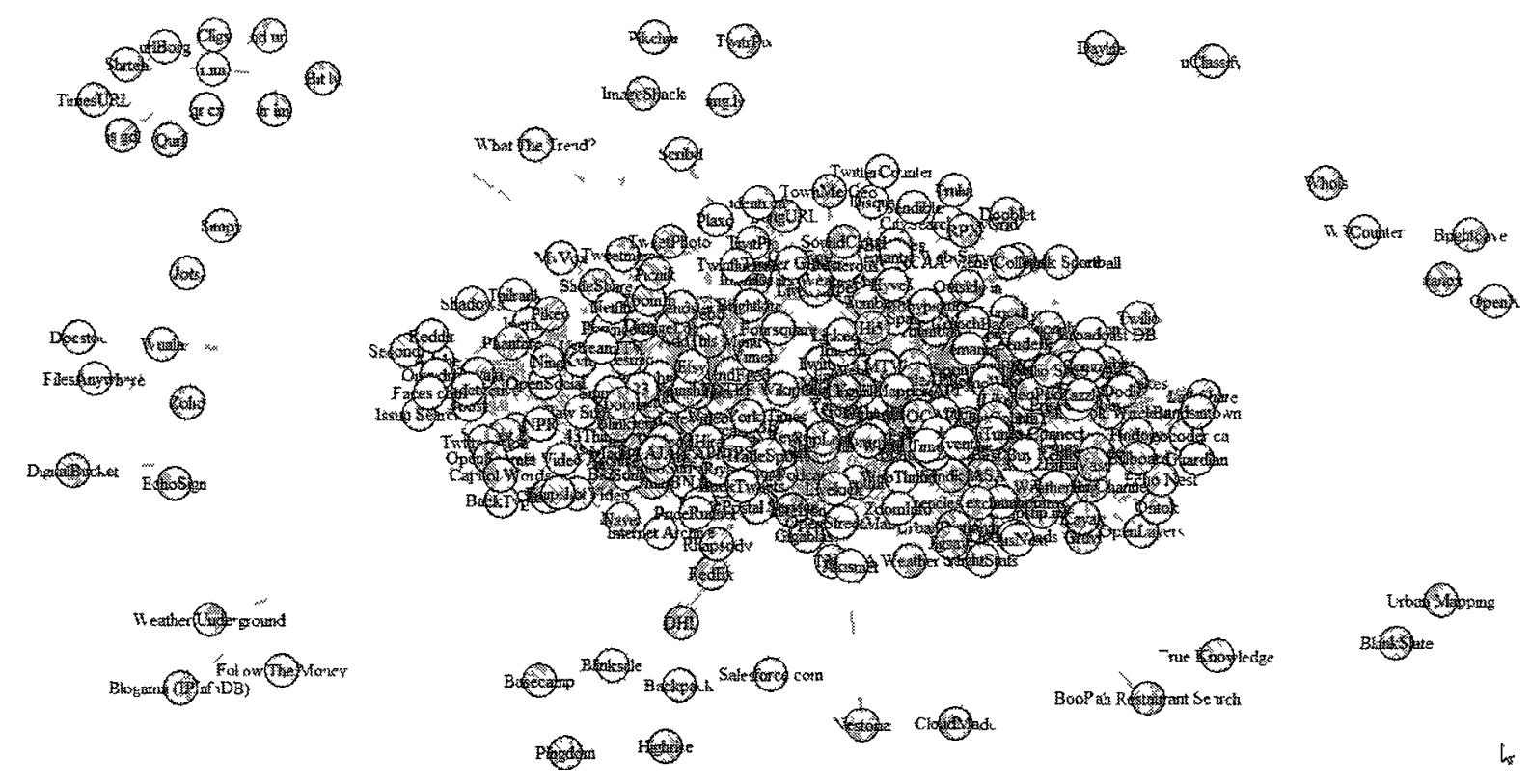

Figure 16: Community structure in the API provider affiliate network

The identification of a core community comprised of $45 \mathrm{API}$ providers indicates that there is a strong degree of interaction between the providers within that collective. This high level of interaction is established when developers employ the APIs released by these providers in the same mashups. The existence of a core collective indicates that these API providers release complementary APIs that appeal to a wide range of developers for mashup development.

A comparison between the large central communities identified in the API provider affiliate network and the API affiliate network, reveals similar associations and relationships within the communities. In other words, a very similar collective structure is revealed in both networks. The core collective identified in the provider affiliate network 
is at a higher level of abstraction than the core collective observed in the API affiliate network.

Six smaller communities are also identified, which are composed of four and eleven providers. Similar to the API affiliate network, these smaller communities have stronger internal links to each other than the rest of the API providers in the network.

Finally, 355 isolated communities containing a single API provider have minimal interactions with other providers in the network. These providers are considered niche entities with a unique contribution to the mashup ecosystem. Thereby, one can also speculate this specialization limits the appeal of the providers' API to mashup developers.

Overall, these results support the findings that the mashup ecosystem tends to be centered on a central group of API providers that form the core of the network. 


\begin{tabular}{|c|c|c|}
\hline Newman cluster number & $\begin{array}{c}\text { Total API providers per } \\
\text { cluster }\end{array}$ & API provider name \\
\hline 188 & 11 & \begin{tabular}{|l} 
Bit.ly \\
Cligs \\
is.gd \\
nd url \\
qr.cx \\
Qurl \\
r.im \\
Shrten \\
TimesURL \\
tr.im \\
urlBorg \\
\end{tabular} \\
\hline 34 & 8 & \begin{tabular}{|l|} 
Findory \\
Commission Junction \\
Netvibes \\
Moreover \\
NewsGator \\
Pageflakes \\
SpringWidgets \\
Syndic88
\end{tabular} \\
\hline 103 & 5 & \begin{tabular}{|l|} 
Map24 AJAX API \\
Clickatell \\
InnerGears Weather by City \\
Rrove \\
SmashFly \\
\end{tabular} \\
\hline 243 & 5 & \begin{tabular}{|l|} 
DigitalBucket \\
Docstoc \\
FilesAnywhere \\
Wuala \\
Zoho
\end{tabular} \\
\hline 4 & 4 & $\begin{array}{l}\text { Backpack } \\
\text { Basecamp } \\
\text { Highrise } \\
\text { Pingdom } \\
\end{array}$ \\
\hline 307 & 4 & $\begin{array}{l}\text { img.ly } \\
\text { Pikchur } \\
\text { photobucket } \\
\text { TwitrPix }\end{array}$ \\
\hline
\end{tabular}

Table 19: Sample of the communities in the API provider affiliate network 


\subsubsection{Key player analysis}

The results of the KPP-Negative and KPP-Positive analysis conducted on the API provider affiliation network are presented in Appendix $\mathrm{J}$ and $\mathrm{K}$. The KPP-Negative analysis was based on fragmentation criterion and the KPP-Positive analysis was based on reciprocal distance index criterion.

For the KPP-Negative analysis, the optimal set of key players was determined based by measuring fragmentation increase as nodes were removed from the network. The removal of Google causes a 0.147 fragmentation in the network, which equates to a fragmentation increase of $488 \%$. This equates to the isolation of 29 API providers from the remaining network and the removal of 596 connecting edges. With continual removal of nodes, one can deduce that optimal network fragmentation occurs when a set of five nodes is removed from the network.

The removal of Google, Yahoo, Amazon, Twitter, and Facebook result in a 1384\% from the baseline fragmentation value of 0.025 , resulting in the isolation of 76 providers from the remaining network and the removal of 1441 edges. As seen in the figure 18 below, this translates to the creation of 7 new networks comprised of two providers, one network comprised of 4 providers and one core network. 


\section{Fragmentation level}

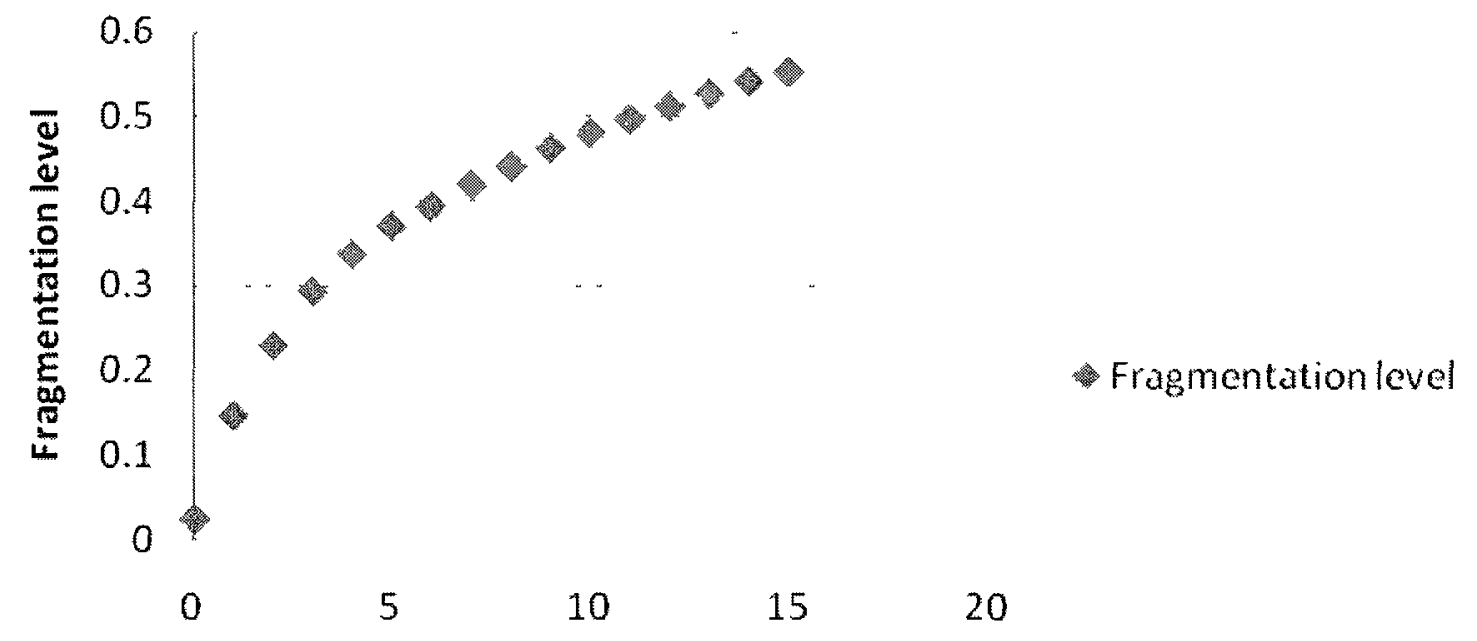

Number of nodes removed

Figure 17: Network fragmentation level for the API provider affiliate network

The reciprocal index method was used to resolve the KPP-Positive problem and identify the optimal set of nodes that are most connected and would have the fastest reach in the network. The results of KPP-Positive analysis are shown in Appendix K. The optimal set of key players consists of Google, Yahoo, Digg, Twitter, and Box.net. These five providers have a reciprocal distance index of $88.8 \%$ and therefore have the maximal reach with the minimal set of nodes. As observed in the plot below, the change in reciprocal distance index reaches a steady state level as the API provider set size increases. 


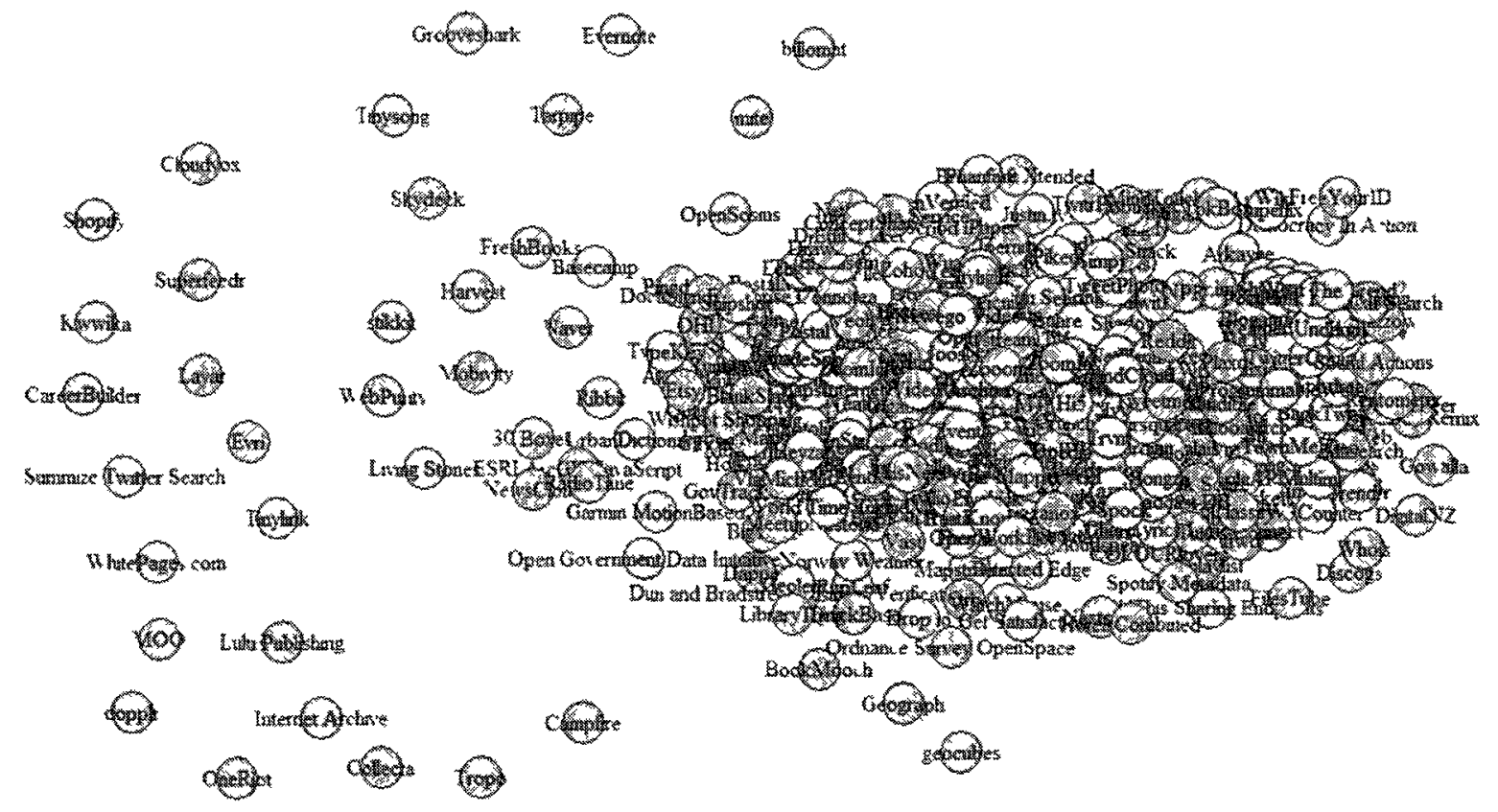

Figure 18: Fragmentation of the API provider affiliate network

The reciprocal distance index measurement indıcates that these providers are influential because of the breadth of their connections and is influenced by the number of indirect links these providers have to others in the network. APIs released by these providers appeal to a wide range of mashup developers and are used in mashups delivering different solutions to the end user Companies looking to enter the mashup ecosystem would want to look at the busıness strategy taken by these providers to ensure that their product draws interest from mashup developers and is used in number mashups. 


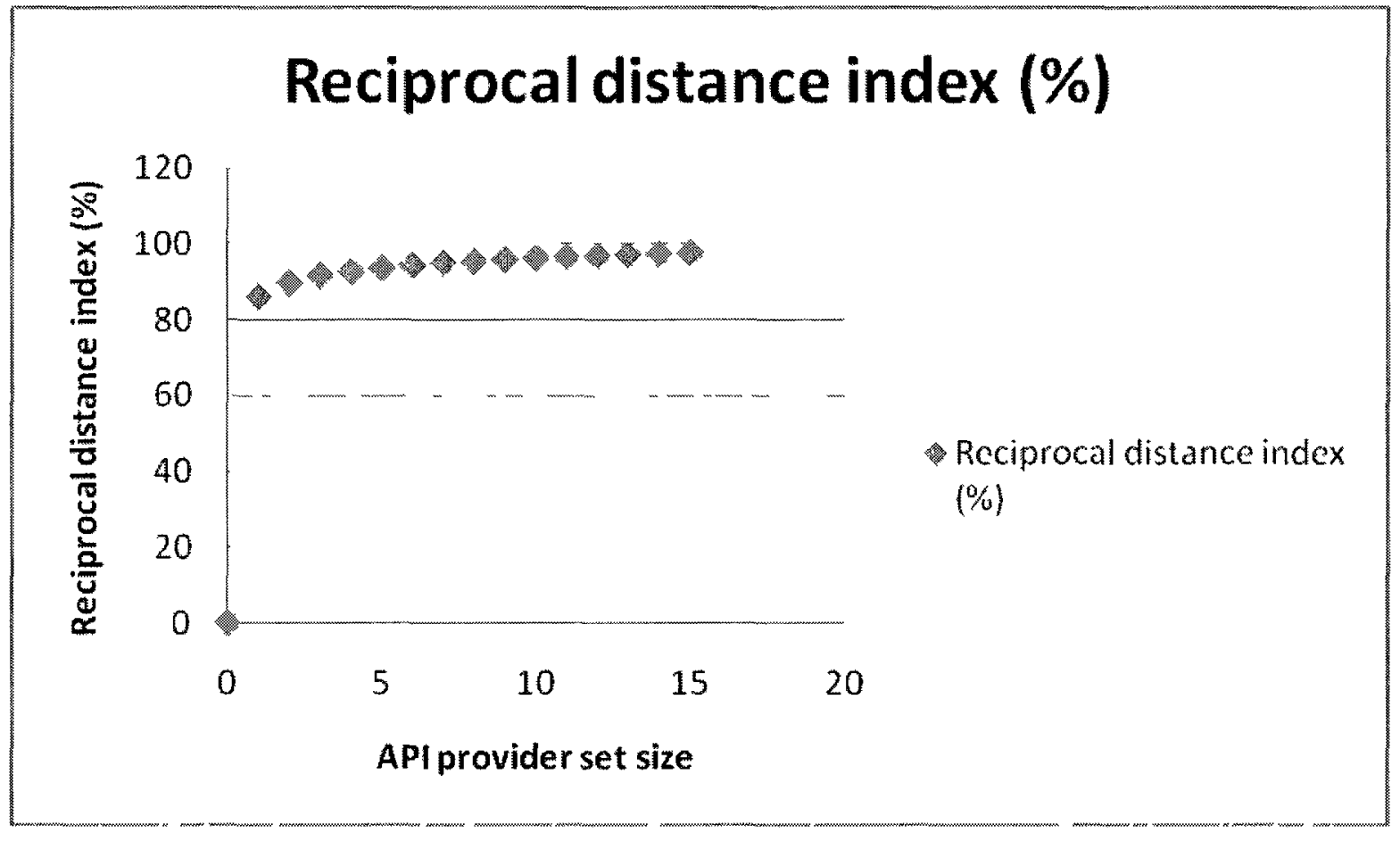

Figure 19: Reciprocal distance index for the API provider affiliate network

\begin{tabular}{|l|l|l|}
\hline KPP algorithm & Group size & Key players \\
\hline KPP-Negative & & Google \\
& 5 & $\begin{array}{l}\text { Yahoo } \\
\text { Amazon } \\
\end{array}$ \\
\hline & & Twitter \\
Facebook \\
KPP-Positive & 5 & Google \\
& & Yahoo \\
& & Digg \\
& & Twitter \\
& & Box.net \\
\hline
\end{tabular}

Table 20: Optimal key player sets in the API provider affiliate network 
It is not surprising that Google and Yahoo belong to both sets of key players identified by both algorithms as they release a large number of APIs into the mashup ecosystem However, API providers like Twitter, Facebook, Digg and Box.net release one API each yet they rank as one of the key players. This also signifies that these specialised APIs are popular due to the data provided and their popular appeal to mashup developers. The sets of key player sets observed here are similar to what was observed in the API affiliate network.

\subsubsection{Topological importance analysis}

The topological importance measurements for the API provider affiliation network are presented in Appendix $L$. The index was calculated for path lengths, $n=1, n=2, n=3$, and $n=5$ to determine the positional importance of the providers and their effect on the other providers in the network. With a path length of one, the provider with the highest $\mathrm{Tl}_{1}$ value is Google, with a $\mathrm{TI}=65.53$. Google is followed by two Amazon and Yahoo, with $\mathrm{TI}_{1}$ values of 39.12 and 25.67 , respectively.

The TI calculations were then carried out with a path length of two. Unlike, the API affiliate network, the results do not indicate a shift in the topological positioning of the top three API providers. With a path length of two, Google, Amazon, and Yahoo rank as having the highest positions in the network. However, there is a decrease in the $\mathrm{TI}$ value across all three providers. Furthermore, there is an increase in the $\mathrm{Tl}$ index measurement for 12 seconds.tv and 23. 


\begin{tabular}{|l|l|}
\hline API provider & TI index $(\mathbf{n}=\mathbf{1})$ \\
\hline Google & 65.53 \\
\hline Amazon & 39.12 \\
\hline Yahoo & 25.67 \\
\hline Facebook & 14.73 \\
\hline Box.net & 12.58 \\
\hline Microsoft & 9.77 \\
\hline Digg & 8.03 \\
\hline AOL & 7.51 \\
\hline eBay & 7.08 \\
\hline Last.fm & 6.05 \\
\hline Bit.ly & 5.15 \\
\hline Eventful & 4.85 \\
\hline Geo Names & 4.80 \\
\hline 12seconds.tv & 4.53 \\
\hline 23 & 4.15 \\
\hline
\end{tabular}

Table 21: TI index $(n=1)$ for the API provider affiliate network

The TI measurements for a path of length of three are presented in Table 22. As the path length increases, there is a shift in the positional importance of API providers. At the stage, Amazon holds the highest TI index, followed by Google, 12seconds.tv, and Yahoo. 


\begin{tabular}{|l|l|}
\hline API provider & TI index $(\mathbf{n}=\mathbf{2})$ \\
\hline Google & 41.47 \\
\hline Amazon & 34.10 \\
\hline Yahoo & 17.60 \\
\hline 12seconds.tv & 10.42 \\
\hline Facebook & 9.45 \\
\hline 23 & 8.98 \\
\hline Box.net & 8.85 \\
\hline AOL & 8.23 \\
\hline Microsoft & 7.21 \\
\hline Digg & 6.56 \\
\hline 43 Things & 6.09 \\
\hline 5 min & 5.25 \\
\hline eBay & 5.06 \\
\hline 411Sync & 4.87 \\
\hline Bit.ly & 4.69 \\
\hline
\end{tabular}

Table 22: TI index $(n=2)$ for the API provider affiliate network

\begin{tabular}{|l|l|}
\hline API provider & TI index $(\mathbf{n}=\mathbf{3})$ \\
\hline Amazon & 34.05 \\
\hline Google & 33.04 \\
\hline 12 seconds.tv & 18.75 \\
\hline Yahoo & 15.00 \\
\hline 23 & 11.23 \\
\hline AOL & 8.45 \\
\hline 43 Things & 8.10 \\
\hline Facebook & 7.72 \\
\hline Box.net & 7.36 \\
\hline Microsoft & 6.50 \\
\hline 30Boxes & 6.31 \\
\hline 5 min & 6.12 \\
\hline Digg & 5.67 \\
\hline 411 Sync & 5.18 \\
\hline Adobe & 4.94 \\
\hline
\end{tabular}

Table 23: $\mathrm{Tl}$ index $(n=3)$ for the API provider affiliate network 
Similar results are observed when $\mathrm{Tl}$ index calculations are performed with a path length of five. The top 5 APIs based on positional importance are: Amazon, 12seconds.tv, Google, 23, and Yahoo.

\begin{tabular}{|l|l|}
\hline API provider & TI index $(\mathbf{n}=\mathbf{5})$ \\
\hline Amazon & 29.10 \\
\hline 12seconds.tv & 26.28 \\
\hline Google & 23.21 \\
\hline 23 & 11.59 \\
\hline Yahoo & 10.91 \\
\hline 43Things & 9.16 \\
\hline AOL & 7.63 \\
\hline 30Boxes & 7.45 \\
\hline 5min & 6.39 \\
\hline Box.net & 5.54 \\
\hline Facebook & 5.45 \\
\hline 411Sync & 5.12 \\
\hline Microsoft & 5.10 \\
\hline Adobe & 4.26 \\
\hline Digg & 4.15 \\
\hline
\end{tabular}

Table 24: TI index $(n=5)$ for the API provider affiliate network

Similar to the API affiliate network, changes in the path length result in a change in the positional importance and the effect a provider has on the network. The table below presents the $\mathrm{TI}$ index calculation with different path lengths. $\mathrm{AOL}$ maintains its positional importance suggesting that they occupy a unique position in the network. The comparison also reveals that companies like 23,12 seconds.tv, and 43Things have an increase in their positional importance as the path length increases, while companies like Google, Amazon and Yahoo decrease in their positional importance as the path length decreases. 
One can speculate that companies like Google and Yahoo have many direct connections to other providers on the periphery of the network but has less non-direct connections to other providers, and therefore drop in importance as the path length increase. And hence, their influence is highest on their direct neighbours; however, the opposite is true for 12 seconds.tv and 23 . Similar to what was observed in the API affiliate network, these providers gain importance due to their high eigenvector centrality measurements and their connections to more central providers in the network.

\begin{tabular}{|l|l|l|l|l|l|}
\hline $\begin{array}{l}\text { API } \\
\text { provider }\end{array}$ & $\begin{array}{l}\text { TI index } \\
(\mathbf{n}=\mathbf{1})\end{array}$ & $\begin{array}{l}\text { TI index } \\
(\mathbf{n}=\mathbf{2})\end{array}$ & $\begin{array}{l}\text { TI index } \\
(\mathbf{n}=\mathbf{3})\end{array}$ & $\begin{array}{l}\text { TI index } \\
(\mathbf{n = 5})\end{array}$ & Change \\
\hline Google & 65.53 & 41.47 & 33.04 & 23.21 & $\downarrow$ \\
\hline Amazon & 39.12 & 34.1 & 34.05 & 29.1 & $\downarrow$ \\
\hline Yahoo & 25.67 & 17.6 & 15 & 10.91 & $\downarrow$ \\
\hline Facebook & 14.73 & 9.45 & 7.72 & 5.45 & $\downarrow$ \\
\hline Box.net & 12.58 & 8.85 & 7.36 & 5.54 & $\downarrow$ \\
\hline Microsoft & 9.77 & 7.21 & 6.5 & 5.1 & $\downarrow$ \\
\hline Digg & 8.03 & 6.56 & 5.67 & 4.15 & $\downarrow$ \\
\hline AOL & 7.51 & 8.23 & 8.45 & 7.63 & $\leftrightarrow$ \\
\hline eBay & 7.08 & 5.06 & 4.24 & 3.08 & $\downarrow$ \\
\hline Last.fm & 6.05 & 3.99 & 3.34 & 2.39 & $\downarrow$ \\
\hline 12seconds.tv & 4.53 & 10.42 & 18.75 & 26.28 & $\uparrow$ \\
\hline 23 & 4.15 & 8.98 & 11.23 & 11.59 & $\uparrow$ \\
\hline Twitter & 4.12 & 2.36 & 1.75 & 1.15 & $\downarrow$ \\
\hline 43Things & 2.68 & 6.09 & 8.1 & 9.16 & $\uparrow$ \\
\hline 5min & 2.03 & 5.25 & 6.12 & 6.39 & $\uparrow$ \\
\hline
\end{tabular}

Table 25: Comparison of TI measurements for API provider affiliate network 


\subsection{Summary}

In this research, the mashup ecosystem was examined by applying specific analytic techniques to the API affiliate network and the API provider affiliate network. The applied methods provide different results as they examine different structural and positional properties. The results obtained provide a comparative analysis of analytical approaches used.

The centrality measurements used examine specific network properties and quantify the positional importance of the nodes. They identify the most central nodes in the networks. Borgatti's key player analysis was conducted to identify a set of key players that cause the optimal network fragmentation and have the widest reach within the network. Topological importance index was then calculated to reveal nodes with the most effect on the rest of the nodes in the network.

The Girvan-Newman community detection algorithm was implemented and executed to reveal that the networks have a central, closely linked collective composed of a small number of network entities. The remaining entities are more peripheral and may play a lesser role in the network. 


\section{CONCLUSIONS}

The objective of this thesis was to study the mashup ecosystem structure using analytical techniques that have been applied to the study of networks in sociology, anthropology, and natural ecosystems. The study focused on understanding the structure of the mashup ecosystem, as well as the positions of the entities, such as API providers, within that ecosystem.

The mashup ecosystem is a unique business ecosystem as it is dependent on user innovation for its growth and success. The research examines this business ecosystem to verify the accuracy to provider researchers, management and entrepreneurs with a better understanding of the ecosystem structure. The mashup ecosystem was studies by examining the API affiliate network and the API provider affiliate network.

This chapter is organized into four sections. The first section concludes the key findings and the second section highlights the contributions. The third and fourth sections discuss limitations and future research.

\subsection{Key findings}

The research key findings are:

1) The mashup ecosystem is centered on a collective of API providers that contribute to the mashup ecosystem through the release of API that are deployed in mashup development.

2) Multiple smaller collectives of API providers exist in the mashup ecosystem. 
3) The combination of different and complementary analytical techniques provides the richest insights into network structure and key player roles

4) Examining the ecosystem as having multiple key players uncovers ecosystem complexities that may have otherwise been missed

5) When examining business ecosystems it is advantageous to examine the ecosystem as having a number of key players versus a single keystone. It is clear that some entities are more critical than others, however it is difficult to confirm that there is one single keystone in the mashup ecosystem.

\subsection{Contributions}

The research presented in this thesis examines the structure and organization of the mashup ecosystem. It applies reliable mathematical and analytic techniques to identify key players. The research contributes to both academia and business management as it provides new insights into the current mashup ecosystem model.

The research confirms that the roles of entities are depended on their position within the mashup ecosystem network. The research reveals that the methods used for key player identification are complementary in nature. By combining and comparing the results obtained by the different analytical methods, the research uncovered ecosystem complexities that may have otherwise been missed. This exploration of the current structure of the mashup ecosystem lays the foundation for future research related to the structure and organization of other ecosystems.

This research revealed the key players within the mashup ecosystem and that the ecosystem is centered around a central core of API providers. These findings can help 
incumbents and new entrants when developing business strategies and collaborative efforts in the mashup ecosystem. As suggested by Weiss and Gangadharan (2010), new entrants can follow or complement the strategies of key players to achieve successful entry into the ecosystem. This is also true for incumbent providers who are looking to improve their position and their role within the ecosystem.

The examination of the API affiliate network and the API provider affiliate network contributes new findings regarding the roles of entities within the mashup ecosystem. The examination of the API provider network strengthens the current academic research in this realm.

\subsection{Limitations}

The main limitation of this study is the generation of the API provider network. The provider network was manually generated because ProgrammableWeb does not identify all the providers except for the major API providers

\subsection{Future research}

Three future research opportunities are identified in this research.

First, future research can replicate the analytic methods on longitudinal snap-shots to study the evolution of the mashup ecosystem over time. This will reveal information on how the release of certain APIs or the entry of a new API provider impacts the structure and the positions of entities within the network.

Second, a future study can examine the API provider affiliation network by examining business strategies and actions that impacted a provider's entry, success or failure within the mashup ecosystem. 
Fourth, future research can apply methods and techniques used here on other business ecosystem to examine if results are more broadly applicable. 


\section{REFERENCES}

Adner, R. 2006. Match your innovation strategy to your innovation ecosystem. Harvard Business Review, 84(4): 98-107.

Basole, R. C. 2009. Visualization of interfirm relations in a converging mobile ecosystem. Journal of Information Technology (Palgrave Macmillan), 24(2): 144159.

Bonacich, P. 2007. Some unique properties of eigenvector centrality. Social Networks, 29: 555-564.

Borgatti, S.P. 2003. The Key Player Problem. In R. Breiger, K. Carley, P. Pattison (Eds.) Dynamic Social Network Modeling and Analysis: Workshop Summary and Papers: 241-252. National Academy of Sciences Press.

Borgatti, S.P. 2005. Centrality and network flow. Social Networks, 27 (1): 55-57.

Borgatti, S.P. 2006. Identifying sets of key players in a network. Computational, Mathematical and Organizational Theory. 12(1): 21-34

Brown, J. S., Davison, L., Hagel III, J. 2008. Shaping strategy in a world of constant disruption. Harvard Business Review, 86(10): 80-89.

Brown, J. S., Hagel III, J. 2006. Creation nets: Getting the most from open innovation. McKinsey Quarterly, 2: 40-51.

Chen, H., Liu, W., Davis, A. J., Jordan, F., Hwang, M., Shao, K. 2008. Network position of hosts in food webs and their parasite diversity. Oikos, 117: 1847-1855.

Clauset, A., Newman, M. E. J., Moore, C. 2004. Finding community structure in very large networks. Physical Review E, 70(6): 661-6.

Fichter, D. 2009. What is a mashup? In N.C. Engrad (Eds.) Library Mashups:

Exploring New Ways to Deliver Library Data: 3-18. Medford, New Jersey: Information Today Inc.

Girvan, M., Newman, M.E.J., 2002. Community structure in social and biological networks. Proceedings of the National Academy of Science, 99(12): 7821-7826

Gnyawali, D. R., Madhavan, R. 2001. Cooperative Networks and competitive dynamics: a structural embeddedness perspective. Academy of Management Review, 26: 431445. 
lansiti, M., Levien, R. 2004. Keystone advantage: What the new dynamics of business ecosystems mean for strategy, innovation, and sustainability. Boston, MA. Harvard Business School Press.

lansiti, M., Levien, R. 2004. Strategy as ecology. Harvard Business Review, 82(3): 6878.

lansiti, M., Richards, G. L. 2006. The information technology ecosystem: Structure, health, and performance. Antitrust Bulletin, 51(1): 77-110.

lansiti, M., Richards, G. 2009. Six years later: The impact of the evolution of the IT ecosystem. Antitrust Law Journal, 75(3): 705-721.

Ings, T. C., et al. 2009. Review: Ecological networks - beyond food webs. Journal of Animal Ecology, 78(1): 253-269.

Isckia, T. 2009. Amazon's evolving ecosystem: A cyber-bookstore and application service provider. Canadian Journal of Administrative Sciences , 26(4): 332-343.

lyer, B., Davenport, T. H. 2008. Reverse engineering Google's innovation machine. Harvard Business Review, 86(4): 58-68.

lyer, B., Lee, C., Venkatraman, N. 2006. Managing in a "small world ecosystem": Lessons from the software sector. California Management Review, 48(3): 28-47.

Jordán, F. 2001. Seasonal changes in the positional importance of components in the trophic flow network of the Chesapeake Bay. Journal of Marine Systems, 27(4): 289300.

J Jordán, F. 2001. Is the role of trophic control larger in a stressed ecosystem? Community Ecology, 1(2): 139-146.

Jordán, F. 2009. Keystone species and food webs. Philosophical Transactions of the Royal Society Biological Science, 364(1524): 1733-1741.

Jordán, F., Liu, W., Davis, A. J. 2006. Topological keystone species: Measures of positional importance in food webs. Oikos, 112(3): 535-546.

Jordán, F., Okey, T. A., Bauer, B., Libralato, S. 2008. Identifying important species: Linking structure and function in ecological networks. Ecological Modelling, 216(1): 75-80.

Jordán, F., Scheuring, I. 2002. Searching for keystones in ecological networks. Oikos, 99(3): 607-612. 
Jordán, F., Valentini R. 2010. CoSBiLab Graph: the network analysis module of CoSBiLab. Environmental Modelling and Software, 25:886-888.

$\mathrm{Li}, \mathrm{Y}$. 2009. The technological roadmap of cisco's business ecosystem. Technovation, 29(5): 379-386.

Libralato, S., Christensen, V., Pauly, D. 2006. A method for identifying keystone species in food web models. Ecological Modelling, 195(3-4): 153-171.

Moore, J. F. 1996. The Death of Competition: Leadership \& Strategy in the Age of Business Ecosystems. New York: HarperBusiness.

Moore, J. F. 2006. Business ecosystems and the view from the firm. Antitrust Bulletin, 51(1): 31-75.

Newman, M. E. J. 2004. Detecting community structure in networks. The European Physical Journal B, 38(2): 321-330.

Newman, M. E. J. 2006. Finding community structure in networks using the eigenvectors of matrices. Physical Review E, 74(3): 36104-31-19.

Ning, D., Ling, Z., Zhuo, W., Liu Wei-jie. 2009. The trend of enterprise business model development-business ecosystem. China-USA Business Review, 8(1): 18-22.

Peltoniemi, M. 2006. Preliminary theoretical framework for the study of business ecosystems. Emergence: Complexity \& Organization, 8(1): 10-19.

Pierce, L. 2009. Big losses in ecosystem niches: How core firm decisions drive complementary product shakeouts. Strategic Management Journal, 30(3): 323-347.

Scott, J. 1991. Social network analysis: A handbook. London: Newbury Park, California: SAGE Publications.

Tian, C. H., Ray, B. K., Lee, J. 2008. BEAM: A framework for business ecosystem analysis and modeling. IBM Systems Journal, 47(1): 101-114.

Wasserman, S., Faust, K. 1994. Social network analysis: Methods and applications. Cambridge. New York: Cambridge University Press,.

Weiss, M., Gangadharan, G. 2010. Modeling the mashup ecosystem: Structure and growth. R\&D Management, 40(1): 40-49.

Yu,S., Woodward,C. 2009. Innovation in the programmable web: characterizing the mashup ecosystem. Service-Oriented Computing - ICSOC 2008 Workshops, 6: 136147. 


\section{APPENDICES}

Appendix A - Sample of edgelist for the API affiliate network

\begin{tabular}{|l|l|}
\hline API 1 & API 2 \\
\hline 411Sync & Yahoo Geocoding \\
\hline eBay & hostip.info \\
\hline Last.fm & YouTube \\
\hline 411 Sync & Google Search \\
\hline Flickr & Google Maps \\
\hline buySAFE & eBay \\
\hline Flickr & Google Maps \\
\hline 411Sync & Yahoo Geocoding \\
\hline Flickr & Geo Names \\
\hline Flickr & Google Maps \\
\hline Geo Names & Google Maps \\
\hline Google Maps & Microsoft Virtual Earth \\
\hline Google Maps & Yahoo Geocoding \\
\hline Google Maps & Zillow \\
\hline Microsoft Virtual Earth & Yahoo Geocoding \\
\hline Microsoft Virtual Earth & Zillow \\
\hline Yahoo Geocoding & Zillow \\
\hline 411Sync & Microsoft Bing \\
\hline 411Sync & Yahoo Shopping \\
\hline Microsoft Bing & Yahoo Shopping \\
\hline Amazon eCommerce & Last.fm \\
\hline 411Sync & Microsoft Bing \\
\hline ClearForest Semantic Web Services1 & Google Calendar \\
\hline Google Homepage & Rhapsody \\
\hline Google Homepage & Rhapsody \\
\hline Google Homepage & YouTube \\
\hline Rhapsody & YouTube \\
\hline Last.fm & Rhapsody \\
\hline Blogger & ClearForest Semantic Web Services1 \\
\hline Blogger & Technorati \\
\hline ClearForest Semantic Web Services1 & Technorati \\
\hline geocoder & Google Maps \\
\hline 411Sync & Windows Sidebar Gadgets \\
\hline 411Sync & WeatherBug \\
\hline Amazon eCommerce & AOL Instant Messenger \\
\hline & \\
\hline & \\
\hline
\end{tabular}


Appendix B - Sample of centrality measurements for the API affiliate network

\begin{tabular}{|l|l|l|l|l|}
\hline API name & $\begin{array}{l}\text { Degree } \\
\text { centrality }\end{array}$ & $\begin{array}{l}\text { Betweeness } \\
\text { centrality }\end{array}$ & $\begin{array}{l}\text { Closeness } \\
\text { centrality }\end{array}$ & $\begin{array}{l}\text { Eigenvector } \\
\text { centrality }\end{array}$ \\
\hline Google Maps & 329 & 39002.08 & 0.13 & 0.92 \\
\hline Flickr & 301 & 18044.54 & 0.13 & 1.00 \\
\hline YouTube & 294 & 16756.21 & 0.13 & 0.99 \\
\hline Twitter & 290 & 24429.70 & 0.13 & 0.96 \\
\hline Facebook & 221 & 10663.73 & 0.13 & 0.79 \\
\hline Amazon eCommerce & 218 & 12502.03 & 0.13 & 0.82 \\
\hline Google Search & 199 & 5663.24 & 0.13 & 0.84 \\
\hline del.icio.us & 198 & 6710.02 & 0.13 & 0.84 \\
\hline Yahoo Search & 194 & 6054.00 & 0.13 & 0.82 \\
\hline Last.fm & 180 & 5213.02 & 0.13 & 0.78 \\
\hline Google Ajax Search & 179 & 3601.54 & 0.13 & 0.79 \\
\hline Digg & 169 & 6574.39 & 0.13 & 0.79 \\
\hline Technorati & 162 & 2285.08 & 0.13 & 0.77 \\
\hline Google Picasa & 149 & 1800.00 & 0.13 & 0.77 \\
\hline FriendFeed & 139 & 989.92 & 0.13 & 0.73 \\
\hline eBay & 138 & 3109.00 & 0.13 & 0.69 \\
\hline Amazon EC2 & 136 & 3245.52 & 0.13 & 0.68 \\
\hline Amazon S3 & 134 & 2855.13 & 0.13 & 0.55 \\
\hline Wikipedia & 133 & 2097.65 & 0.13 & 0.70 \\
\hline Eventful & 130 & 1756.21 & 0.13 & 0.67 \\
\hline Upcoming.org & 127 & 1117.40 & 0.13 & 0.69 \\
\hline Google AdSense & 125 & 2461.01 & 0.13 & 0.53 \\
\hline Yahoo Image Search & 119 & 1864.21 & 0.13 & 0.66 \\
\hline Yahoo Video Search & 117 & 654.78 & 0.13 & 0.67 \\
\hline Yahoo Local Search & 109 & 2620.86 & 0.13 & 0.61 \\
\hline Vimeo & 106 & 734.57 & 0.13 & 0.53 \\
\hline AOL Video & 105 & 745.52 & 0.13 & 0.61 \\
\hline Photo bucket & 99 & 557.90 & 0.13 & 0.58 \\
\hline Geo Names & 98 & 1339.93 & 0.13 & 0.42 \\
\hline Yahoo Geocoding & 96 & 2267.60 & 0.13 & 0.37 \\
\hline Smugmug & 96 & 667.82 & 0.13 & 0.57 \\
\hline BBC & 94 & 409.73 & 0.13 & 0.61 \\
\hline Bing & 93 & 472.45 & 0.13 & 0.59 \\
\hline Cafe Press & 93 & 399.19 & 0.13 & 0.59 \\
\hline Viddler & 93 & 293.71 & 0.13 & 0.58 \\
\hline & & & & \\
\hline
\end{tabular}


Appendix C - Sample of community detection results for API affiliate network

\begin{tabular}{|l|l|l|}
\hline Newman cluster number & $\begin{array}{l}\text { Total APIs per } \\
\text { cluster }\end{array}$ & API name \\
\hline 0 & 56 & 12seconds.tv \\
& & 43Things \\
& & 5min \\
& Amazon EC2 \\
& AOL Video \\
& arXiv \\
& BBC \\
& BibSonomy \\
& Bing \\
& Blinkx \\
& Blip.fm \\
& Blip.tv \\
& Blogmarks \\
& Buzznet \\
& Cafe Press \\
& del.icio.us \\
& Digg \\
& Digital Podcast \\
& eBay \\
& Eventful \\
& Flickr \\
& Floobs \\
& FriendFeed \\
& Google Ajax Search \\
& Google Book Search Data \\
& Google Friend Connect \\
& Google Picasa \\
& Grouper Video \\
& Howcast \\
& indeed \\
& ISBN db \\
& Last.fm \\
& LazyTune \\
\hline & \\
& \\
&
\end{tabular}




\begin{tabular}{|c|c|c|}
\hline & & $\begin{array}{l}\text { LiveVideo } \\
\text { Ma.gnolia } \\
\text { Photo bucket } \\
\text { Raw Sugar } \\
\text { Revver } \\
\text { Riya } \\
\text { ShareThis } \\
\text { Simply Hired Jobs } \\
\text { Smugmug } \\
\text { Spraci } \\
\text { Twitter } \\
\text { Viddler } \\
\text { VideoSurf } \\
\text { Vodpod } \\
\text { WebShots } \\
\text { Wikipedia } \\
\text { Yahoo Answers } \\
\text { Yahoo Image Search } \\
\text { Yahoo Local Search } \\
\text { Yahoo Mail } \\
\text { Yahoo Related Suggestions } \\
\text { Yahoo Video Search } \\
\text { Zooomr }\end{array}$ \\
\hline 354 & 4 & $\begin{array}{l}\text { DigitalBucket } \\
\text { Docstoc } \\
\text { FilesAnywhere } \\
\text { Wuala }\end{array}$ \\
\hline 440 & 4 & $\begin{array}{l}\text { img.ly } \\
\text { Pikchur } \\
\text { Twitgoo } \\
\text { TwitrPix }\end{array}$ \\
\hline 242 & 3 & $\begin{array}{l}\text { Google Apps Email Migration } \\
\text { Highrise } \\
\text { Pingdom }\end{array}$ \\
\hline 360 & 3 & $\begin{array}{l}\text { Blogama (IPInfoDB) } \\
\text { New York Times Movie Reviews } \\
\text { Weather Underground }\end{array}$ \\
\hline
\end{tabular}




\begin{tabular}{|l|l|l|}
\hline 403 & 3 & $\begin{array}{l}\text { Dun and Bradstreet Business } \\
\text { Verification } \\
\text { QuickBase }\end{array}$ \\
\hline 129 & 2 & $\begin{array}{l}\text { Geograph } \\
\text { Geocubes }\end{array}$ \\
\hline 160 & 2 & $\begin{array}{l}\text { Mapstraction } \\
\text { Nextstop }\end{array}$ \\
\hline 170 & 2 & $\begin{array}{l}\text { Mobivity } \\
\text { Stikkit }\end{array}$ \\
\hline 172 & 2 & $\begin{array}{l}\text { Strikelron US Census } \\
\text { Strikelron Tax Service }\end{array}$ \\
\hline 174 & 2 & $\begin{array}{l}\text { Windows Live Admin Center } \\
\text { Windows Live Gadgets }\end{array}$ \\
\hline
\end{tabular}


Appendix D - KPP-Negative results for API affiliate network

\begin{tabular}{|c|c|c|}
\hline $\begin{array}{l}\text { Number of } \\
\text { nodes removed }\end{array}$ & Fragmentation & $\begin{array}{l}\text { API Provider } \\
\text { key player set }\end{array}$ \\
\hline$\overline{0}$ & 0.019 & - \\
\hline 1 & 0.068 & Google Maps \\
\hline 2 & 0.095 & $\begin{array}{l}\text { Google Maps } \\
\text { Twitter }\end{array}$ \\
\hline 3 & 0.116 & $\begin{array}{l}\text { Google Maps } \\
\text { Twitter } \\
\text { Facebook }\end{array}$ \\
\hline 4 & 0.136 & $\begin{array}{l}\text { Google Maps } \\
\text { Twitter } \\
\text { Facebook } \\
\text { Box.net }\end{array}$ \\
\hline 5 & 0.156 & $\begin{array}{l}\text { Google Maps } \\
\text { Google } \\
\text { Homepage } \\
\text { Twitter } \\
\text { Facebook } \\
\text { Box.net }\end{array}$ \\
\hline 6 & 0.171 & $\begin{array}{l}\text { Google Maps } \\
\text { Flickr } \\
\text { Google } \\
\text { Homepage } \\
\text { Twitter } \\
\text { Facebook } \\
\text { Box.net }\end{array}$ \\
\hline 7 & 0.185 & $\begin{array}{l}\text { Google Maps } \\
\text { del.icio.us } \\
\text { Flickr } \\
\text { Google } \\
\text { Homepage } \\
\text { Twitter } \\
\text { Facebook } \\
\text { Box.net }\end{array}$ \\
\hline
\end{tabular}




\begin{tabular}{|c|c|c|}
\hline $\begin{array}{l}\text { Number of } \\
\text { nodes removed }\end{array}$ & Fragmentation & $\begin{array}{l}\text { API Provider } \\
\text { key player set }\end{array}$ \\
\hline 8 & 0.199 & $\begin{array}{l}\text { Google Maps } \\
\text { Amazon } \\
\text { eCommerce } \\
\text { Flickr } \\
\text { YouTube } \\
\text { Google } \\
\text { Homepage } \\
\text { Twitter } \\
\text { Facebook } \\
\text { Box.net }\end{array}$ \\
\hline 9 & 0.219 & $\begin{array}{l}\text { Google Maps } \\
\text { del.icio.us } \\
\text { Amazon } \\
\text { eCommerce } \\
\text { Flickr } \\
\text { YouTube } \\
\text { Google } \\
\text { Homepage } \\
\text { Twitter } \\
\text { Facebook } \\
\text { Box.net }\end{array}$ \\
\hline 10 & 0.232 & $\begin{array}{l}\text { Google Maps } \\
\text { del.icio.us } \\
\text { Amazon } \\
\text { eCommerce } \\
\text { Flickr } \\
\text { Yahoo Local } \\
\text { Search } \\
\text { YouTube } \\
\text { Google } \\
\text { Homepage } \\
\text { Twitter } \\
\text { Facebook } \\
\text { Box.net }\end{array}$ \\
\hline
\end{tabular}




\begin{tabular}{|c|c|c|}
\hline $\begin{array}{l}\text { Number of } \\
\text { nodes removed }\end{array}$ & Fragmentation & $\begin{array}{l}\text { API Provider } \\
\text { key player set }\end{array}$ \\
\hline 11 & 0.243 & $\begin{array}{l}\text { Google Maps } \\
\text { del.icio.us } \\
\text { Amazon } \\
\text { eCommerce } \\
\text { Google Search } \\
\text { Flickr } \\
\text { Yahoo Local } \\
\text { Search } \\
\text { YouTube } \\
\text { Google } \\
\text { Homepage } \\
\text { Twitter } \\
\text { Facebook } \\
\text { Box.net }\end{array}$ \\
\hline 12 & 0.254 & $\begin{array}{l}\text { Google Maps } \\
\text { del.icio.us } \\
\text { Amazon } \\
\text { eCommerce } \\
\text { Flickr } \\
\text { Yahoo Maps } \\
\text { Yahoo } \\
\text { Geocoding } \\
\text { Yahoo Local } \\
\text { Search } \\
\text { YouTube } \\
\text { Google } \\
\text { Homepage } \\
\text { Twitter } \\
\text { Facebook } \\
\text { Box.net }\end{array}$ \\
\hline
\end{tabular}




\begin{tabular}{|c|c|c|}
\hline $\begin{array}{l}\text { Number of } \\
\text { nodes removed }\end{array}$ & Fragmentation & $\begin{array}{l}\text { API Provider } \\
\text { key player set }\end{array}$ \\
\hline 13 & 0.265 & $\begin{array}{l}\text { Google Maps } \\
\text { 4. del.icio.us } \\
\text { 6. Amazon } \\
\text { eCommerce } \\
\text { Google Search } \\
\text { Flickr } \\
\text { Yahoo Maps } \\
\text { Yahoo } \\
\text { Geocoding } \\
\text { Yahoo Local } \\
\text { Search } \\
\text { YouTube } \\
\text { Google } \\
\text { Homepage } \\
\text { Twitter } \\
\text { Facebook } \\
\text { Box.net }\end{array}$ \\
\hline 14 & 0.276 & $\begin{array}{l}\text { Google Maps } \\
\text { del.icio.us } \\
\text { Amazon } \\
\text { eCommerce } \\
\text { Google Search } \\
\text { Flickr } \\
\text { Yahoo Maps } \\
\text { Yahoo } \\
\text { Geocoding } \\
\text { Yahoo Local } \\
\text { Search } \\
\text { YouTube } \\
\text { Google } \\
\text { Homepage } \\
\text { Twitter } \\
\text { Facebook } \\
\text { Box.net } \\
\text { Google App } \\
\text { Engine }\end{array}$ \\
\hline
\end{tabular}




\begin{tabular}{|c|c|c|}
\hline $\begin{array}{l}\text { Number of } \\
\text { nodes removed }\end{array}$ & Fragmentation & $\begin{array}{l}\text { API Provider } \\
\text { key player set }\end{array}$ \\
\hline 15 & 0.289 & $\begin{array}{l}\text { Google Maps } \\
\text { del.icio.us } \\
\text { Amazon } \\
\text { eCommerce } \\
\text { Google Search } \\
\text { Flickr } \\
\text { Yahoo Maps } \\
\text { Yahoo } \\
\text { Geocoding } \\
\text { Yahoo Local } \\
\text { Search } \\
\text { Salesforce.com } \\
\text { YouTube } \\
\text { Google } \\
\text { Homepage } \\
\text { Twitter } \\
\text { Facebook } \\
\text { Google App } \\
\text { Engine }\end{array}$ \\
\hline
\end{tabular}


Appendix E - KPP-Positive results for API affiliate network

\begin{tabular}{|c|c|c|}
\hline API group size & $\begin{array}{l}\text { Reciprocal } \\
\text { distance index (\%) }\end{array}$ & $\begin{array}{l}\text { API key player } \\
\text { set }\end{array}$ \\
\hline 0 & 0 & - \\
\hline 1 & 73.9 & Google Maps \\
\hline 2 & 82.6 & $\begin{array}{l}\text { Google Maps } \\
\text { Twitter }\end{array}$ \\
\hline 3 & 85.7 & $\begin{array}{l}\text { Google Maps } \\
\text { YouTube } \\
\text { Twitter }\end{array}$ \\
\hline 4 & 87.6 & $\begin{array}{l}\text { Google Maps } \\
\text { Flickr } \\
\text { YouTube } \\
\text { Twitter }\end{array}$ \\
\hline 5 & 88.8 & $\begin{array}{l}\text { Google Maps } \\
\text { Amazon } \\
\text { eCommerce } \\
\text { Flickr } \\
\text { YouTube } \\
\text { Twitter }\end{array}$ \\
\hline 6 & 89.7 & $\begin{array}{l}\text { Google Maps } \\
\text { Amazon } \\
\text { eCommerce } \\
\text { Flickr } \\
\text { YouTube } \\
\text { Twitter } \\
\text { Box.net }\end{array}$ \\
\hline 7 & 90.5 & $\begin{array}{l}\text { Google Maps } \\
\text { Amazon } \\
\text { eCommerce } \\
\text { Flickr } \\
\text { YouTube } \\
\text { Twitter } \\
\text { Facebook } \\
\text { Box.net }\end{array}$ \\
\hline
\end{tabular}




\begin{tabular}{|c|c|c|}
\hline API group size & $\begin{array}{l}\text { Reciprocal } \\
\text { distance index (\%) }\end{array}$ & $\begin{array}{l}\text { API key player } \\
\text { set }\end{array}$ \\
\hline 8 & 91.2 & $\begin{array}{l}\text { Google Maps } \\
\text { Amazon } \\
\text { eCommerce } \\
\text { Flickr } \\
\text { YouTube } \\
\text { Digg } \\
\text { Twitter } \\
\text { Facebook } \\
\text { Box.net }\end{array}$ \\
\hline 9 & 91.9 & $\begin{array}{l}\text { Google Maps } \\
\text { Amazon } \\
\text { eCommerce } \\
\text { Yahoo Search } \\
\text { Flickr } \\
\text { YouTube } \\
\text { Digg } \\
\text { Twitter } \\
\text { Facebook } \\
\text { Box.net }\end{array}$ \\
\hline 10 & 92.6 & $\begin{array}{l}\text { Google Maps } \\
\text { Amazon } \\
\text { eCommerce } \\
\text { Yahoo Search } \\
\text { Flickr } \\
\text { YouTube } \\
\text { Google } \\
\text { Homepage } \\
\text { Digg } \\
\text { Twitter } \\
\text { Facebook } \\
\text { Box.net }\end{array}$ \\
\hline
\end{tabular}




\begin{tabular}{|c|c|c|}
\hline API group size & $\begin{array}{l}\text { Reciprocal } \\
\text { distance index (\%) }\end{array}$ & $\begin{array}{l}\text { API key player } \\
\text { set }\end{array}$ \\
\hline 13 & 94.1 & $\begin{array}{l}\text { Google Maps } \\
\text { Amazon } \\
\text { eCommerce } \\
\text { Yahoo Search } \\
\text { Flickr } \\
\text { Microsoft Virtual } \\
\text { Earth } \\
\text { Yahoo Maps } \\
\text { YouTube } \\
\text { Google } \\
\text { Homepage } \\
\text { Digg } \\
\text { Twitter } \\
\text { Basecamp } \\
\text { Facebook } \\
\text { Box.net }\end{array}$ \\
\hline 14 & 94.5 & $\begin{array}{l}\text { Google Maps } \\
\text { Amazon } \\
\text { eCommerce } \\
\text { Yahoo Search } \\
\text { Flickr } \\
\text { Microsoft Virtual } \\
\text { Earth } \\
\text { Yahoo Maps } \\
\text { YouTube } \\
\text { Google } \\
\text { Homepage } \\
\text { Amazon EC2 } \\
\text { Digg } \\
\text { Twitter } \\
\text { Basecamp } \\
\text { Facebook } \\
\text { Box.net }\end{array}$ \\
\hline
\end{tabular}




\begin{tabular}{|l|l|l|}
\hline API group size & $\begin{array}{l}\text { Reciprocal } \\
\text { distance index (\%) }\end{array}$ & $\begin{array}{l}\text { API key player } \\
\text { set }\end{array}$ \\
\hline 15 & 94.9 & Google Maps \\
& & Amazon \\
& & eCommerce \\
Yahoo Search \\
& & Flickr \\
& & Microsoft Virtual \\
& & Earth \\
& & Yahoo Maps \\
& & YouTube \\
& & Google \\
& & Homepage \\
& & Amazon EC2 \\
& & Digg \\
& & Twitter \\
& & Basecamp \\
& & Facebook \\
& & Box.net \\
& & Shopify \\
& & \\
\hline
\end{tabular}


Appendix F - Sample of topological importance results for the API affiliate network

\begin{tabular}{|l|l|l|l|l|}
\hline API & $\begin{array}{l}\text { II index } \\
(\mathbf{n}=\mathbf{1})\end{array}$ & $\begin{array}{l}\text { TI index } \\
(\mathbf{n}=\mathbf{2})\end{array}$ & $\begin{array}{l}\text { TI index } \\
(\mathbf{n = 3})\end{array}$ & $\begin{array}{l}\text { TI index } \\
(\mathbf{n}=\mathbf{5})\end{array}$ \\
\hline Google Maps & 38.60 & 24.16 & 17.70 & 11.32 \\
\hline Amazon eCommerce & 31.08 & 27.19 & 27.58 & 22.90 \\
\hline Flickr & 21.12 & 15.42 & 12.22 & 7.93 \\
\hline Facebook & 16.18 & 11.68 & 9.41 & 6.21 \\
\hline AmazonEC2 & 13.45 & 16.41 & 18.35 & 18.16 \\
\hline Box.net & 12.36 & 8.93 & 7.19 & 4.90 \\
\hline del.icio.us & 11.72 & 9.22 & 7.56 & 5.09 \\
\hline Digg & 8.80 & 7.79 & 6.56 & 4.41 \\
\hline AmazonS3 & 8.27 & 10.32 & 11.05 & 9.29 \\
\hline 23 & 5.61 & 10.01 & 13.19 & 13.90 \\
\hline 12seconds.tv & 4.80 & 12.45 & 22.58 & 34.20 \\
\hline 43Things & 2.93 & 7.26 & 10.46 & 12.65 \\
\hline 5min & 2.30 & 6.35 & 8.12 & 8.91 \\
\hline Google Homepage & 7.66 & 4.38 & 3.02 & 1.83 \\
\hline Google Search & 7.61 & 5.09 & 3.66 & 2.25 \\
\hline AOL Video & 6.76 & 8.42 & 8.99 & 8.02 \\
\hline Google App Engine & 6.46 & 4.51 & 3.44 & 2.20 \\
\hline Google Ajax Search & 6.10 & 5.03 & 4.04 & 2.63 \\
\hline 411Sync & 5.08 & 5.84 & 6.57 & 7.54 \\
\hline Twitter & 4.57 & 2.41 & 1.62 & 0.98 \\
\hline Bing & 4.59 & 5.98 & 6.27 & 5.21 \\
\hline Blogger & 6.05 & 7.68 & 7.66 & 6.01 \\
\hline Bit.ly & 6.03 & 5.93 & 5.08 & 3.46 \\
\hline Last.fm & 5.91 & 3.48 & 2.41 & 1.47 \\
\hline Adobe Share & 3.09 & 5.00 & 5.51 & 4.75 \\
\hline Amazon Cloud Watch & 0.57 & 3.97 & 4.91 & 5.55 \\
\hline AmazonA9OpenSearch & 3.08 & 6.42 & 7.85 & 8.12 \\
\hline BBC & 2.85 & 4.56 & 4.74 & 3.95 \\
\hline eBay & 5.53 & 5.12 & 4.27 & 2.87 \\
\hline Eventful & 5.35 & 4.95 & 4.13 & 2.77 \\
\hline Microsoft Virtual Earth & 5.18 & 2.99 & 2.06 & 1.25 \\
\hline Geo Names & 5.07 & 4.25 & 3.55 & 2.37 \\
\hline Google Ad Sense & 4.40 & 3.97 & 3.20 & 2.10 \\
\hline & & & & \\
\hline
\end{tabular}


Appendix G - Sample of edgelist for the API provider affiliate network

\begin{tabular}{|l|l|}
\hline API provider 1 & API provider 2 \\
\hline BBC & Google \\
\hline FeedMap & Google \\
\hline Yahoo & Prodigem \\
\hline Amazon & Google \\
\hline Yahoo & Google \\
\hline Google & Yahoo \\
\hline Google & Smugmug \\
\hline Google & HotOrNot \\
\hline Amazon & Yahoo \\
\hline eBay & Google \\
\hline Yahoo & Yahoo \\
\hline Eventful & Google \\
\hline Google & Microsoft \\
\hline Google & NASA \\
\hline Google & OpenLayers \\
\hline NASA & OpenLayers \\
\hline NASA & Yahoo \\
\hline OpenLayers & Yahoo \\
\hline Eventful & Microsoft \\
\hline Amazon & Backpack \\
\hline Amazon & Technorati \\
\hline Backpack & Yahoo \\
\hline Backpack & Google \\
\hline Backpack & Technorati \\
\hline Yahoo & Technorati \\
\hline Google & Technorati \\
\hline Amazon & Bloglines \\
\hline Amazon & LiveJournal \\
\hline Amazon & TypePad \\
\hline Google & Bloglines \\
\hline Google & Google \\
\hline Google & LiveJournal \\
\hline Google & TypePad \\
\hline & \\
\hline
\end{tabular}


Appendix $\mathrm{H}$ - Sample of centrality measurements for the API provider affiliate network

\begin{tabular}{|l|l|l|l|l|}
\hline API provider & $\begin{array}{l}\text { Degree } \\
\text { centrality }\end{array}$ & $\begin{array}{l}\text { Betweenness } \\
\text { centrality }\end{array}$ & $\begin{array}{l}\text { Closeness } \\
\text { centrality }\end{array}$ & $\begin{array}{l}\text { Eigenvector } \\
\text { centrality }\end{array}$ \\
\hline Google & 497.00 & 51237.38 & 0.14 & 1.00 \\
\hline Yahoo & 409.00 & 25355.46 & 0.13 & 0.94 \\
\hline Twitter & 210.00 & 11240.71 & 0.13 & 0.52 \\
\hline Amazon & 196.00 & 7886.92 & 0.13 & 0.47 \\
\hline Microsoft & 159.00 & 2375.15 & 0.13 & 0.58 \\
\hline Facebook & 147.00 & 4154.29 & 0.13 & 0.43 \\
\hline eBay & 134.00 & 2832.85 & 0.13 & 0.44 \\
\hline Last.fm & 134.00 & 2617.81 & 0.13 & 0.45 \\
\hline Digg & 127.00 & 4130.92 & 0.13 & 0.45 \\
\hline Technorati & 111.00 & 756.80 & 0.13 & 0.41 \\
\hline AOL & 108.00 & 1051.87 & 0.13 & 0.41 \\
\hline FriendFeed & 108.00 & 407.84 & 0.13 & 0.43 \\
\hline Eventful & 92.00 & 466.60 & 0.13 & 0.37 \\
\hline Wikipedia & 91.00 & 960.45 & 0.13 & 0.36 \\
\hline Vimeo & 81.00 & 261.45 & 0.13 & 0.33 \\
\hline Photo bucket & 80.00 & 186.32 & 0.13 & 0.37 \\
\hline Smugmug & 76.00 & 223.56 & 0.13 & 0.36 \\
\hline Buzznet & 75.00 & 177.68 & 0.13 & 0.35 \\
\hline Viddler & 74.00 & 104.88 & 0.13 & 0.36 \\
\hline BBC & 70.00 & 138.14 & 0.13 & 0.32 \\
\hline WebShots & 69.00 & 98.00 & 0.13 & 0.35 \\
\hline indeed & 66.00 & 110.52 & 0.13 & 0.32 \\
\hline MySpace & 66.00 & 407.59 & 0.13 & 0.25 \\
\hline Revver & 65.00 & 105.10 & 0.13 & 0.32 \\
\hline Zooomr & 65.00 & 82.88 & 0.13 & 0.31 \\
\hline Box.net & 64.00 & 4051.20 & 0.13 & 0.20 \\
\hline Blip.tv & 63.00 & 52.97 & 0.13 & 0.31 \\
\hline Grouper Video & 63.00 & 97.22 & 0.13 & 0.32 \\
\hline LiveVideo & 63.00 & 52.38 & 0.13 & 0.33 \\
\hline Cafe Press & 62.00 & 90.51 & 0.13 & 0.30 \\
\hline & & & & \\
\hline
\end{tabular}


Appendix I - Sample of community detection results for API provider affiliate network

\begin{tabular}{|c|c|c|}
\hline $\begin{array}{l}\text { Newman cluster } \\
\text { number }\end{array}$ & $\begin{array}{l}\text { Total API } \\
\text { providers per } \\
\text { cluster }\end{array}$ & API provider name \\
\hline 0 & 45 & $\begin{array}{l}\text { 12seconds.tv } \\
\text { 43Things } \\
\text { 5min } \\
\text { Amazon } \\
\text { AOL } \\
\text { arXiv } \\
\text { BBC } \\
\text { BibSonomy } \\
\text { Blinkx } \\
\text { Blip.fm } \\
\text { Blip.tv } \\
\text { Blogmarks } \\
\text { Buzznet } \\
\text { Cafe Press } \\
\text { Digital Podcast } \\
\text { eBay } \\
\text { Eventful } \\
\text { Floobs } \\
\text { FriendFeed } \\
\text { Google } \\
\text { Grouper Video } \\
\text { Howcast } \\
\text { indeed } \\
\text { ISBN db } \\
\text { Last.fm } \\
\text { LazyTune } \\
\text { LiveVideo } \\
\text { Ma.gnolia } \\
\text { Microsoft } \\
\text { Photo bucket } \\
\text { Raw Sugar } \\
\text { Revver } \\
\text { Riya }\end{array}$ \\
\hline
\end{tabular}




\begin{tabular}{|l|l|}
\hline & ShareThis \\
& Simply Hired Jobs \\
& Smugmug \\
& Spraci \\
& Technorati \\
& Viddler \\
& VideoSurf \\
& Vodpod \\
& WebShots \\
& Wikipedia \\
& Yahoo \\
& Zooomr \\
\hline
\end{tabular}




\begin{tabular}{|c|c|c|}
\hline $\begin{array}{c}\text { Newman cluster } \\
\text { number }\end{array}$ & $\begin{array}{c}\text { Total API } \\
\text { providers per } \\
\text { cluster }\end{array}$ & API provider name \\
\hline 188 & 11 & $\begin{array}{l}\text { Bit.ly } \\
\text { Cligs } \\
\text { is.gd } \\
\text { nd url } \\
\text { qr.cx } \\
\text { Qurl } \\
\text { r.im } \\
\text { Shrten } \\
\text { TimesURL } \\
\text { tr.im } \\
\text { urlBorg }\end{array}$ \\
\hline 34 & 8 & $\begin{array}{l}\text { Findory } \\
\text { Commission Junction } \\
\text { Netvibes } \\
\text { Moreover } \\
\text { NewsGator } \\
\text { Pageflakes } \\
\text { SpringWidgets } \\
\text { Syndic88 }\end{array}$ \\
\hline 103 & 5 & $\begin{array}{l}\text { Map24 AJAX API } \\
\text { Clickatell } \\
\text { InnerGears Weather by } \\
\text { City } \\
\text { Rrove } \\
\text { SmashFly } \\
\end{array}$ \\
\hline 243 & 5 & $\begin{array}{l}\text { DigitalBucket } \\
\text { Docstoc } \\
\text { FilesAnywhere } \\
\text { Wuala } \\
\text { Zoho }\end{array}$ \\
\hline 4 & 4 & $\begin{array}{l}\text { Backpack } \\
\text { Basecamp } \\
\text { Highrise } \\
\text { Pingdom }\end{array}$ \\
\hline 307 & 4 & $\begin{array}{l}\text { img.ly } \\
\text { Pikchur } \\
\text { photobucket } \\
\text { TwitrPix }\end{array}$ \\
\hline 75 & 2 & $\begin{array}{l}\text { Geograph } \\
\text { geocubes }\end{array}$ \\
\hline
\end{tabular}


Appendix J - KPP-Negative results for API provider affiliate network

\begin{tabular}{|c|c|c|}
\hline $\begin{array}{l}\text { Number of nodes } \\
\text { removed }\end{array}$ & Fragmentation & $\begin{array}{l}\text { API Provider key } \\
\text { player set }\end{array}$ \\
\hline 0 & 0.025 & - \\
\hline 1 & 0.147 & Google \\
\hline 2 & 0.23 & $\begin{array}{l}\text { Google } \\
\text { Yahoo } \\
\end{array}$ \\
\hline 3 & 0.294 & $\begin{array}{l}\text { Google } \\
\text { Yahoo } \\
\text { Twitter } \\
\end{array}$ \\
\hline 4 & 0.338 & $\begin{array}{l}\text { Google } \\
\text { Yahoo } \\
\text { Amazon } \\
\text { Twitter } \\
\end{array}$ \\
\hline 5 & 0.371 & $\begin{array}{l}\text { Google } \\
\text { Yahoo } \\
\text { Amazon } \\
\text { Twitter } \\
\text { Facebook }\end{array}$ \\
\hline 6 & 0.394 & $\begin{array}{l}\text { Google } \\
\text { Yahoo } \\
\text { Amazon } \\
\text { Twitter } \\
\text { Facebook } \\
\text { Box.net }\end{array}$ \\
\hline 7 & 0.42 & $\begin{array}{l}\text { Google } \\
\text { Yahoo } \\
\text { Amazon } \\
\text { Microsoft } \\
\text { Geo Names } \\
\text { Twitter } \\
\text { Facebook } \\
\end{array}$ \\
\hline 8 & 0.442 & $\begin{array}{l}\text { Google } \\
\text { Yahoo } \\
\text { Amazon } \\
\text { Microsoft } \\
\text { Geo Names } \\
\text { Twitter } \\
\text { Facebook } \\
\text { Box.net }\end{array}$ \\
\hline
\end{tabular}




\begin{tabular}{|c|c|c|}
\hline $\begin{array}{l}\text { Number of nodes } \\
\text { removed }\end{array}$ & Fragmentation & $\begin{array}{l}\text { API Provider key } \\
\text { player set }\end{array}$ \\
\hline $\begin{array}{l}\text { Number of nodes } \\
\text { removed }\end{array}$ & Fragmentation & $\begin{array}{l}\text { API Provider key } \\
\text { player set }\end{array}$ \\
\hline (2) & 0.463 & $\begin{array}{l}\text { Google } \\
\text { Yahoo } \\
\text { Amazon } \\
\text { eBay } \\
\text { Microsoft } \\
\text { Geo Names } \\
\text { Twitter } \\
\text { Facebook } \\
\text { Box.net }\end{array}$ \\
\hline 10 & 0.481 & $\begin{array}{l}\text { Google } \\
\text { Yahoo } \\
\text { Amazon } \\
\text { eBay } \\
\text { Microsoft } \\
\text { Geo Names } \\
\text { Twitter } \\
\text { Facebook } \\
\text { Box.net } \\
\text { OpenStreetMap }\end{array}$ \\
\hline 11 & 0.496 & $\begin{array}{l}\text { Google } \\
\text { Yahoo } \\
\text { Amazon } \\
\text { eBay } \\
\text { Microsoft } \\
\text { Technorati } \\
\text { Last.fm } \\
\text { Geo Names } \\
\text { Twitter } \\
\text { Facebook } \\
\text { Box.net }\end{array}$ \\
\hline
\end{tabular}




\begin{tabular}{|c|c|c|}
\hline $\begin{array}{l}\text { Number of nodes } \\
\text { removed }\end{array}$ & Fragmentation & $\begin{array}{l}\text { API Provider key } \\
\text { player set }\end{array}$ \\
\hline 12 & 0.513 & $\begin{array}{l}\text { Google } \\
\text { Yahoo } \\
\text { Amazon } \\
\text { eBay } \\
\text { Microsoft } \\
\text { Geo Names } \\
\text { Digg } \\
\text { Twitter } \\
\text { Facebook } \\
\text { Box.net } \\
\text { Bit.ly } \\
\text { IP Address Lookup }\end{array}$ \\
\hline 13 & 0.528 & $\begin{array}{l}\text { Google } \\
\text { Yahoo } \\
\text { Amazon } \\
\text { eBay } \\
\text { Microsoft } \\
\text { Last.fm } \\
\text { Geo Names } \\
\text { Digg } \\
\text { Twitter } \\
\text { Facebook } \\
\text { Box.net } \\
\text { Bit.ly } \\
\text { IP Address Lookup }\end{array}$ \\
\hline
\end{tabular}




\begin{tabular}{|c|c|c|}
\hline $\begin{array}{l}\text { Number of nodes } \\
\text { removed }\end{array}$ & Fragmentation & $\begin{array}{l}\text { API Provider key } \\
\text { player set }\end{array}$ \\
\hline 14 & 0.542 & $\begin{array}{l}\text { Google } \\
\text { Yahoo } \\
\text { Amazon } \\
\text { eBay } \\
\text { Microsoft } \\
\text { Technorati } \\
\text { Last.fm } \\
\text { Geo Names } \\
\text { Digg } \\
\text { Twitter } \\
\text { Facebook } \\
\text { Box.net } \\
\text { Bit.ly } \\
\text { IP Address Lookup }\end{array}$ \\
\hline 15 & 0.553 & $\begin{array}{l}\text { Google } \\
\text { Yahoo } \\
\text { Amazon } \\
\text { eBay } \\
\text { Microsoft } \\
\text { Technorati } \\
\text { Last.fm } \\
\text { Geo Names } \\
\text { Digg } \\
\text { Twitter } \\
\text { Facebook } \\
\text { Box.net } \\
\text { OpenStreetMap } \\
\text { Bit.ly } \\
\text { IP Address Lookup }\end{array}$ \\
\hline
\end{tabular}


Appendix K - KPP-Positive results for API provider affiliate network

\begin{tabular}{|c|c|c|}
\hline API group size & $\begin{array}{l}\text { Reciprocal distance } \\
\text { index }(\%)\end{array}$ & $\begin{array}{l}\text { API key } \\
\text { player set }\end{array}$ \\
\hline 0 & 0 & - \\
\hline 1 & 86.2 & Google \\
\hline 2 & 89.8 & $\begin{array}{l}\text { Google } \\
\text { Yahoo }\end{array}$ \\
\hline 3 & 91.8 & $\begin{array}{l}\text { Google } \\
\text { Yahoo } \\
\text { Twitter }\end{array}$ \\
\hline 4 & 92.8 & $\begin{array}{l}\text { Google } \\
\text { Yahoo } \\
\text { Digg } \\
\text { Twitter }\end{array}$ \\
\hline 5 & 93.8 & $\begin{array}{l}\text { Google } \\
\text { Yahoo } \\
\text { Digg } \\
\text { Twitter } \\
\text { Box.net }\end{array}$ \\
\hline 6 & 94.5 & $\begin{array}{l}\text { Google } \\
\text { Yahoo } \\
\text { Amazon } \\
\text { Digg } \\
\text { Twitter } \\
\text { Box.net }\end{array}$ \\
\hline 7 & 95.1 & $\begin{array}{l}\text { Google } \\
\text { Yahoo } \\
\text { Amazon } \\
\text { Digg } \\
\text { Twitter } \\
\text { Facebook } \\
\text { Box.net }\end{array}$ \\
\hline
\end{tabular}




\begin{tabular}{|c|c|c|}
\hline API group size & $\begin{array}{l}\text { Reciprocal distance } \\
\text { index (\%) }\end{array}$ & $\begin{array}{l}\text { API key } \\
\text { player set }\end{array}$ \\
\hline 8 & 95.5 & $\begin{array}{l}\text { Google } \\
\text { Yahoo } \\
\text { Amazon } \\
\text { Digg } \\
\text { Twitter } \\
\text { Facebook } \\
\text { Box.net } \\
\text { mite }\end{array}$ \\
\hline 9 & 95.9 & $\begin{array}{l}\text { Google } \\
\text { Yahoo } \\
\text { Amazon } \\
\text { Digg } \\
\text { Twitter } \\
\text { Facebook } \\
\text { Box.net } \\
\text { Superfeedr } \\
\text { Shopify }\end{array}$ \\
\hline 10 & 96.3 & $\begin{array}{l}\text { Google } \\
\text { Yahoo } \\
\text { Amazon } \\
\text { Digg } \\
\text { Twitter } \\
\text { Facebook } \\
\text { Box.net } \\
\text { Superfeedr } \\
\text { mite } \\
\text { Cloudvox }\end{array}$ \\
\hline 11 & 96.7 & $\begin{array}{l}\text { Google } \\
\text { Yahoo } \\
\text { Amazon } \\
\text { Digg } \\
\text { Twitter } \\
\text { Facebook } \\
\text { Box.net } \\
\text { FreshBooks } \\
\text { Superfeedr } \\
\text { mite } \\
\text { Shopify }\end{array}$ \\
\hline
\end{tabular}




\begin{tabular}{|c|c|c|}
\hline API group size & $\begin{array}{l}\text { Reciprocal distance } \\
\text { index (\%) }\end{array}$ & $\begin{array}{l}\text { API key } \\
\text { player set }\end{array}$ \\
\hline 12 & 97 & $\begin{array}{l}\text { Google } \\
\text { Yahoo } \\
\text { Amazon } \\
\text { Last.fm } \\
\text { Digg } \\
\text { Twitter } \\
\text { Facebook } \\
\text { Box.net } \\
\text { FreshBooks } \\
\text { Kwwika } \\
\text { billomat } \\
\text { Cloudvox }\end{array}$ \\
\hline 13 & 97.3 & $\begin{array}{l}\text { Google } \\
\text { Yahoo } \\
\text { Amazon } \\
\text { Microsoft } \\
\text { Last.fm } \\
\text { Digg } \\
\text { Twitter } \\
\text { Facebook } \\
\text { Box.net } \\
\text { FreshBooks } \\
\text { Superfeedr } \\
\text { billomat } \\
\text { Shopify }\end{array}$ \\
\hline
\end{tabular}




\begin{tabular}{|c|c|c|}
\hline API group size & $\begin{array}{l}\text { Reciprocal distance } \\
\text { index }(\%)\end{array}$ & $\begin{array}{l}\text { API key } \\
\text { player set }\end{array}$ \\
\hline 14 & 97.5 & $\begin{array}{l}\text { Google } \\
\text { Yahoo } \\
\text { Amazon } \\
\text { Microsoft } \\
\text { Last.fm } \\
\text { Digg } \\
\text { Twitter } \\
\text { Facebook } \\
\text { Box.net } \\
\text { NewsCloud } \\
\text { FreshBooks } \\
\text { Superfeedr } \\
\text { billomat } \\
\text { Shopify }\end{array}$ \\
\hline 15 & 97.7 & $\begin{array}{l}\text { Google } \\
\text { Yahoo } \\
\text { Amazon } \\
\text { eBay } \\
\text { Microsoft } \\
\text { Last.fm } \\
\text { Digg } \\
\text { Twitter } \\
\text { Facebook } \\
\text { Box.net } \\
\text { NewsCloud } \\
\text { FreshBooks } \\
\text { Superfeedr } \\
\text { billomat } \\
\text { Shopify }\end{array}$ \\
\hline
\end{tabular}


Appendix $L$ - Sample of topological importance results for the API provider affiliate network

\begin{tabular}{|l|l|l|l|l|}
\hline API provider & $\begin{array}{l}\text { TI index } \\
(\mathbf{n}=\mathbf{1})\end{array}$ & $\begin{array}{l}\text { TI index } \\
(\mathbf{n}=\mathbf{2})\end{array}$ & $\begin{array}{l}\text { TI index } \\
(\mathbf{n}=\mathbf{3})\end{array}$ & $\begin{array}{l}\text { TI index } \\
(\mathbf{n}=\mathbf{5})\end{array}$ \\
\hline Google & 65.53 & 41.47 & 33.04 & 23.21 \\
\hline Amazon & 39.12 & 34.10 & 34.05 & 29.10 \\
\hline Yahoo & 25.67 & 17.60 & 15.00 & 10.91 \\
\hline Facebook & 14.73 & 9.45 & 7.72 & 5.45 \\
\hline Box.net & 12.58 & 8.85 & 7.36 & 5.54 \\
\hline Microsoft & 9.77 & 7.21 & 6.50 & 5.10 \\
\hline Digg & 8.03 & 6.56 & 5.67 & 4.15 \\
\hline AOL & 7.51 & 8.23 & 8.45 & 7.63 \\
\hline eBay & 7.08 & 5.06 & 4.24 & 3.08 \\
\hline Last.fm & 6.05 & 3.99 & 3.34 & 2.39 \\
\hline Bit.ly & 5.15 & 4.69 & 3.96 & 2.76 \\
\hline Eventful & 4.85 & 4.18 & 3.74 & 2.91 \\
\hline Geo Names & 4.80 & 3.37 & 2.72 & 1.94 \\
\hline 12seconds.tv & 4.53 & 10.42 & 18.75 & 26.28 \\
\hline 23 & 4.15 & 8.98 & 11.23 & 11.59 \\
\hline Twitter & 4.12 & 2.36 & 1.75 & 1.15 \\
\hline Bright kite & 3.87 & 4.05 & 3.84 & 3.03 \\
\hline 5min & 2.03 & 5.25 & 6.12 & 6.39 \\
\hline FriendFeed & 3.48 & 2.90 & 2.61 & 1.99 \\
\hline BBC & 3.20 & 3.98 & 4.04 & 3.48 \\
\hline 43 Things & 2.68 & 6.09 & 8.10 & 9.16 \\
\hline CNET & 3.18 & 3.53 & 3.45 & 2.79 \\
\hline Adobe & 3.12 & 4.68 & 4.94 & 4.26 \\
\hline 411 Sync & 2.80 & 4.87 & 5.18 & 5.12 \\
\hline MySpace & 2.80 & 1.94 & 1.61 & 1.15 \\
\hline ImageShack & 2.75 & 2.39 & 1.88 & 1.22 \\
\hline Basecamp & 2.74 & 2.61 & 2.27 & 1.56 \\
\hline Calais & 2.62 & 2.49 & 2.10 & 1.57 \\
\hline CafePress & 2.51 & 3.16 & 3.17 & 2.65 \\
\hline CommissionJunction & 2.47 & 2.25 & 1.85 & 1.34 \\
\hline BibSonomy & 2.41 & 2.56 & 2.69 & 2.34 \\
\hline Bebo & 2.35 & 4.01 & 3.96 & 3.35 \\
\hline Buzznet & 2.33 & 2.63 & 2.46 & 2.00 \\
\hline & & & & \\
\hline & & & & \\
\hline
\end{tabular}

